\title{
CLIMATE PLANNING IN POLITICALLY CONSERVATIVE CITIES: A CASE STUDY OF SEVEN CLIMATE ACTION PLANS
}

\author{
A Thesis \\ presented to \\ the Faculty of California Polytechnic State University, \\ San Luis Obispo
}

In Partial Fulfillment

of the Requirements for the Degree of

Master of City \& Regional Planning

by

Coleman Moore Frick

June 2014 
(C) 2014

Coleman Moore Frick

SOME RIGHTS RESERVED

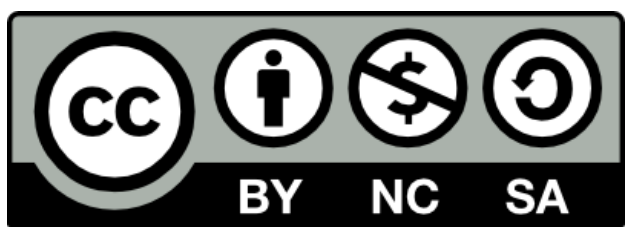

This work is licensed under a Creative Commons Attribution/Non-

Commercial/Share-Alike 3.0 Unported License. This license lets others remix, tweak, and build upon your work non-commercially, as long as they credit you and license their new creations under the identical terms.

To view a copy of this license, visit http://creativecommons.org/licenses/by-ncsa/3.0/ or send a letter to Creative Commons, 444 Castro Street, Suite 900, Mountain View, California, 94041, USA. 
COMMITTEE MEMBERSHIP

TITLE:

Climate Planning in Politically Conservative Cities:

A Case Study of Seven Climate Action Plans

AUTHOR:

Coleman Moore Frick

DATE SUBMITTED: $\quad$ June 2014

COMMITTEE CHAIR: $\quad$ Michael Boswell, Ph.D

Professor, City and Regional Planning

California Polytechnic State University

COMMITTEE MEMBER: W. David Conn, DPhil

Professor, City and Regional Planning

California Polytechnic State University

COMMITTEE MEMBER: Elizabeth Lowham, Ph.D

Associate Professor, Political Science

California Polytechnic State University 


\author{
ABSTRACT \\ Climate Planning in Politically Conservative Cities: A Case Study of Seven \\ Climate Action Plans
}

Coleman Moore Frick

Current research indicates that the potential risks associated with humaninduced climate change are likely to increase in frequency and intensity. Although there have been several attempts, no effective international treaty or policy has been enacted by the United States with the purpose of combating this global issue. In the past decade, local climate action plans (CAPs) have emerged as a planning solution designed to reduce greenhouse emissions (GHGs). Previous studies have examined CAP attributes, but no research has focused solely on climate planning in politically conservative jurisdictions. This research finds that of $245 \mathrm{CAPs}$ completed to date nationally, approximately 90 percent are located in communities identified as politically Democratic based on county level 2012 Presidential Election data. In order to expand climate planning in politically conservative communities, it is important evaluate the characteristics of CAPs in these communities.

This thesis aims to fill the current research gap by analyzing CAPs and conducting stakeholder interviews in seven conservative communities. The central hypothesis is: Climate action plans adopted in conservative communities differ in motivations, type, and political backing, when compared to climate action plans in general. The findings of this case study indicate that CAPs created in conservative communities do not differ substantially from CAPs in general. However, the findings suggest political opposition is heightened in these communities. In addition, the evidence shows that in conservative communities: economic co-benefits are stressed, cost-saving measures are over emphasized, CAP terminology is altered, business community involvement is crucial, and state mandates motivate CAP creation. The results of this research are distilled into 12 lessons and best practices for planning practitioners, and establish a basis for future research focusing on the political nature of climate action planning.

Keywords: climate action planning, CAP, climate planning politics, co-benefits, climate change, Agenda-21, sustainability, energy efficiency, case study 


\section{ACKNOWLEDGMENTS}

This thesis endeavor could not have been accomplished without the support of many individuals involved in the process. I would like to thank my committee chair Professor Michael Boswell for inspiring my interest in the topic and guiding my research. I owe a debt of gratitude in particular to my thesis committee members Professor W. David Conn and Associate Professor Elizabeth Lowham for imparting knowledge and useful advice throughout this process. I truly appreciate Professor Boswell and Associate Professor Adrienne Greve for allowing me to use the CAP resources they created, without which this research would not have been possible. I cannot express enough appreciation for the individuals in each of the seven case cities who agreed to participate in phone interviews-your insights were above and beyond what I could have asked for and comprise the backbone of this study. I would like to acknowledge the tireless efforts of my friends: Amanda Wolf, Rebecca Elliott, Cooper Fleishman, Luke Sweeney, Erin Maehr, and specifically Stephan Schmidt who lent their time, offered advice, and unequivocally agreed to review portions of this thesis. I would also like to thank my parents Julia Frick and Kathleen Moore for instilling in me a desire to learn and seek out knowledge objectively. Lastly, this undertaking increased my interest in the planning professional which would not have been possible without the resources and support of California Polytechnic State University, and the City and Regional Planning Department and faculty in particular. 


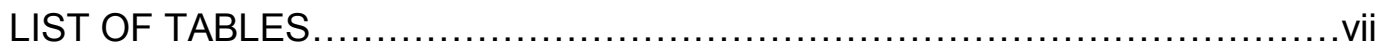

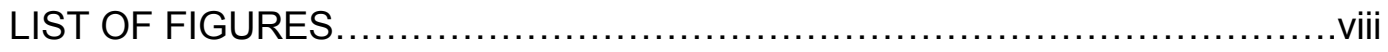

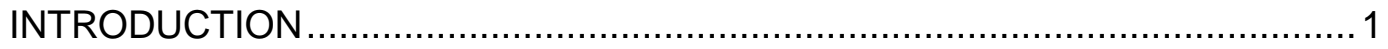

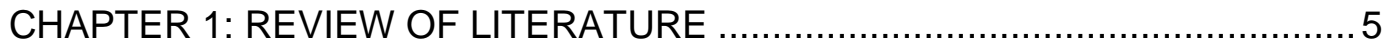

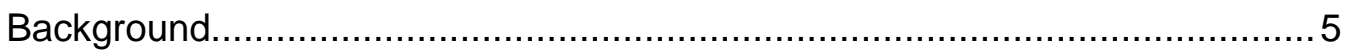

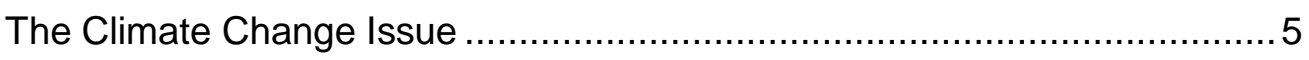

Conservative vs. Liberal Attitudes..........................................................

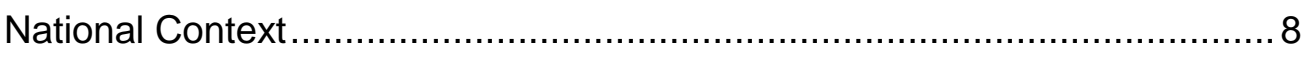

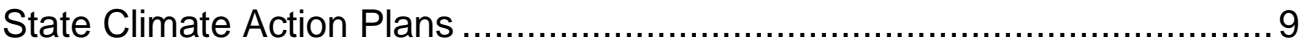

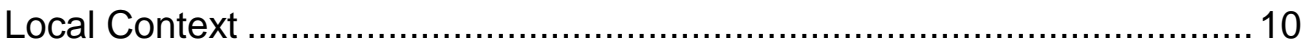

Climate Action Plan Research................................................................... 13

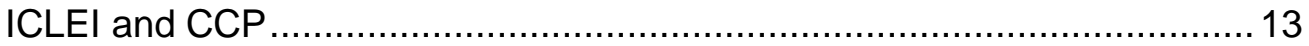

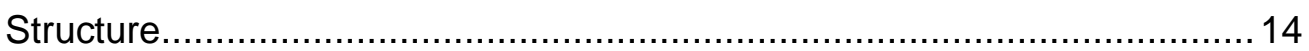

Why Adopt a Climate Action Plan? ………………………………...... 15

CAPs in Liberal vs. Conservative Communities ........................................... 16

Lessons for Successful Climate Action Planning .......................................... 19

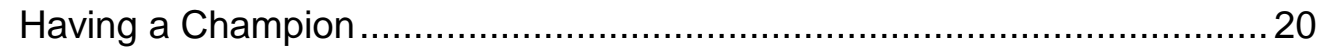

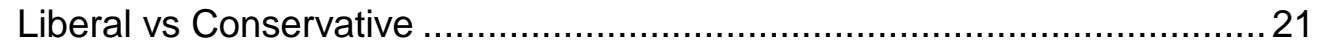

CHAPTER 2: PROCEDURES AND METHODOLOGY ..................................24

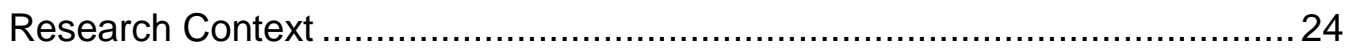

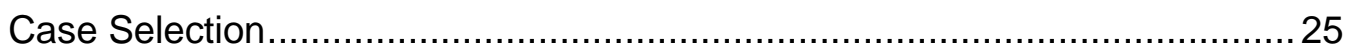

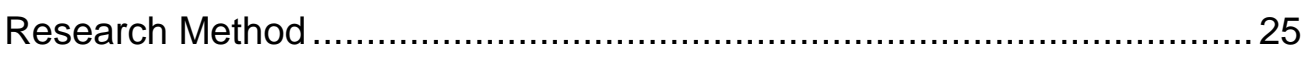

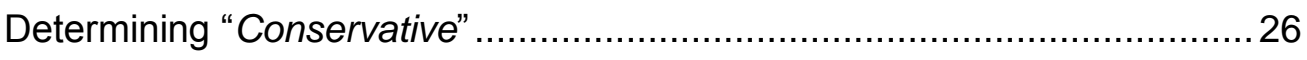

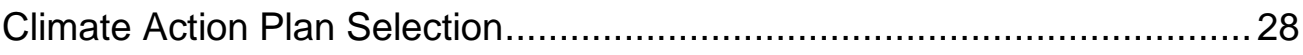

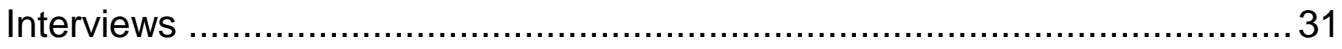

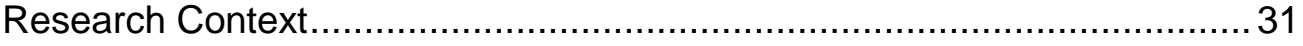

Interview Procedure

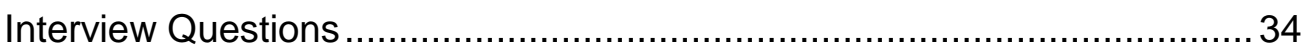

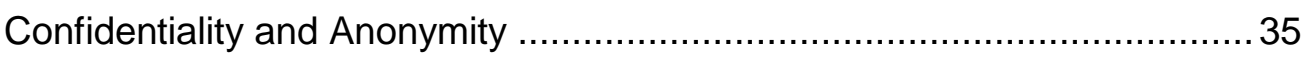

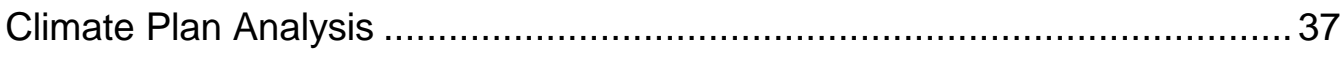




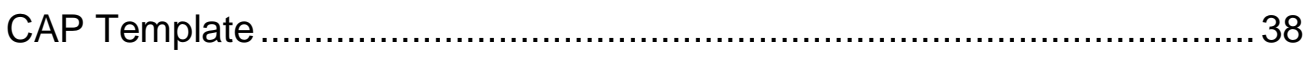

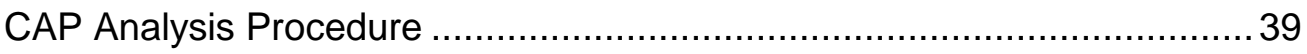

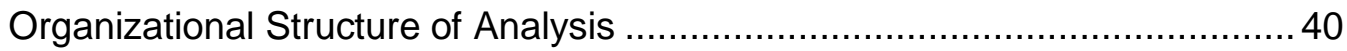

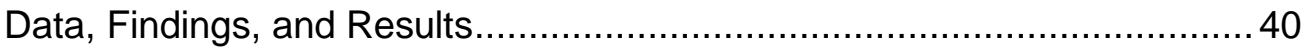

Summary and Discussion .............................................................. 42

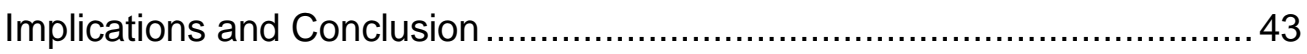

CHAPTER 3: DATA, FINDINGS, AND RESULTS …...................................... 44

Case Study Organization..................................................................... 44

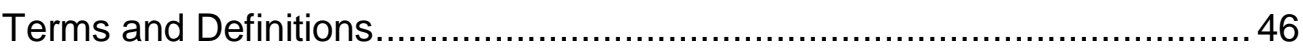

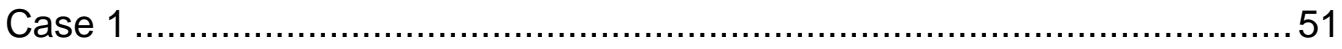

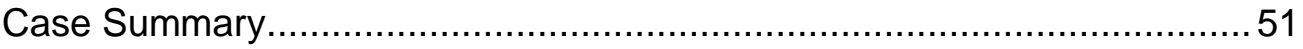

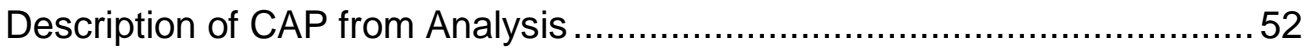

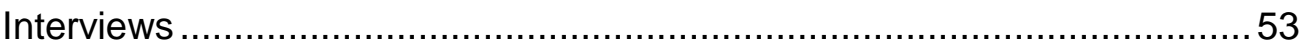

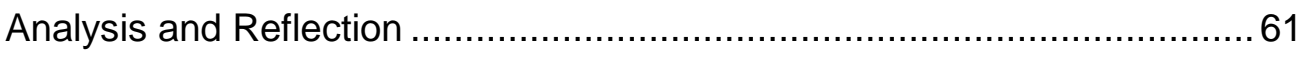

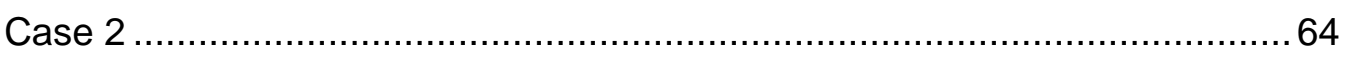

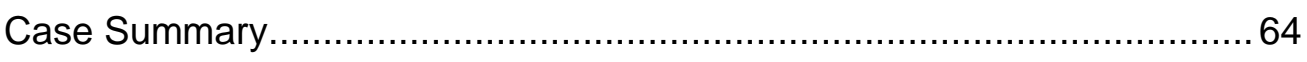

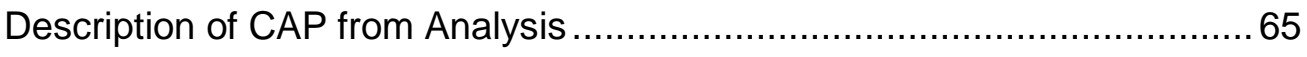

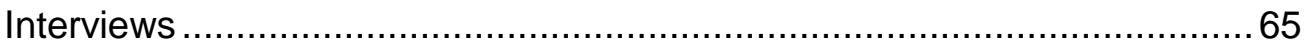

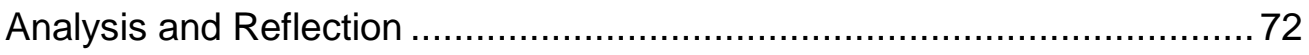

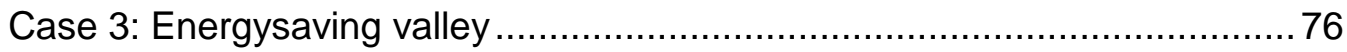

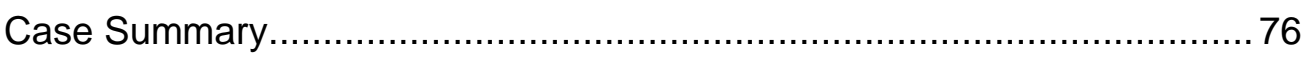

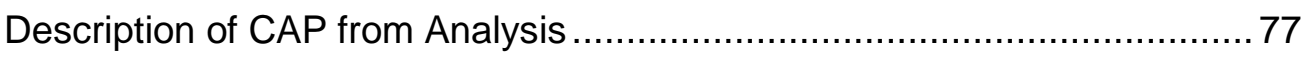

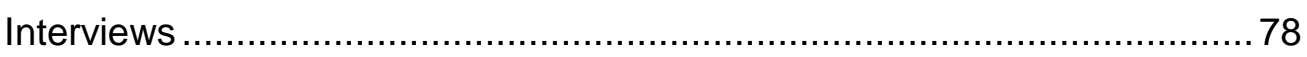

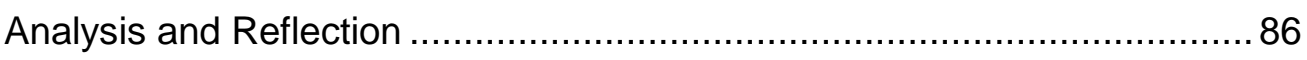

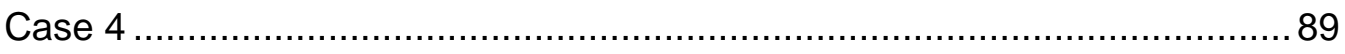

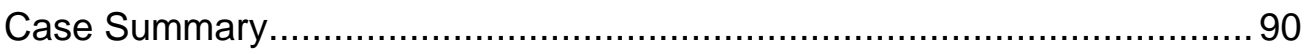

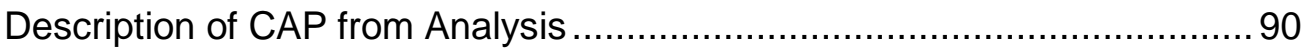

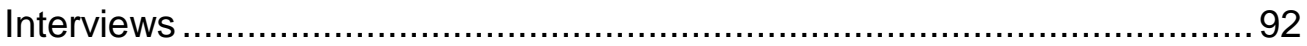

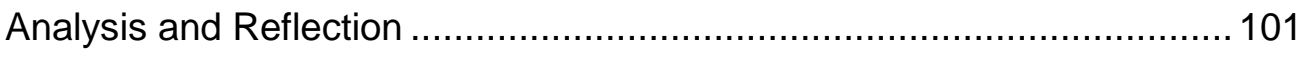

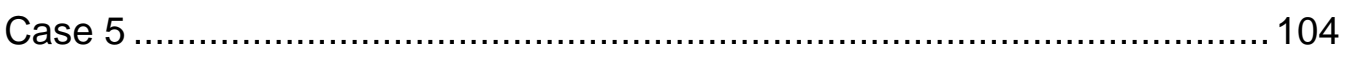

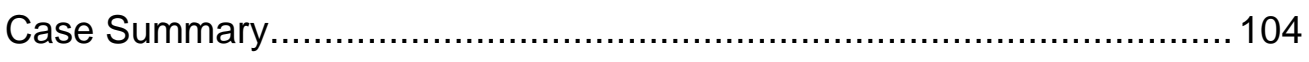

Description of CAP from Analysis ...................................................... 105

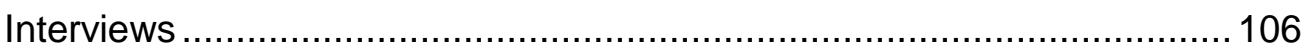




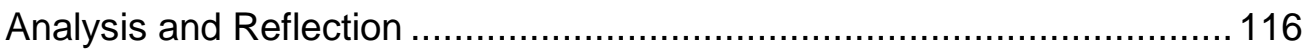

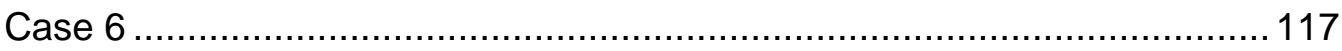

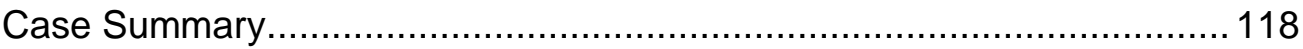

Description of CAP from Analysis .........................................................119

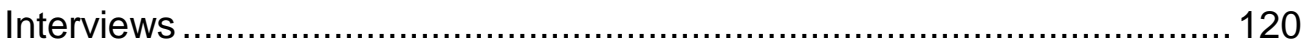

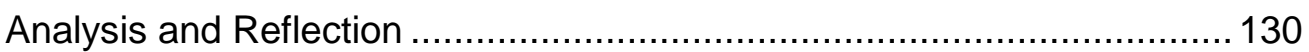

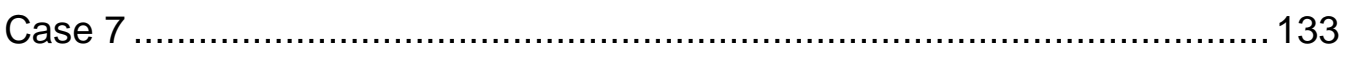

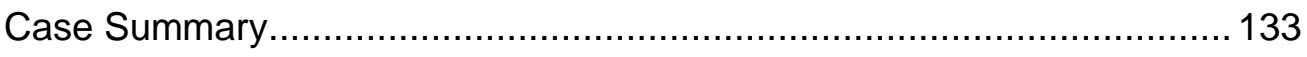

Description of CAP from Analysis ......................................................... 134

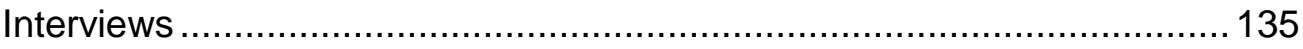

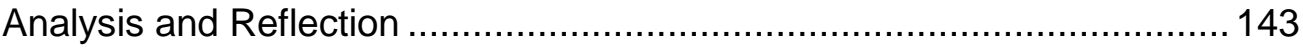

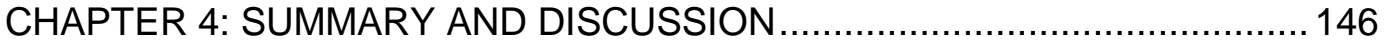

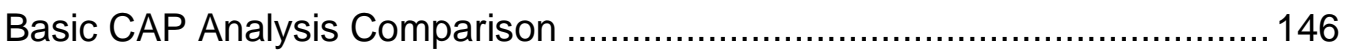

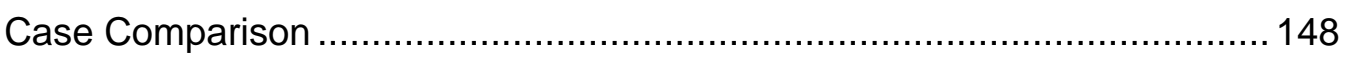

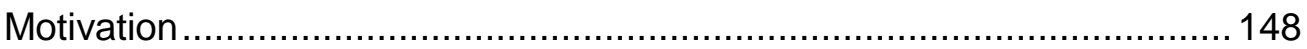

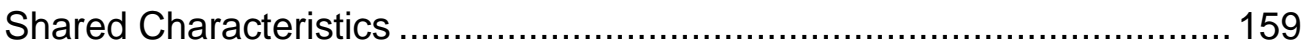

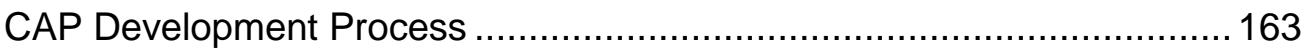

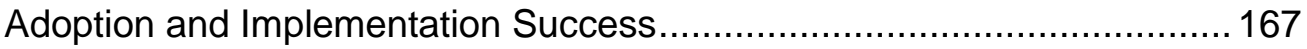

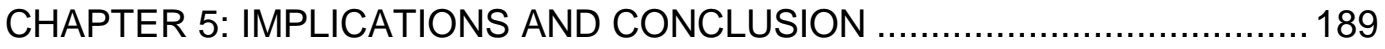

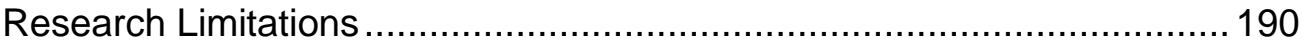

Hypothesis and Research Questions................................................ 191

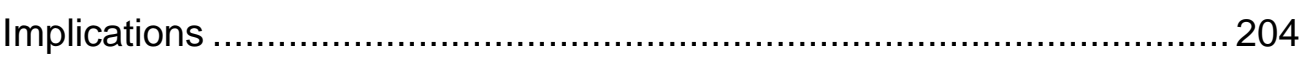

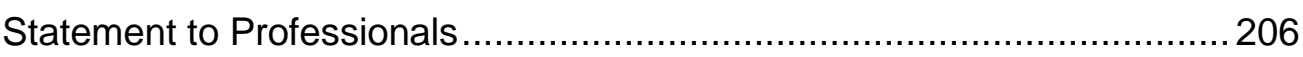

Future Research and Research Outcome ........................................210

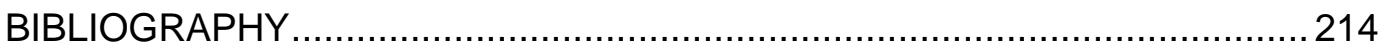

APPENDIX

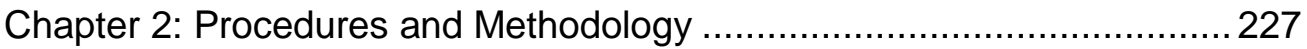

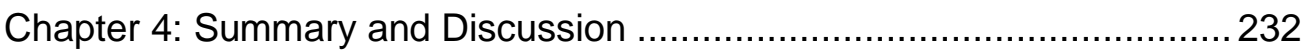




\section{LIST OF TABLES}

Table Page

1. Evidence Supporting/Refuting Hypothesis...............................199

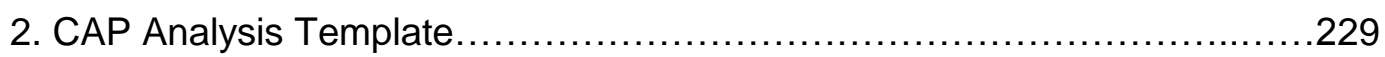

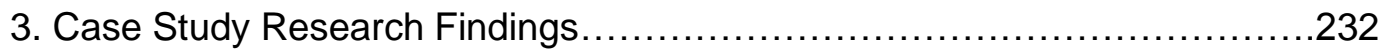




\section{LIST OF FIGURES}

Figure Page

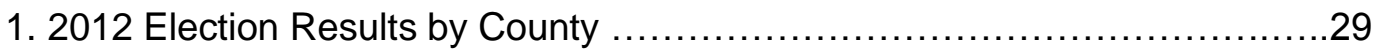

2. Cities Signed-on to Climate Protection Agreement............................47

3. How Much More or Less Private Utilities Cost than Public Utilities.............235

4. State Level Anti-Agenda 21 Legislation .....................................236 


\section{INTRODUCTION}

In the last 10 years many cities and counties in the United States have adopted climate action plans (CAPs). These have primarily been created in order to reduce greenhouse emissions (GHGs) or address issues with climate vulnerability. Climate plans can be (and are) named in a variety ways (e.g. Energy Action Plan, Sustainability Plan) but include components universally recognized as making them CAPs. For the purpose of this research, all policy documents that include these requisite components will be referred to as CAPs. Based on the analysis included in this research, it appears that approximately 90 percent of adopted CAPs have been created in communities identified as politically Democratic based on county level 2012 Presidential Election data.

Previous studies have indicated that many climate action plans created in politically liberal communities reinforce and condense planning efforts and policies already present in their target communities (Betsill, 2001; Betsill \& Bulkeley, 2004; Feiock, Francis \& Kassekert, 2010; Millard-Ball, 2012). For local climate action planning to be successful on a national scale, it seems important for communities to adopt emission reduction and adaptation strategies in places that may not be naturally receptive to environmental concerns. Research has shown that indirect benefits of planning efforts can be created through the plan making, adoption, and implementation process (Betsill, 2001; Kousky \& Schneider, 2003; Kamal-Chaoui \& Roberts, 2009; Dolan, 2010; Feiock et al., 2010). These benefits include providing information and generating social capital, among others. Yet, in order to achieve a nationwide reduction in GHG emissions, 
communities that already apply many environmental policies and programs cannot be the only jurisdictions that employ climate action planning in their long term policy goals. Conservative communities must see it as imperative to adopt various climate action planning strategies for their own benefit and stability in order for this type of planning to be successful in reducing GHG emissions on a meaningful scale.

Various studies have analyzed the phenomenon of increased climate action planning (Betsill, 2001; Betsill \& Bulkeley, 2004; Lindseth, 2004; Wheeler, 2008; Bassett et al., 2010; Pitt, 2010a; Sharp et al., 2011). Each of these has identified unique attributes of climate action plans such as structure, content, stakeholder involvement and efficacy. Some have studied the variables of political will (Betsill, 2001; Wheeler, 2008), political climate (Leiserowitz, 2006; Bassett \& Shandas, 2010; Reams, Clinton, \& Lam, 2012), and the trend of environmental policies and programs being created in communities that vote for Democratic/Republican representatives (Hanak, Bedsworth, Swanbeck, \& Malaczynski, 2008; Lubell, Feiock, \& Handy, 2009; Pitt, 2010b; Portney and Berry, 2010; Hawkins \& Wang, 2012) as an element of the research. However, no study was identified that specifically analyzes climate action planning in politically conservative communities as its sole aim. Prior research indicates that there are research gaps in the study of climate action planning. Some have concluded that a broader spectrum and more purposeful evaluation of CAP case study research should be pursued (Millard-Ball, 2012; Zahran, Grover, Brody, \& Vedlitz, 2008a). Others have stated that more information is needed in terms of the characteristics jurisdictions possess that have adopted CAPs; and how nonparticipants can become engaged in climate policies and planning (Pitt, 2010). 
This thesis seeks to elucidate the characteristics of climate action plans involved in politically conservative communities by analyzing a case study of a number of cities. For this research, a "conservative" community is operationalized as one that has a voting record of supporting Republican candidates in the 2012 Presidential Election. This sets out to differentiate communities where politics are, to a greater or lesser degree, to the right of center on the political spectrum. Clearly this classification leaves out the multifaceted nature of the various types of conservatives present in the United States. Operationalizing conservative in this way also does not account for Democrats in local government (e.g. Mayor, City Council), but is seen as the most logical way to characterize a community as conservative based on resources available and previous CAP research. This case study research will be framed by focusing on the unit of analysis of CAPs in Republican jurisdictions (as a proxy for CAPs adopted in conservative cities).

Results from prior research regarding the characteristics of successful CAPs are applied to climate action planning in conservative communities. Previous case study research examining CAPs is used to define CAPs created in characteristically liberal cities for comparison. This decision was made because by applying the same criteria used in this study (county level 2012 Presidential Election data) to prior CAP research, it was determined that the vast majority of CAP research has been focused on politically liberal communities. By comparing characteristics of CAPs as whole to conservative cases in this study, it can be determined whether differences exist in terms of motivation and adoption. Similarities and differences are determined by investigating key attributes through content analysis of primary sources (such as CAPs themselves, meeting/hearing minutes, etc.) in each selected jurisdiction, and insights from 
interviews of key players in the CAP production process. Lessons revealed from the analysis of climate action planning in conservative communities provides broader insight/best practices for creating CAPs and reducing emissions nationally in politically hostile environments. Findings from the research will prove valuable to future climate and sustainability efforts in so called conservative communities.

\section{Questions to be addressed:}

- Are the same characteristics of successful climate planning found in prior CAP research applicable to climate action plans created in politically conservative communities?

- Can CAP structure, language, or co-benefits influence the perceptions of GHG emissions reduction strategies that may be present in conservative communities?

- Does the political climate of conservative communities affect the structure, motivation or success of the CAPs created within them?

- Can analysis of CAP processes and attributes in conservative communities provide valuable information regarding how to implement future climate planning strategies in places with a similar political climate?

\section{Hypothesis:}

Climate action plans adopted in conservative communities differ in motivations, type, and political backing, when compared to climate action plans in general. 


\section{CHAPTER 1: REVIEW OF LITERATURE}

Chapter 1 outlines the existing literature relevant to climate action planning in politically conservative communities. This chapter discusses the background and context of climate policy, the current body of existing CAP research, and a summary of prior CAP research focused on the political aspect of climate planning.

\section{BACKGROUND}

This background section summarizes the research to date regarding climate change and climate policy, applicable to this case study. The section is divided into five categories:

- The Climate Change Issue

- Conservative versus Liberal Attitudes regarding climate change

- The National Context in the United States

- State and Climate Action

- The Local Context for climate action

\section{The Climate Change Issue}

Scientific research identifying the potential risks of climate change due to greenhouse gas emissions (GHGs) entered the forefront of the world's consciousness in the early 1990s. International concern regarding this issue 
came to a head in 1997 when many nations signed the United Nations Framework Convention on Climate Change's (UNFCCC) Kyoto Protocol, a treaty aimed at reducing global emissions to 1990 levels. However, the U.S. has never ratified the treaty due in part to fears tied to economic impacts, structure, approach, and the overall political implications of signing on. This international reluctance (specifically from some of the largest emitters) to address the global GHG emissions issue has led many nations to pursue their own GHG mitigation techniques and targets.

As the scientific body of work has grown regarding the potential health, environmental, and economic impacts of allowing GHG emissions to increase unabated, the focus of reducing emissions has become the primary aim of climate discussions internationally as well as nationally (Bedsworth \& Hanak, 2010). Additionally, with the climate risks rising, and the frequently stagnant status of international action on climate change, it has become increasingly important to adopt a multilevel and bottom up approach to GHG reduction strategies. An important factor to consider when approaching the issue of global GHG emissions reduction is that the majority of the world's population lives in cities, and this trend is only increasing (Gremillion, 2011). Furthermore, "by some estimates, more than three-fourths of global carbon emissions come from cities" and almost two-thirds of Americans live in cities (Feiock et al., 2010, p.1). Betsill and Bulkeley (2006) argue that the most desirable approach to climate planning is policy and action at the local level. This bottom up approach is important because it focuses on addressing the source of GHG emissions. Due to this, local action is viewed as integral to the goal of reducing GHG emissions through climate planning. 


\section{Conservative vs. Liberal Attitudes}

Almost immediately, conservative think tanks and activists began dissecting the science behind climate science research (Dunlap \& McCright, 2008; McCright \& Dunlap, 2003). The question of anthropogenic vs. natural causes as the driver behind climate change has been debated at length. This issue has led to political gridlock on the topic of climate change and GHG emissions mitigation at the federal level (Brunner, 2001). The debate over the validity of climate science has played out on the national stage. There is a substantial divide between liberals and conservatives over the risk and causes of climate change. Liberals tend to hold views more consistent with the current scientific consensus, but both groups rely on a certain set of information that often reinforces views that they already held (McCright \& Dunlap, 2011). Often this has increased the divide between each group, entrenching their opinions.

Research by Leiserowitz (2006) found that the issue of climate change currently lacks a sense of urgency. Risk perception, values, and Americans' world view have been identified as the most important factors in determining attitudes regarding climate change. Moreover, "messages about climate change need to be tailored to the needs and predispositions of particular audiences; in some cases to directly challenge fundamental misconceptions, in others to resonate with strongly held values" (p. 64). This finding may have bearing on approaching climate planning in conservative communities. However, the political divide present at the national level is not necessarily representative of ideological attitudes towards global climate change. Although Democrats and liberals often convey stronger support for GHG reduction policies than Republicans and 
conservatives, the majority of Republicans still support climate change policies to a certain degree (Leiserowitz, 2006).

\section{National Context}

In the United States, the topic of GHG emissions reduction has faced political hurdles similar to those present on the international stage. Politically, the United

States is a nation comprised of states, each containing city and county governments which are largely autonomous in terms of development, land-use decisions, and local laws. Local governments and planners play an important role influencing these decisions (Betsill \& Bulkeley, 2004). Some of the notable policies that fall under the local umbrella of jurisdictions include transportation, development, energy usage, preservation of open space, and waste/waste water management (ICLEI, 1995; Kousky \& Schneider, 2003).

The Yale Project on Climate Change Communication releases a frequent report on American's attitudes towards global warming. This project is titled "Global Warming's Six Americas;" six categories are identified and tracked; these range from those who have the strongest belief that global warming is a threat to those who do not think it will have any impact and are as follows: alarmed, concerned and cautious to disengaged, doubtful, and dismissive (Leiserowitz et al., 2012). The September 2012 report found that the majority of Americans fall into the first three categories (Alarmed, Concerned and Cautious) and represent 70 percent of the population nationally. Importantly, these individuals believe that the United States should reduce emissions, even if other countries do not; this is important considering the political roadblocks currently present internationally as well as 
nationally, and opens the door for local action and climate planning initiatives. Additionally, all Six Americas identified the primary drawback of addressing global warming as increased government regulation and higher energy prices. This study is representative of the political tightrope that must be walked when enacting environmental programs such as $\mathrm{GHG}$ emissions reduction policies. This case study seeks to address these national political issues.

\section{State Climate action Plans}

In the past decade, a number of states have taken on leadership roles in CAP creation and have encouraged their jurisdictions to adopt CAPs. In the face of politically gridlocked efforts nationally to address climate change, many states have taken it on themselves to sign the Kyoto Protocol and enact other legislation and agreements geared towards reducing GHG emissions. Some of these include two 2005 agreements, the Sierra Club's Cool Cities campaign and the U.S. Conference of Mayors' Climate Protection Agreement (Wheeler, 2008). These memberships are important variables to consider when analyzing which cities and counties elect to adopt climate action plans.

The role that states play in GHG emissions reduction is important for making policies, laws and mandates that influence emissions sources within their borders. State CAPs are also reliant on the cities and counties that they are comprised of to meet these goals. A study by Lutsey and Sperling (2008) found that if the 17 states that had adopted policies aimed at reducing GHG emissions to date were able to reach their goal of 1990 emissions by 2020 , nationally 
"emissions would be stabilized at 2010 levels by 2020" (p. 683). The study goes on to conclude that the measures taken by states and cities towards climate mitigation in terms of policies and action will provide important lessons for future federal policy and programs to reduce GHG emissions.

\section{Local Context}

As international and national cooperation lags, local government seems a plausible route for adopting the most impactful policies to address GHG emissions. As local support grows in terms of policies and citizen engagement, it is possible that these actions will ultimately influence national and international action on climate change (Gremillion, 2011). In the past two decades, considering the lack of effective policies and hurdles faced nationally, cities have set the example in the United States by enacting mitigation strategies (Kousky \& Schneider, 2003). According to the U.S. Conference of Mayors at least 1,000 cities have taken initiative on reducing GHG emissions (Feiock et al., 2010).

Only in recent years have scholars begun examining the role city governments can play in reducing GHG emissions through sustainability policies (such as climate action plans) (Sharp et al., 2011). Research into the proliferation of municipal GHG mitigation strategies is important to study from a planning perspective. Evaluation of the approaches employed by local jurisdictions is essential because energy use is so intertwined with actions and policies created by local governments (Pitt, 2010a). Local governments are in charge of policies that have a significant impact on GHG emissions as most emissions sources are 
located within their jurisdiction. Many are also incentivized by their own vulnerability to climate change impacts. Although a number of local governments have begun pursuing climate planning as a result of international and federal stagnation, this top down reluctance to prioritize GHG mitigation and lack of guidance can hinder local government efforts to reduce GHGs (Lindseth, 2004).

Another difficulty in addressing the issue of climate change is framing and contextualizing it. Weber (2006) found that low-probability events often lack the ability to generate concern from the general public unless an event directly impacts individuals and that "The time-delayed, abstract, and often statistical nature of the risks of global warming does not evoke strong visceral reactions" (p.103). This is also compounded by the view that many people may share, that one community cannot buffer itself by local action alone in the face of such a global issue. Climate change is a borderless issue and a criticism some communities pose is that even if they reduce emissions within their own jurisdiction, the negative impacts of emissions from other areas may have a spillover effect regardless (Sharp, et al., 2011). This issue can overwhelm some jurisdictions into inaction in the face of making economic sacrifices in order to reduce their own emissions. Because of this, research has shown (Dolan, 2010) that it is important to promote awareness, engage citizenry, and encourage grass root efforts in order to institutionalize GHG reduction policies at the local level. In this way it may be possible to influence the context of the national climate change debate.

Even though climate change studies and preliminary policies were adopted by cities as early as the late 1980s and early 1990s, climate action plans, as they 
are structured today, did not come about until Portland, Oregon, created a community-wide plan aimed at decreasing GHG emissions in 1993 (Wheeler, 2006). This was in part a response to the International Council for Local Environmental Initiatives' (ICLEI) Cities for Climate Protection (CCP) Campaign (Pitt, 2010a), as well as The U.S. Environmental Protection Agency's (EPA) new policy of providing grants for states creating GHG mitigation plans (Wheeler, 2008). A number of "pioneer" cities and states followed suit, creating climate action plans. It should be noted that the umbrella of "climate action plan" contains comprehensive policies with other names such as "energy plan", and "sustainability plan" (to name a couple), but are structured with inventories, targets, and policy goals that make them CAPs. However, it is important to note that there are also policy documents that may sound similar but do not contain the same crucial components that comprise a CAP.

Although many municipalities have adopted GHG emissions reduction initiatives in the past two decades, planning scholars have only recently begun addressing this recent phenomenon of climate action planning. Nationally, many climate action plans vary widely in structure, policy strategies, scope, quality and ability to implement once adopted (Bassett \& Shandas, 2010). Climate plans do not abide by a uniform naming convention, whereas each policy document included Climate Action Plan in the title. The field of climate planning is also new and varied, making it extremely challenging to address and evaluate. Research by Wheeler (2008) has shown that the ability to negotiate and implement climate action plans is a difficult task for local governments, and an ideal answer is not obvious. Local governments often face institutional barriers when creating policies to address GHG emissions (Betsill, 2001). In some cases these can be 
political. From a political standpoint addressing climate change can be challenging for local governments. Interests are often deep-rooted and powerful in sectors affected by GHG emissions reduction such as transportation and energy, and these same sectors are associated with economic growth (Maggioni, Nelson, \& Mazmanian, 2012, Kamal-Chaoui \& Roberts, 2009).

\section{CLIMATE ACTION PLAN RESEARCH}

The climate action plan research section is a review and analysis of prior CAP research. This section includes a discussion of the primary focus of previous CAP research, descriptions of CAP characteristics, motivations for undertaking climate planning, and research exploring the impact of political affiliation on climate planning.

\section{ICLEI AND CCP}

A large portion of the available research that analyzes CAPs focuses on ICLEl's Cities for Climate Protection (CCP) program and its member cities (Betsill, 2001; Betsill \& Bulkeley, 2004; Betsill, 2006; Lindseth, 2004; Millard-Ball, 2012; Sharp et al., 2012; Wheeler, 2008; Zahran, et at., 2008a; Zahran, Brody, Vedlitz, Grover, \& Miller, 2008b), as this membership is one of the few consistent and uniform lists of cities engaged in climate action planning available. While this research is valuable in determining trends in climate action planning, it leaves out communities that have created CAPs through different avenues. Because CCP members receive resources and guidance from ICLEI, many CCP CAPs look 
very similar structurally. Bassett and Shandas (2010) identify that "ICLEI can either act as a homogenizing force in planning, limiting innovation through standardization, or it can facilitate the development of robust place-based strategies that reflect local biophysical, political, and economic realities" (p. 437). Due to this fact, it seems prudent to address CCP membership as an attribute when evaluating CAPs, yet shift effort away from using CCP membership as a limiting factor for case selection.

The support that ICLEI provides has been important and essential in shaping the first generation of climate action plans. Yet, sometimes the choice to join ICLEI can have as much to do with politics as a genuine desire to reduce GHG emissions. Research has shown that ICLEI members tend to be already predisposed to having concern for environmental issues, and have colleges located within their borders (Pitt, 2010b). In contrast, Reams et al. (2012) found that the most important factor for achieving ICLEI milestones was length of ICLEI membership and that factors likely to discourage membership include greater automobile dependency and high levels of hazardous air pollution. When it comes to implementation, joining ICLEI does not always transform into the creation of new policies or programs aimed at GHG emissions reduction (Sharp et al., 2011).

\section{Structure}

The primary method to date with which local jurisdictions have attempted to address GHG mitigation is by developing emissions inventories. Inventories afford a structure for evaluating GHG emissions reduction efforts (Wheeler, 
2008). Climate actions plans use this inventory as a baseline; they then set reduction targets and use policy tools to achieve mitigation goals (Tang, Brody, Quinn, Chang, \& Wei, 2010). In terms of policy, the majority of CAPs focus on seven specific categories: zoning ordinances, transit, bicycle infrastructure, tree planting, energy efficiency, public outreach, and education (Bassett \& Shandas 2010).

\section{WHY ADOPT A CLIMATE ACTION PLAN?}

Research into climate action planning at the local level has drawn a number of conclusions as to the ways a particular city elects to begin the climate planning process. Some studies have found that co-benefits (discussed in detail later) such as livability, improved air quality, and cost savings can be important motivators (Kousky \& Schneider, 2003; Sharp et al., 2011). In addition, citizen and stakeholder participation, nearby colleges and universities, environmental nonprofit organizations, a concern for local vulnerability to climate impacts, the desire to enhance overall environmental quality and to shrink global GHG emissions have been found to increase the likelihood that a community will adopt a vast array of GHG mitigation policies (Pitt, 2010a). Furthermore, a city's decision to create a climate action plan has been linked to having leadership from an elected official such as a Mayor (Bassett \& Shandas, 2010). Millard-Ball (2012) found that an important factor can be a community's pre-existing environmental leaning and desire to market itself as a "green" leader in the region. 


\section{CAPS IN LIBERAL VS. CONSERVATIVE COMMUNITIES}

Most academic studies that have evaluated CAPs have selected one or a number of criteria in order to predict or analyze specific CAP attributes or characteristics. By and large these studies have focused on climate planning in liberal communities (counties that voted for the Democratic candidate in the 2012 Presidential Election as defined by this thesis). Existing literature has used criteria such as membership in climate conscious organization such as Cities for Climate Protection, The U.S. Conference of Mayors Climate Protection Agreement, ICLEI and others as predictors of climate plan initiation (Bassett and Shandas, 2010).

A number of scholars have argued that in some cases CAPs have little impact in communities already focused on the set of policies, values, and programs targeted by climate planning. Liberal communities that adopt CAPs may just be reinforcing existing values. In certain locations, climate policy may be largely symbolic in order to appeal politically to certain constituencies (Feiock et al., 2010, Zahran et al., 2008b). Moreover, CAP adoption may only unify programs that already exist (Betsill, 2001). CCP membership has helped frame existing concerns, yet, often climate policies are the same or similar to existing policies that are present, but not explicitly aimed at GHG emissions mitigation (Betsill \& Bulkeley, 2004).

By adopting CAPs, some jurisdictions may be creating policies and taking action that would have been done regardless. Plans sometimes only address policy decisions enacted before a jurisdiction's CAP was initiated, creating a unifying 
document based on policies already in motion without adding substantial new policies or actions (Millard-Ball, 2012). Betsill and Bulkeley (2004) unearthed valuable insight regarding the counterintuitive nature of CCP membership. This study found that the motivations behind CCP members were substantially motivated by values, funding, and political clout-rather than a desire to receive technical assistance. Bassett and Shandas (2010) found that most municipalities favor CAP policies that are clearly noticeable to the public, such as tree planting (visual), and energy efficiency (economic).

Climate action planning can be a difficult task politically. In many communities (setting aside political affiliation), a common way to address this problem is by focusing on ancillary benefits (or co-benefits) provided by the resulting policy action (Betsill \& Bulkeley, 2004; Dolan, 2010; Lindseth, 2004; Kamal-Chaoui \& Roberts, 2009). A policy that addresses not only GHG emissions reduction goals but also additional benefits to the community is much more viable. By broadcasting co-benefits to the community at large, the global issue of climate change can become localized (Kousky \& Schneider, 2003). This provides justification for new laws or policies and allows jurisdictions to financially invest in new initiatives.

In communities that may be reluctant to address climate change for the purpose of reducing GHG emissions alone, emphasizing the cost saving aspect of policies such as energy efficiency can be more persuasive (Dolan, 2010). Other co-benefits often cited include reduced air pollution (Reams et al., 2012), livability, and other auxiliary environmental benefits (Betsill, 2001). It is possible that this way of framing GHG emissions reduction policy could be palpable in 
conservative communities that may not otherwise be inclined to engage in climate action planning initiatives. However, Krause (2011b) found that cobenefits, while valuable for initiating CAPs, can be unfavorable in that they may focus too heavily on cost savings which can reduce the breadth of long-term planning activities aimed at community-wide GHG emissions reduction.

Research by Maggioni et al. (2012), of state climate action plans concluded that CAPs created in states with Republican governors were not found to have lower GHG reduction targets in the energy sectors than states with CAPs as a whole. Additionally, although the national political environment is extremely partisan on the issue of climate change, states are largely nonpartisan in their approach to climate change, largely due to potential economic growth opportunities of leading in sectors such as alternative energy. Terminology can also address political concerns about adopting climate policy. Bassett \& Shandas (2010) found that some individuals involved in climate action planning in conservative communities consciously chose to leave out policy language mentioning climate, carbon reduction, or environmental terms, instead focusing emphasis on cost savings and economics. By evaluating the process, motives, and political climate of CAPs adopted (or those that have reached their final stage of completion) in conservative communities, this case study will contribute meaningfully to CAP research as a whole. 


\section{LESSONS FOR SUCCESSFUL CLIMATE ACTION PLANNING}

Several studies have looked to answer the question: what makes a successful climate action plan? An analysis of early climate action plans found that the best way to address the issue of climate change is not to tackle the daunting task of facing global GHG emissions head on, but rather to frame it in a local context, to "think globally, and act locally" (Lindseth, 2004). It is important to involve the community early in the initial stages in order to attain momentum throughout the planning process, and having allocating dedicated staff to the CAP (Pitt, 2010a). Successful climate planning initiatives share the common thread of receiving considerable backing through regional collaboration (Pitt, 2010b; Hanak, Bedsworth, Swanbeck, \& Malaczynski, 2008), as well as from stakeholders (Wheeler, 2008) and other private actors (Pitt, 2010a).

The decision to prepare a CAP in the first place requires considerable leadership and political will; these two factors also shape a CAP's eventual successes in terms of adoption and implementation (Bassett \& Shandas, 2010). Politics can also play a role in the decision to join CCP. The personal connections, financial incentives, respect, and political admiration associated with CCP membership can be considerable incentives (Betsill \& Bulkeley, 2004). Once a CAP is initiated, following through with adopted policies can be a function of what led to the CAP's creation in the first place. Research by Pitt (2010b) highlights an important finding for analyzing the impact of a jurisdiction's political makeup on the CAP process. A significant finding shows that "the extent to which municipalities actually adopt climate mitigation plans and policies is primarily a function of internal political and institutional characteristics" (p. 868). This is 
essential to consider, because these institutional characteristics within city government can be difficult to alter.

Wheeler (2008) published a study analyzing the content and impact of state and municipal climate action plans. Goals, strengths and weaknesses, measures, and implementation were evaluated through content analysis of CAPs, and interviews. Wheeler's research provides a number of important lessons relating to climate plan structure. The findings conclude that the first generation of state and municipal climate plans varies widely in terms of GHG targets, and that some are lacking a framework for implementation. Importantly, they also appear to have heightened public awareness of climate change impacts. This research is important as it outlines lessons for successful climate planning. These include: stating and defining measures for GHG reduction, having a mechanism for monitoring progress, and effectively implementing policies rather letting them sit on a shelf (Wheeler, 2008). Plan quality is also important for CAP success. Research on climate action plan quality conducted by Tang et al. (2010) found that the most notable predictor for high quality CAPs is the influence of state mandates.

\section{Having a Champion}

When creating climate action plans, it can be important to have a local champion. This can be a leader who takes the reins of a CAP project and is important for its success (Betsill \& Bulkeley, 2004). Individuals often have differing motivations for becoming involved in the process. Some see it as a moral obligation or potential for political gain (Betsill, 2001). In other situations, this champion is an individual 
with a unique ability to organize. The skill of creating or enhancing grassroots organizations or possessing technical expertise can greatly affect the creation or outcome of climate planning policies (Pitt, 2010a). The role (or lack) of local champions is one criterion that will be evaluated when comparing case studies in this research.

\section{LiBeral vs Conservative}

Considering that climate planning is still controversial in many jurisdictions, it is important to understand how this manifests itself in conservative and liberal communities. States that are predominantly conservative and vote Republican have been found to have difficulty establishing support for climate planning unless it has been made clear that the long term economic benefits of climate action outweigh the upfront costs (Carter \& Culp, 2010). Instituting climate planning initiatives can be valuable in spotlighting the topic of GHG emissions and related impacts, as well as raising public awareness in communities that may have limited political support initially (Moser \& Ekstrom, 2011; Tang et al., 2010). Additionally, in localities where climate planning is politically difficult, state or federal mandates aimed at GHG emissions reduction can offer political shelter (Bedsworth, 2010).

Cities engaged in climate planning often exhibit characteristics in common, including comparatively more educated citizens, larger populations, and Democratic political leanings (Krause, 2011a). Zahran et al. (2008b) found that the odds of a municipality joining CCP increased in areas voting for Democrats, those that recycle, and which have a higher quantity of environmentally minded 
nonprofit organizations. In Sustainable Development Governance: Citizen Participation and Support Networks in Local Sustainability Initiatives, Hawkins and Wang (2012) found a similar correlation between residents voting Democratic, and participation in sustainability initiatives. However, Lubell et al. (2009) found that in California's Central Valley, establishing viable sustainability policies does not correlate with Democratic affiliation explicitly. More important factors cited include: larger cities, intellectual capital leading to innovation, responses to rapid growth, and areas with high socioeconomic status.

In a study of California cities and counties, Hanak et al. (2008) highlight a number of notable characteristics concerning political affiliation and climate policy. "Communities with a higher Republican share are less likely to be conducting emissions inventories, developing climate action plans, and incorporating measures to reduce GHG emissions in various local planning and regulatory tools" (p. 35). In this study, predominantly Republican communities were found to be less proactive in identifying likely effects of climate change, as well as implementing specific planning measures, polices, and programs. Sharp et al. (2011) found that cities with a larger proportion of Democratic voters were more likely to advance policy implementation, have organized interests in favor of climate change policy, and become members of ICLEI.

Krause (2011b) researched 250 cities' climate action planning programs. This study indicates that the number of programs a given locality enacts has a strong correlation with a few specific variables. These include communities that are politically supporters or members of the Democrat party, have larger population, higher per capita general revenue, and strong backing from local government 
and local officials. Factors associated with a larger number of climate planning activities include a desire to reduce global GHG emissions, increasing public wellbeing, and energy and cost savings. Another study (Zahran et al., 2008a) looked at barriers to CAP creation and found that, "Metropolitan regions contributing most to the problem through $\mathrm{CO}_{2}$ emissions are the least likely to participate in the CCP" program (p. 469). This is a notable in terms of the influence of politics, because it is likely that communities with carbon intensive industries may have entrenched interests to maintain the status quo as well as considerable political clout.

The existing CAP research is divided on which variables have the most impact on successful climate planning. When evaluating the impact of political affiliation, this divide is even more apparent, with some studies indicating that it has little to no impact and other research demonstrating a significant correlation. The qualitative case study approach of this thesis contributes to past CAP research by filling in knowledge gaps. No previous CAP research has focused explicitly on climate planning in Republican jurisdictions. By evaluating successful CAP characteristics from previous research, this case study determines if the same attributes are present in conservative communities, explicitly. This study also addresses a knowledge gap in how party affiliation affects the contents, motivation, and adoption of CAPs. Finally, this thesis illuminates one of most poorly understood aspects of CAP research: what attributes may be important for expanding climate planning to politically conservative communities. 


\section{CHAPTER 2: PROCEDURES AND METHODOLOGY}

In terms of methodology, research for this thesis is centered on case selection, CAP analysis, and interviews of individuals with intimate knowledge of, or important roles in, the climate planning process. Interviews comprise the bulk of data in this thesis.

\section{RESEARCH CONTEXT}

Prior research evaluating climate action plans provided valuable insight into the methodology and analysis techniques utilized in this thesis to assess climate action plans in politically conservative communities. Notably, Bassett and Shandas (2010) analyzed CAPs using a three-pronged method. First, plans were selected, then evaluated, and finally interviews were conducted of key informants. The process used in this research mirrors these three steps.

Research conducted by Sharp et al. (2011) offers a number of valuable insights into structuring a CAP research endeavor. One aspect of this study is extremely important for the research question included in this thesis. Sharp et al. warn against the potential pitfall of case selection being narrow in scope, raising issues of generalizability. With this in mind, the scope of this thesis is to draw comparisons between cases identified as politically conservative through interviews and climate action plan analysis. Certain assumptions have to be made when discussing implications and drawing conclusions from research findings. To the greatest extent possible these assumptions are well defined 
when addressing research questions and the hypothesis of this thesis. Another attribute of research conducted by Sharp et al. (2011) is that it relies on previous CAP research to determine variable selection. This is the same approach used in this case study.

\section{CASE SELECTION}

\section{Research Method}

The method of analysis employed in this research is the case study approach, structured by interviews and content analysis. Content analysis is primarily based on each selected city's CAP document. This is supplemented by newspaper articles, meeting/hearing minutes, and staff reports. The unit of analysis for this research is CAPs in Republican jurisdictions (as a proxy for conservative CAPs). For this thesis, Republican jurisdictions are defined as cities located in counties that voted for the Republican candidate in the 2012 Presidential Election. This is explained in more detail in subsequent sections.

Previous studies of CAPs have identified unique criteria and characteristics present in climate action plans in terms of design, creation, and adoption. Through analysis of the data utilized in these studies, it was determined that the vast majority of CAP research to date has focused on climate plans created in politically liberal cities (cities that are Democratic as defined by the research methodology in this thesis). For this thesis, prior CAP research analyzing climate plans is used as a control for CAPs in general. This information is then analyzed 
in the context of this case study evaluation of CAPs in conservative communities. By structuring the analysis in this way, the vulnerability and clear criticism regarding whether findings are indicative of conservative CAPs alone or just CAPs in general is addressed.

\section{Determining "Conservative"}

In order to begin the case study process, it was essential to first identify how to define if a community was conservative. To this aim a number of data sources were drawn upon. Quantitative analysis of election results and voter registration statistics were the primary source of this information. This information was used to identify CAPs adopted by jurisdictions located in counties with a Republican voting record in the national 2012 Presidential Election. In the absence of this, a Republican majority of registered voters was used.

This method was selected instead of alternatives for a variety of reasons. In the field of political science, voter registration level is considered a more nuanced source of political leanings (Wattenberg \& Brians, 2002; Cooper, Haspel, \& Knotts, 2009). Voter registration statistics are primarily available through each state's Secretary of State (or Lieutenant Governor's) office. There is a significant variety in the level of statistical detail each state keeps and makes available for this information. The vast majority of states do not have jurisdiction level public voter registration data. Because of this, there is no uniform data set at the national level which can be drawn upon. Additionally, no national, uniform data set was located detailing 2012 U.S. Presidential Election results at the jurisdictional level. The most nuanced, uniform, and reliable data set located was 
county level election results. For the 2012 U.S. Presidential Election, the Associate Press compiled results for each county in the nation. Two news outlets that house this data were used for this research (Rogers and Cage, 2012; The Washington Post, 2013).

For this research, county data is extrapolated in order to draw conclusions regarding smaller communities located within their boundaries. This approach of using voting records/voter registration in order to determine political attitudes has been used in a number of CAP studies (Pitt, 2010b; Krause, 2011b; Sharp et al., 2011; Zahran, et al., 2008b; Hawkins \& Wang, 2012; Lubell et al., 2009; Reams, et al., 2012). Political attitudes are often used as a proxy for conservative vs. liberal in a similar manner in prior CAP research. It should also be noted that although 2012 election results were used to determine politically conservative cities, six of seven CAPs in this study were initially developed between 2007 and 2011. The most recent election results (2012) were used rather than 2008 results in order to identify communities with a conservative political make-up at present; however, this approach is a constraint of 2012 elections results as proxy measure for politically conservative cities. 2008 results may be a better measure for indicating each city's political attitudes at the time of CAP development.

The primary limitation in using this type of data in such a way is that that county level election data is not necessarily representative of the political leanings of cities contained in them. Furthermore, because the political make-up of the United States is primarily a two party system, communities who vote Republican do so for myriad reasons. These can be social, political, or economic, among others. This is also a limitation as even the most detailed voter registration or 
election data at the jurisdiction level would not alleviate this criticism. Election data alone cannot possibly capture the nuances of conservative ideology in America. This aim of this thesis however, is not to define what it means to be politically conservative, but rather to understand if political ideology that may be skeptical of climate change affects the climate planning process. Many CAPs face opposition to some degree, and this thesis seeks to determine if CAPs in jurisdictions selected using the methodology outlined in this thesis are affected by the political atmosphere in their communities more so than CAPs in general.

\section{Climate Action Plan Selection}

Professor Michael Boswell, Ph.D and Associate Professor Adrienne Greve, Ph.D. of California Polytechnic State University maintain a national CAP database. This database includes 325 climate action plans and is updated numerous times annually (Boswell \& Greve, 2013a). Of the 325 CAPs included in the database, 245 have been completed (adopted, accepted, or reached their final stage) 2012 U.S. Presidential Election county level data was cross referenced with this database in order to identify potential cases for this thesis.

By including 2012 election results as a criterion in the CAP database, of 245 completed CAPs, 22 were identified as being created in cities located in a county that voted a majority Republican. This represents approximately 9 percent of completed climate plans in the database. Meaning of course, that over 90 percent of CAPs in the database were created in cities that are located in a county voting a majority Democrat. 
Figure 1 illustrates the geographical patterns of voting behaviors in the 2012 Presidential Election by county. The map is organized according to winning candidate's percentage of the vote, with red representing Republican and blue representing Democrat; the darker the color, the higher percentage of the vote. The map highlights the high proportion of counties that voted Republican in the 2012 election. Research shows that urban centers in general have tended to vote Democratic in recent elections (Jacobson, 2013). That being said, the fact that the vast majority of counties in the U.S. voted Republican, yet such a small percentage of CAPs in the database were identified as being located in Republican counties is noteworthy. Even if the criteria used in this thesis to determine conservative CAPs does not account for the nuanced nature of U.S. politics, the methodology seems to highlight the trend of CAP development being concentrated in cities located in counties that vote Democratic. This finding demonstrates the necessity to expand climate planning to Republican jurisdictions.

Figure 1: 2012 Election Results by County

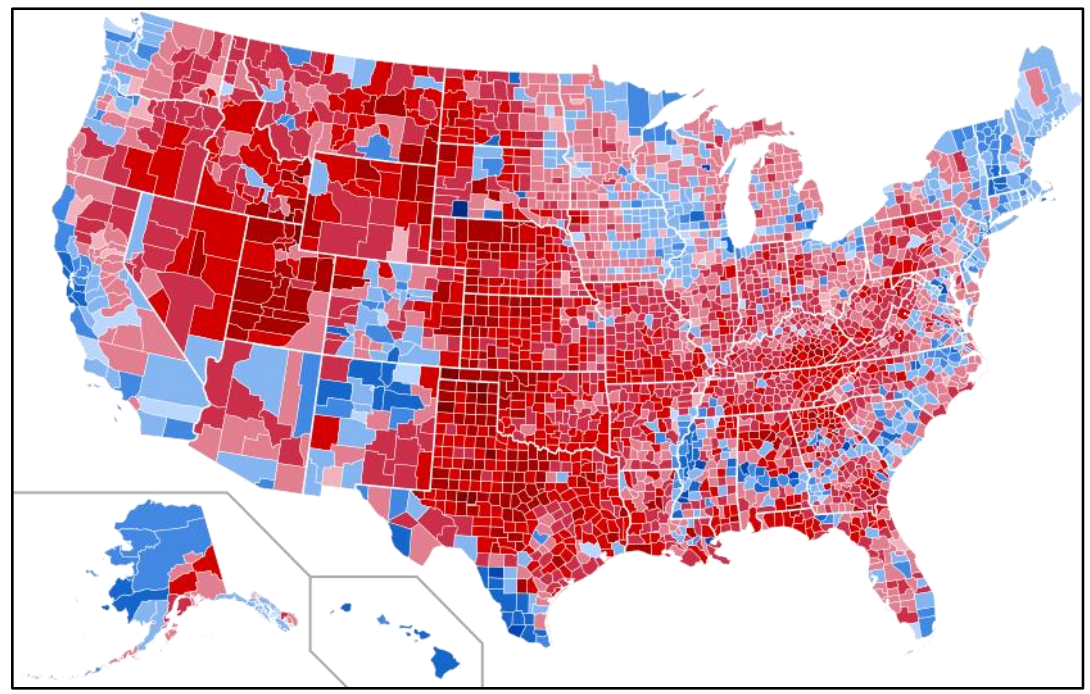

(Wikipedia, 2014) 
Of the 22 cities identified as conservative, 15 were deemed appropriate for case study research. This was concluded by analyzing each CAP. Seven of the 22 CAPs were evaluated as unsuitable due to their scope or absence of an essential component identified in prior research as necessary for being considered a complete CAP. This included components such as a GHG emissions reduction target, an emissions inventory, an emissions forecast, or CAP measures. The list of 15 was further narrowed using a number of criteria. If more than one CAP existed in a single county, the CAP in the city with the largest population was selected. This assumed that the city with the larger population would be more representative of the counties' voting habits due to its share of eligible voters in comparison to other cities in the county. Cities universally recognized as liberal enclaves in conservative counties were also excluded (for example, college towns). The final way that cases were removed is if contacting interview participants was impossible, or those involved in the CAP process were unwilling to partake in the study (two cases were removed using this criterion).

As a result, seven CAPs were selected for inclusion in the case study. Four of these are located in California, one in Tennessee, one in Colorado, and one in Kansas. Interviews of those involved in the CAP process, or those with intimate knowledge of it, were conducted. The content included (or omitted) in CAP document was also analyzed. 


\section{INTERVIEWS}

\section{Research CONTEXT}

The interview process is essential for the case study approach utilized in this thesis. Conducting interviews is a useful method for researching the intricacies of climate planning in politically conservative communities due to the insights provided through candid conservations, and, behind-the-scenes information about official processes. A number of prior CAP studies address this process. The value of interviews is that they can outline a jurisdiction's keys for success in conducting GHG emissions mitigation policies (Pitt, 2010a).

Pitt (2010b) indicates that elected officials and high-level administrators have an intimate understanding of local institutional and political characteristics that cannot be assessed without insider knowledge. Although interviewing high level officials is important, focusing on those individuals alone may exclude some insight from additional individuals closely involved in the CAP process. Other CAP research (Millard-Ball, 2012) focuses on interviewing a variety of stakeholders; including "city staff members, elected officials, environmental advocates, developers, and staff from regional agencies" (p. 10). Identifying and reaching these individuals is also important. Research by Pitt (2010b) includes a detailed description of a methodological approach for contacting jurisdictions and conducting interviews regarding CAPs - the approach of this case study is loosely based on this. The process outlined in this study emphasizes pinpointing, contacting, and interviewing the most knowledgeable individuals in each community. For this thesis the most knowledgeable or involved city staff, 
contractors, and community members for each of the seven cases were contacted for interviews. These individuals were located through review of the CAP document, contacting the department that managed the plan process, reviewing local newspapers, or examining city council meeting minutes.

Interview question structure is important to consider because it can dictate what types of responses are received. Kousky and Schneider's (2003) telephone interviews focused on motivations to initiate CAPs, and utilized an open-ended question structure in order to elicit varied, free flowing responses. Wheeler (2008) conducted telephone interviews of state and local officials and focused on methodology including question type and guaranteed anonymity so that responses weren't filtered by concerns about backlash. For this thesis, telephone (rather than in person) interviews were the selected method as the physical distance between each case city is substantial. Furthermore, telephone interviews allow for more flexibility with time commitment.

Part of the aim of each interview was to assess the attitudes of respondents participating in CAPs located in conservative communities. A study by Leiserowitz (2006) includes a number of interview questions designed to assess perceptions and opinions of the climate change issue. Review of these questions was important in framing some of the interview questions selected for this case study.

Formal interviews are essential to the case study approach and focus all other methods of analysis. For this research, interviews offer a structural backbone, and comprise the bulk of material used in analysis. They provide qualitative data, 
valuable insight, and intimate knowledge that other methods cannot. By analyzing interview data factual information can be cross referenced, and themes, beliefs, prejudices, and biases can be explored. Questions can be answered and information gathered that is not inherently clear based on plan review or other research methods.

\section{Interview Procedure}

Drawing on the research of Bassett and Shandas (2010), Kousky \& Schneider (2003), Millard-Ball (2012), and Pitt (2010b); interview participants were selected, contacted, and interview questions were devised. Through analysis of each CAP, individuals with a high level of involvement in the planning process were identified. In some cases this was supplemented with web searches of municipal websites and newspaper articles in order to narrow down key informants. Interview participants were contacted by e-mail or telephone and asked to participate in the climate plan study.

Two of seven high level officials contacted passed the interview request on to staff or working group members most integral to, or familiar with, the CAP. In this way, the most knowledgeable participants were interviewed in each case. Pitt (2010b) argues that this variability in the study population (of those with different role, motives, and perspectives) is not ideal. However, Pitt (2010b) found that this "was a necessary trade-off to ensure that the most knowledgeable individuals were surveyed or interviewed for each municipality" (p. 722). A comparable trade-off was also found to be advantageous for the purpose of this thesis. In order to further mitigate this potential issue, multiple interviews were conducted 
for each case study in order to reduce the bias inherent in evaluating individual perspectives. At the conclusion of each interview, participants were asked for recommendations of other knowledgeable or involved members of the community who may be contacted as potential interviewees. In this way, 21 interviews were conducted for the seven case studies included in this research.

Elected officials, city staff, climate plan working group members, and community stakeholders were selected for interviews. In the vast majority of cases, individuals interviewed were staff members or consultants who authored or managed the plan, or members of CAP work groups that led the CAP process. Interview participants were asked for permission to record each interview in order to improve transcription accuracy and promote a conversational structure. Each interview lasted between 30 and 90 minutes. One minor deception was used to reduce bias in the interview process. Subjects were told that the research topic's pursuit was to "assess what factors contribute to the successful adoption of climate planning initiatives" leaving out the "politically conservative communities" aspect of the research. This decision was made in order to elicit responses to all interview questions, instead of drawing focus to political aspects exclusively. The decision was also reviewed and approved by California Polytechnic State University's Human Subjects Committee.

\section{INTERVIEW QUESTIONS}

Both short-form and long-form interview structures were used in order to account for how much time and interest each interviewee had in answering questions. 
In each interview, a list of questions was asked derived from the thesis questions and hypothesis. Additional questions were included as a result of the literature review of past CAP research. The approach Kousky \& Schneider's (2003) used of deliberately asking open-ended questions was used in this research in order to produce less restrictive, narrative-style, responses.

For this thesis, question structure was fashioned so that the basic aim of each question would be answered, but it also allowed interview participants to elaborate in whatever way they chose. Because there was such a variety in the nature of plan involvement for each interview subject, in some interviews, certain questions were not asked. Interview question topics included in this research are: the CAP process, motivations, political atmosphere, community involvement, implementation outlook, and personal reflection. Broad categories were used to organize each set of questions. These categories are: General Questions, Post Adoption (or Acceptance, Approval), and Personal Reflection. See Appendix for the list of interview questions.

\section{Confidentiality And Anonymity}

Confidentiality is an important issue when conducting interviews in case study research. The political nature of this thesis topic raises a number of moral and ethical questions due to its focus on interviews as part of a case study structure. Agreeing to be interviewed on a potentially controversial topic represents an important decision for prospective interviewees. Fear of reprisals from

employers, media, and those in the community can in some instances outweigh a 
desire to participate. In order to elicit candid responses from those involved, this study employs a well-defined level of confidentiality for interviewees.

In Case Study Research: Design and Methods, Yin (1994) discusses the necessity in some case study research to make the identity of interview subjects anonymous. Yin argues that there are levels of anonymity that can be employed, but that full anonymity is the least desirable approach because it reduces the researcher's ability to structure the analysis in an ideal manner, and that data/results cannot be peer reviewed with the same level of detail. Theoretically, for this case study, it would be most desirable to include the name of cities, interview participants, and the CAP itself. However, in this digital age, dedicated research using any one of these variables can reduce anonymity considerably. A strategy with the highest level of confidentiality thought possible, without compromising the research, was constructed as a way to ensure participants' protection for the frankness of their responses.

For this research, the names of cities, interview participants, and places of employment have been removed in order to maintain confidentially for those involved. The title of each climate plan is also absent due to the fact that many climate plans are named in a unique way. Plan titles are described by identifying common terminology that is present or absent. Specific departments, committees or work groups responsible for the plan that could be easily identified are given a generalized term such as "committee." However, some important details deemed to have a negligible impact on confidentiality and viewed as important for providing context for this thesis have been included. The state each climate plan is located in is clearly specified. The title of each interviewee as well as their role 
in the CAP is also included. There is also a short description of the community where the CAP was created and its political make-up (based on interviews); both are highly generalized and could just as easily define other communities in the state. This being said, there is no way to completely and assuredly protect anonymity without removing the vast majority of substance from the case study method.

\section{CLIMATE PLAN ANALYSIS}

For this research, climate action plan analysis was primarily used to identify cases and supplement interview data. Each CAP was analyzed in order to gain familiarity with the plan and process, identify key attributes, and determine key stakeholder and staff involvement. Additionally, CAP analysis was used to draw comparisons and create a summary of characteristics for each case.

An important aspect of CAP analysis was to identify variables that are present within CAPs. Independent variables are defined and described in detail in CAP studies conducted by Zahran et al., 2008b; Reams, et al., 2012; Tang et al., 2010; and Wheeler, 2008. This previous research was relied upon heavily in determining which characteristics in CAPs would be analyzed. Research by Millard-Ball (2012) was also important for locating, assessing, and analyzing a number of characteristics in each jurisdiction relating to CAPs. These include, CAPs themselves, staff reports, and meeting minutes. 


\section{CAP TEMPLATE}

A variety of additional attributes were also measured and evaluated for each plan. These include attributes identified by previous CAP research as well a template created by Dr. Michael Boswell and Dr. Adrienne Greve (Boswell \& Greve, 2013b), of California Polytechnic State University designed for CAP review and analysis. This template was modified in order to include important variables and attributes identified in previous CAP research. Additional alterations were made to accommodate the research questions and hypothesis of this thesis. The aim of this is to determine what each conservative CAP has in common, and what differences they possess. The research template used for CAP analysis can be found in the Appendix (Table 2).

\section{Variables}

Variables and attributes analyzed in each CAP are divided into 11 major categories. Each major category is comprised of multiple variables and attributes. These 11 major categories include*:

- Basic Information

- Contents

- Participation

- GHG Emissions Inventory

- Types of Measures (by Sector) and Number of Measures

- Emissions Reduction 
- Distribution of Emissions Reduction (by Sector) and Reduction Percent Share of Target

- Implementation

- Structure and Motivation

- Memberships

- Regional Influence

- Political Influence

- Other

${ }^{*}$ For a detailed list of variables and attributes see Appendix.

\section{CAP Analysis Procedure}

Each of the seven CAPs included in this case study was evaluated using the variables included in the CAP Analysis Template. Plans were carefully read multiple times in order to accurately identify each variable in the CAP. Information not available through CAP analysis, but included in the template, was found using internet searches, census data, or municipal websites, or asked in interviews. Once information was populated in each template for all seven cases, the Excel spread sheets were combined. Individually, key findings (such as unusual characteristics, or notable correlations) were identified and summarized for each case. Afterwards, the same was done for the cases as a whole. Due to issues regarding confidentially, populated CAP Analysis Templates for the seven cases are not included in the Appendix. 


\section{ORGANIZATIONAL STRUCTURE OF ANALYSIS}

Once interview and CAP analysis information was collected it was analyzed and evaluated. Findings were first identified for each case individually (Chapter 3: Data, Findings, and Results). Next, information collected for all seven cases was compared and evaluated in the context of the existing CAP research (Chapter 4: Summary and Discussion). Finally, these findings were examined in the context of a number of criteria. These include the hypothesis of this thesis, research questions, and prior CAP research. This information is included in the final chapter of the thesis (Chapter 5: Implications and Conclusion).

\section{Data, Findings, ANd Results}

The following is a brief overview of how Chapter 3 is structured and organized. The bulk of information included in this chapter relates to interviews and is supplemented by CAP analysis data. This chapter is organized by case number, and includes five major parts. These elements are:

- Location Description

- Case Summary (highlighting important attributes of the process and key aspects of the interviews)

- Description of CAP from Analysis (including terminology used in CAP title)

- Summary of combined interviews (including a description of interview participants; comprising the most detailed element of the chapter)

- Analysis and Reflection of interview content 
Each case is separated in this chapter. The majority of cross-case comparison and analysis can be found in Chapter 4 .

\section{Interviews}

The interview subsection of Chapter 3 is separated into 10 categories. The category structure is based on responses to interview questions (see Appendix). These categories are:

- Political Makeup of the Community

- Motivation for Plan Creation

- Terminology

- Negative Reactions/Responses to the Plan

- Political Difficulty

- Plan Creation and Community Involvement

- Plan Implementation

- Lessons Learned and Advice

- And finally an Analysis and Reflection of the content of each of the above

Broad definitions of each category are included at the beginning of Chapter 3 . There is also a list explaining terms included in the combined interview summaries that are important for understanding the context of various references. It is important to note that although each interview was conducted separately, the information gathered from transcripts of individual interviews are combined into the interview summaries. This decision was made to support comparisons of answers to each topic (within a single CAP process/jurisdiction), 
and as a way to promote increased confidentiality. The writing style used for the combined interview summaries is journalistic in nature. Unless otherwise specified, every sentence or idea in this section is paraphrased or directly quoted from each interview. The final section, Analysis and Reflection, is primarily a discussion of each interview summary as a stand-alone case.

\section{Climate Plan Analysis}

As previously described, climate plan analysis is used to supplement information derived from interviews. In Chapter 3, this analysis was used to create a description of each of the seven CAPs included in the case study. Key information relating to motivation, notable attributes, quality, and type is summarized for each case using the CAP Analysis Template (see Appendix). This information clarifies important aspects of each of the seven cases, and provides context.

\section{SUMMARY AND DISCUSSION}

In Chapter 4, important findings from the seven case studies, including the CAP analysis and interview data, are summarized. Common themes are presented in the context of prior CAP research. Attributes that emerged through data analysis are divided into four major categories:

- CAP Motivation

- Notable characteristic

- CAP Development Process

- Adoption and Implementation Success (as well as failures). 
The primary sections of the chapter include a statement highlighting key lessons learned for each theme or attribute in the above categories. The ensuing content in each section summarizes the findings and evidence leading to these

conclusions. The research findings for the seven cases as a whole in Chapter 4 provide a platform for Chapter 5 (Implications and Conclusion).

\section{IMPLICATIONS AND CONCLUSION}

Chapter 5 addresses the hypothesis and research questions outlined in the introduction of this thesis. A description of overarching implications for climate planning of this case study research is summarized. In addition, Chapter 5 includes a Statement to Professionals section outlining 12 Lessons and Best Practices for planning practitioners, and a section describing Future Research and Research Outcome. This section includes a reflection of the case study research process and opportunities for future research focused on CAPs in politically conservative communities, as well as CAP research in general. 


\section{CHAPTER 3: DATA, FINDINGS, AND RESULTS}

This chapter encompasses information summarizing each of the seven cases included in this study. Interview transcripts (three for each case) are combined into a single narrative. Interviews were conducted between February $27^{\text {th }}$ and May $1^{\text {st }}, 2014$. These narratives are broken into categories derived from the interview questions (see Appendix). Information from the combined transcripts is supplemented with a short description of key findings from the CAP Analysis. Finally, the findings and results of this data are described in the Reflections and Results section at the end of each case.

\section{Case Study Organization}

Summaries of each case based on the combined interviews are organized into nine primary categories. Unless otherwise specified, all information included in these categories is paraphrased or directly quoted from interviews.

Political Makeup of the Community: Interview participants were asked "How would you characterize the political beliefs/leanings of your community?" Information included in the category for each case city was compiled based on interviewee answers to this question.

Motivation for Plan Creation: This category explains what led each case city to discuss, develop, and create a CAP. 
Terminology: For this category "terminology" is defined as specific terms, language, titles, and scientific information included in each plan. This often involves discussions the authors or individuals driving (or approving) the CAP undertaking may have had regarding how to frame the CAP within the community. This extends to how the plan is named and how terms such as global warming, climate change, and sustainability, are incorporated.

Negative Reactions/Responses to the Plan: This category summarizes interviewee descriptions of negative feedback (or lack thereof) received during the CAP process. This includes responses from the community at large, city staff, CAP committee/work group/task force members, and elected officials.

Political Difficulty: The Political Difficultly category recapitulates interviewee opinions of the issues each CAP faced politically. This category has overlap with the category above, but looks in greater detail at the political nature of the CAP process. It also includes information regarding what was done to address this and mitigate it.

Plan Creation and Community Involvement: This category sums up the CAP process. It recounts which city departments, committees, or citizens groups were most involved in the CAP. It also addresses the issue of a CAP champion, and level of community involvement. Community mobilization and community buy-in are discussed as well.

Plan Implementation: This section includes a discussion of the future outlook for each CAP. It evaluates CAP success to date and monitoring techniques. This category also summarizes the opinions of each interviewee regarding what is 
expected in the future for each CAP, and the level of commitment each city (and its departments) have to incorporate the CAP into city operations.

Lessons Learned and Advice: The final section of each case's interview summary is a compilation of responses to two interview questions:

- Hypothetically, if I were to begin a climate plan in a community similar to yours, what advice would you give me in order to have a successful plan from the beginning to the point of adoption by City Council?

- Do you have any suggestions, best practices, or lessons learned that you would like to share from your experience?

This section comprises a wealth of information derived from each interviewee's unique experiences and involvement in the CAP process. These responses are important to consider for any individual undertaking a CAP in their community.

\section{TeRms AND DEFINITIONS}

When reviewing information in this chapter, it is important to understand a number of terms and definitions that provide context for each case.

\section{U.S. Conference of Mayors Climate Protection Agreement}

This agreement has been signed by over 1,000 mayors nationally as of 2014 (see Figure 2). The agreement represents a commitment from each signatory city to take action on the issues of global GHG emissions, and climate change. For 
many cities signing the agreement has been a precursor to CAP creation. According to the U.S. Conference of Mayor's website (Usmayors.org, 2008), under the Agreement, participating cities commit to take following three actions:

- Strive to meet or beat the Kyoto Protocol targets in their own communities, through actions ranging from anti-sprawl land-use policies to urban forest restoration projects to public information campaigns;

- Urge their state governments, and the federal government, to enact policies and programs to meet or beat the greenhouse gas emission reduction target suggested for the United States in the Kyoto Protocol7\% reduction from 1990 levels by 2012; and

- Urge the U.S. Congress to pass the bipartisan greenhouse gas reduction legislation, which would establish a national emission trading system.

Figure 2: Cities Signed-on to Climate Protection Agreement

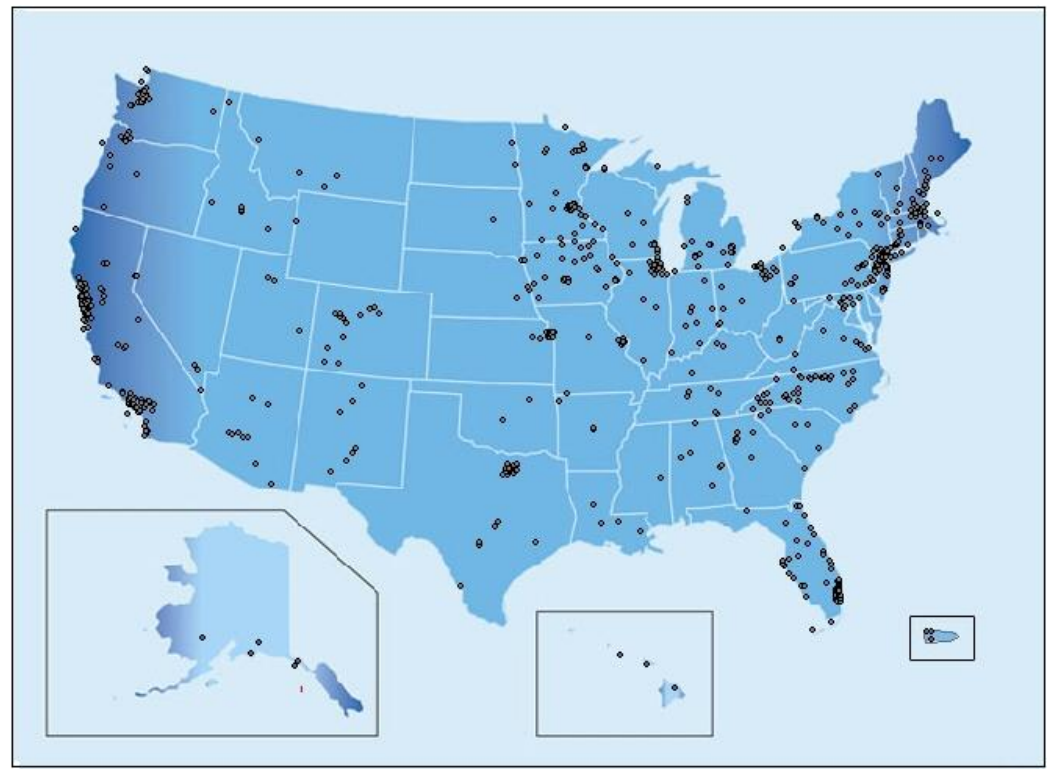

(Usmayors.org, 2014) 


\section{ICLEI}

ICLEI, also known as Local Governments for Sustainability, is a non-profit organization that assists local governments in promoting sustainability. Cities can become ICLEI members, and are provided resources from climate planning and other sustainability initiatives. There are over 1,000 members worldwide (Icleiusa.org, 2014). Some of ICLEI USA's resources for local governments include a Climate Action Handbook, a Climate Protection Manual, example climate action plans, and GHG emissions inventory tools. Many cities use these tools and ICLEI materials to assist in CAP creation.

\section{Agenda 21}

Agenda 21 was developed in 1992 during the United Nations Conference on Environment and Development in Rio de Janeiro, Brazil. It is a voluntary and non-binding action plan for sustainable development (Icleiusa.org, 2014). In total, 178 nations adopted the plan (including the United States under the Bush Administration). Chapter 28 of the Agenda includes a section titled "local Agenda-21" and offers a vision on how sustainability initiatives can be developed by local governments (United Nations, 1992).

In recent years, Agenda 21 has become a political issue in the United States and there has been substantial opposition to the Agenda, as well as the validity of climate science and government regulation in general (Hinkes-Jones, 2012; Jamison, 2012; Kaufman \& Zernike, 2012; Frick, Weinzimmer \& Waddell, 2014). In the United States, some groups and individuals (often affiliated with the Tea 
Party) see Agenda 21 (and in many cases sustainability as a proxy) as part of a U.N. conspiracy focused on controlling the U.S. by regulating land use and property rights. In recent years, public works projects and other planning initiatives have faced obstruction at city council hearings and public meetings due to "anti-Agenda 21" opposition (Frick, et al., 2014). In some cases this vocal opposition has stalled or stopped projects, programs, and policies (Kaufman \& Zernike, 2012). In the Republican Party's 2012 platform there is a reference to Agenda 21; "We strongly reject the U.N. Agenda 21 as erosive of American sovereignty, and we oppose any form of U.N. Global Tax" (Republican Platform 2012, 2012, p. 45). ICLEI has also come under fire due to its connection to Agenda 21. ICLEI provided input to the UN and represented a number of local government organizations in the process. For the purposes of this research, opponents of Agenda 21 will be referred to as "anti-Agenda 21."

\section{Assembly Bill 32 (California)}

AB 32, also known as The Global Warming Solutions Act of 2006, is a California State Law intended to reduce GHG emissions throughout the state. Among a number of policies included in AB 32, it directs the California Air Resources Board (ARB) to use regulations in order to reduce the state's GHG emissions 25 percent to 1990 levels by 2020 . AB 32 represents the state's commitment to combating climate change. Part of the law requires the California ARB to develop a Scoping Plan detailing the state's GHG reduction approach, the first Scoping Plan was adopted in 2008 and the 2013 update is currently in progress. 
As a result of $A B 32$, the California Attorney General's Office began challenging Environmental Impact Reports (EIR) for large projects and General Plan updates which did not account for GHG emissions, reduction targets, and mitigation (Grandterracecityca.iqm2.com, 2014). In 2007, Attorney General Jerry Brown successfully filed a lawsuit against San Bernardino County under AB 32 and the California Environmental Quality Act (CEQA). The lawsuit was filed on the grounds that the County's general plan update violated both laws by failing to account for and mitigate GHG emissions and incorporate an analysis of how proposed growth would affect the state's reduction targets (Puff.lbl.gov, 2014). CEQA and AB 32 were also invoked by the Attorney General in a lawsuit targeting the City of Stockton (Johnson, 2009). This action sent a clear message to other cities and counties in California to account for $A B 32$ in their planning endeavors. The California Attorney General Office's official position on climate plans in the state is that it strongly recommends that jurisdictions create CAPs.

\section{Senate Bill 375 (California)}

SB 375, also known as The Sustainable Communities and Climate Protection Act of 2008, is a California law that builds on AB 32. It specifically targets GHG emissions from passenger vehicles because transportation emissions make up 40 percent of emissions in the state (Ca-ilg.org, 2014). As with AB 32, SB 375 requires the $A R B$ to take action on the issue, in this case by setting regional reduction targets. Each metropolitan planning organization (MPO) in the state, in collaboration with $\mathrm{ARB}$, is directed to set an emissions target for their region (Cailg.org, 2014). An element of each MPO's responsibility under SB 375 is to prepare a Sustainable Communities Strategy (SCS) as part of each MPO's 
regional transportation plan (RTP) (CARB, 2014a). This SCS guides land use, transportation, and housing strategies designed to reduce GHG emissions (if implemented). SB 375 is viewed as an important policy for climate action planning in the state.

\section{CASE 1}

\section{Location Description}

A city in northern California with a population of approximately 100,000 . The city is the largest in a conservative county, but in close proximity to a larger city in a more liberal county. The city is growing in population and can be characterized as "business friendly."

\section{Case Summary}

Interviews were conducted between February $27^{\text {th }}$ and March $20^{\text {th }}, 2014$. The CAP was initially developed during Bush's second term and accepted by City Council during Obama's first term. The community-wide plan is preceded by one focusing exclusively on municipal operations. Both plans focus heavily on costsavings and energy efficiency measures. The city owns and operates its utilities, influencing measures included in the plan. State action such as AB 32 was a motivation for creating a CAP. Scientific discussion regarding human causes of climate change is absent. The plan was created by a committee overseen by the Economic development department. This committee comprises city staff, elected officials and citizen stakeholders. Overall, there was little backlash to the plan 
politically. Members of the business community had the most reservations about specific measures included in the plan. With their input the plan cost-savings were emphasized and compliance was structured as advisory rather than regulatory. Due to concerns from City Council and certain stakeholders, the plan was accepted, rather than adopted by Council; making its implementation voluntary rather than compulsory.

\section{DESCRIPTION OF CAP from AnALysis}

PLAN TITLE: The climate plan title includes sustainability, but not climate.

The plan was guided by city staff and an engineering and consulting firm along with a 35 member committee broken into work groups. Municipal emissions make up less than three percent of overall emissions. Transportation accounts for approximately 45 percent of overall emission. Measures included in the plan reflect this with nearly half focusing on the transportation sector. The expected reduction from these measures is approximately 65 percent. The CAP's overall reduction target is approximately 25 percent by 2035 . To meet this goal the CAP outlines a reduction per capita, rather than the traditional approach of reducing GHG emissions to baseline or 1990 levels.

The CAP does not include a climate science primer. Co-benefits are highly emphasized. These include energy independence, reducing emissions of GHGs and air pollutants, energy efficiency and conservation, creating healthy neighborhoods, creating local jobs, and saving money. The CAP is aimed at meeting regulatory obligations established by federal, state, and regional 
agencies. Each measure included in the plan is extremely detailed. Measures include GHG reduction potential and associated costs and savings, as well as community benefits. The implementation strategy is also extremely detailed. Each measure is assigned to a specific city department and includes phasing.

\section{INTERVIEWS}

Three staff members who worked closely on the plan were interviewed. These included:

- A Deputy City Manager and Economic Development Director who was instrumental in gaining City Council approval of a new task force focused on environmental issues. This task force was a precursor to the development of the climate plan, which was created under its umbrella. The interviewee served as the project manager for the plan in its predevelopment, early stages, and worked closely with the consultant firm contracted to create it. Another staff member described this person as "the driving force behind climate planning in [the city]." This individual eventually left the city partway through the process, before it was completed and accepted.

- A Business Services Analyst and Project Manager for the climate plan. This individual took over as Project Manager for the plan after the original manager left. They originally served as staff for the larger committee that guided plan development, and worked closely on many aspects of the plan before taking over as Project Manager. This individual worked with 
consultants contracted for the plan and guided it through completion and eventual acceptance by City Council.

- An Associate Planner that served as co-project manager on the endeavor. They provided staff support for the plan's steering committee.

\section{Political Makeup of the Community}

In interviews, the community was characterized as a "business friendly suburban community" and "conservative area." The city was described as a "Republican enclave," with a powerful Chamber of Commerce. There was said to be some skepticism in the community about climate change and mandates in general.

\section{Motivation for Plan Creation}

There were a number of motivations for creating a climate plan for the City. Two interviewees described the success of an earlier climate plan focusing strictly on municipal operations as an important factor in developing a more comprehensive community-wide climate plan. This municipal CAP was a way to "lead by example" and set the groundwork for more climate action initiatives. Notability, the municipal plan is very detailed and heavily focused on economics, employing a cost-benefit approach to many of the policies included. The influence of this approach can be seen in the community-wide climate plan, which is extremely detailed (compared to many plans reviewed in this study) and has a breakdown of costs associated with each policy included as well as their related GHG reductions. One staff member also stated that the reduction of GHG impacts, in its own right, was also as motivating factor. 
Another factor that contributed to the impetus for creating the plan, referenced in all of the interviews, was state action and regulation relating to air quality, GHG emissions, and growth. With the passage of Assembly Bill 32, creating a climate plan was seen as a proactive path forward for the community and a way to define its own destiny. There was an implication when speaking to those involved in the plan that the actions of the State Attorney General who had sued municipalities in the past for not incorporating or complying with $A B 32$, could eventually force jurisdictions to take action on climate change. One interviewee said that the Attorney General had been looking at fast growing cities and their compliance with $A B 32$ and SB 375 legislation. In that sense, it seemed more practical to for the city to create its own plan. Creating its own plan was also thought to help the city "achieve community buy-in." Another goal of the plan, along the same lines, was to comply with the Air Quality Board standards. The City hoped that with the plan in place, it could be used as a mitigation measure that would satisfy their requirements. Another important factor indicated in each interview is the detail that the City owns and operates its own electric utility.

\section{Terminology}

All three interviewees stated that discussions took place regarding how to incorporate potentially sensitive terminology into the CAP creation process. Terminology such as climate change, global warming, and other buzzwords were handled delicately. In fact, in the municipal plan that was a precursor to the community-wide plan, climate change "wasn't mentioned" (it focused instead on cost savings). In one interview, it was stated that "Scientific discussion [of climate change] was left out on purpose," and that "[The consultant] is used to doing 
that." Rather than climate change and global warming, the term sustainability was used, under the assumption that it had more of a broad appeal.

\section{Negative Reactions/Responses to the Plan}

Business leaders on the committee were said to be cautious and wary of the plan's implications and wanted to frame certain aspects of it. They were worried about aggressive targets, and associated restrictions. Two interviewees described how a few building community leaders and building officials on the plan's committee were reluctant to accept climate change was happening and as a result, would not sign on to the plan if cost savings associated with it were absent. One staff member believes that one member of the business community would have drummed up opposition "against [the plan] if it was compulsory."

There was more of an overall concern about elements of the plan than outright backlash (these concerns weren't public). Because of this there was a great deal of dialogue with the business community. One staff member stated that having such as diverse panel created many different viewpoints. In order to create a plan that everyone would buy into, numerous questions had to be addressed; this was seen as a constructive process. Another staff member found the plan to be contentious for the public and elected officials. City Council members were in support of the economic benefits associated with the plan, but "didn't want to sign on to global climate change" outright. Within the community there was no resistance to the plan associated with the anti-Agenda 21 movement. 


\section{Political Difficulty}

During the plan creation process, a mayoral change took place. The first Mayor was much more supportive of the plan than the Mayor that replaced him, who was "much less sympathetic." During this election cycle there was also City Council turnover that followed the same pattern, "there was skepticism," but it was not a heated issue and no one ran on a platform against the plan or related issues. One political difficulty described by staff was that of funding mandates for the plan. There was concern relating to funding new actions. One action that would have cost millions to implement was removed from the plan in light of these concerns, "It didn't make sense to endanger the overall plan due to a single measure." The business community was said to "[use] the plan to make sure business views were incorporated." This influenced the measures included in the plan and its legal "teeth." The nation's economic downturn was also identified as an issue for the plan politically in relation to how it was funded. Due to some of the concerns raised by members of the City Council, when the plan was presented to the Council, it was "accepted", rather than "adopted" in the final vote, making it voluntary rather than compulsory.

\section{Plan Creation and Community Involvement}

Based on interviews of city staff a few themes were identified concerning how the plan was developed. The Economic Development Department guided the committee that oversaw the plan, more so than the Planning Department. Planning Commissioners were on the committee, but the Planning Department itself primarily played a supportive role, with one planner serving as a "liaison 
between Planning and the committee." On the other hand, the Electric Utility Department played a strong role due to $\mathrm{GHG}$ emissions reduction regulations included in the plan. This was important in providing incentives to reduce GHG emissions.

A few members of city's staff were said to be local champions of the plan. These included the Project Manager of both the municipal and community-wide plan, and the Utility Director who authorized staff time for the effort (as well as the Electric Department as a whole). Having a champion in the City Manager's office who endorsed the plan was identified as important for the plan's success. In each interview, a local nonprofit that educates citizens about green issues was discussed, and its importance to outreach efforts for the plan was emphasized. The community was said to be mobilized behind the plan by this nonprofit, Earth Day outreach, information about utility programs, noticing the plan, a website, and surveys. This messaging primarily focused on the sustainability aspects of the plan and energy efficiency. Committee meetings were also advertised and opened to the public, with each meeting focusing on a specific sector or topic included in the plan. However, despite these outreach efforts, the final City Council meeting where the plan was accepted was not well attended by the public. Since the plan was accepted, there has been some outreach, but the city "[has not] done too much due to the economic downturn, and losing a major champion." Losing that advocate for the plan was seen as something that may hurt its long term outlook. 


\section{Plan Implementation}

A number of the plan's measures have been implemented to date, but implementation has been mixed overall in terms of success. Some transportation capital projects are underway. Yet, in general, due to the state of the economy, there has been a lack of resources devoted to implementation. One staff member stated that "Many parts of the plan are documenting what we have been doing." To date, some of the most successful measures are those mandated by the state. Going forward, state legislation regarding climate planning is seen as important and it is expected that the state will become more stringent on requiring municipalities to take action. Staff also said that, since acceptance, the plan is not a topic that has had a large presence in City Council or departmental meetings. When asked "How successful do you think implementation will be in your community post-acceptance?" one interviewee responded that the city will use what it can from the plan for future regulatory mandates, but the "plan probably won't go beyond its current state, unless a new staff person is added" to the project. The primary system in place to monitor the plan's progress is tracking by the Utilities Department, and updating the emissions inventory.

\section{Lessons Learned and Advice}

During the CAP creation process, city staff had number of notable lessons and suggestions. One important point was that when creating a plan staff should "Be clear about what benefits you want to get out of it." The process can take longer than CAP developers may think (two and a half years instead of one year, in their case). It is important to "Anticipate how much effort will be needed," for example, 
one and a half full time staff (combined) and a consultant. If you embark on a plan, you cannot always achieve everything you set out to do. An example of this was using the plan as mitigation for CEQA or an EIR. The city ended up being at odds with the Regional Air District regarding some assumptions included in the plan. Air District staff found that "[The plan] did not go far enough to be considered as a CEQA mitigation measure." By not allowing the city to use the plan as a mitigation measure, its application (and a motivation for its creation) was reduced. One staff member said they would have liked to have a more powerful partnership with the Air District; this would have given more insight on thresholds of significance. Another interviewee stressed the importance of involving all city department and identifying champions in each (who can be counted on), "Don't count anyone out." Building on this, it was seen as imperative to keep managers and those "at the top of the food chain" informed because "They don't want to be surprised."

Looking back, staff would have liked to have involved the development community to a greater extent. Timing is very important (i.e. the ongoing economic downturn), and members of the Council and community were worried about hurting business. The way that the committee was set up, it included many sectors and interests in the community; this was seen as an asset. It was important to utilize a good communications strategy, including: why the plan is good for business and why it is good for the environment, why it saves money. These aims do not have to be mutually exclusive. Upon reflection, staff advised any city setting out to create a climate plan to tailor the message to different audiences, using various pitches to gain support. CAP developers must know their audience, and be forthright with what you are trying to achieve. "It can be a 
very technical discipline. The way that you bring the message to the public is important. [It] must be easy to digest." Education is key and sets good groundwork for the plan. The plan's former Project Manager advised those involved in climate planning to fall back on legislation when needed, for example, "SB 375 says we have to do ___; in this way focus is put on the state rather than on "your city."

\section{ANALYSIS AND REFLECTION}

In comparison to other plans evaluated in the case study, Case \#1 stands out in a number of respects. Evaluating the individual measures revealed that each policy or program included in the plan is extremely detailed in comparison to those in the other plans that were analyzed. Aside from detailing each measure, a breakdown of reduction potential is present which includes cost/benefit assumptions separated by costs to the city, the private sector, and expected GHG reduction associated with each. This level of detail seems to reflect the heavy economic emphasis of the municipal plan (one of the authors was an engineer and economist) that preceded the community-wide plan. One staff member commented that it may have made more sense in retrospect to have made a combined municipal and community inventory; this makes sense if considering the inventory alone. However, in the context of other plans evaluated in this study, it seems that by creating a municipal plan beforehand, many lessons from that process were applied to Case \#1's community-wide plan.

Although the plan had heavy buy-in from staff and the City Manager's office, due to concerns from the business and development community and the City Council, 
the plan was accepted rather than adopted. Although this is not an ideal situation from the perspective of those involved in the plan, it is a pragmatic approach in a city where there is some opposition to certain aspects of the plan. By making the plan $100 \%$ voluntary it was more politically palatable. However, there is no certainty that this approach will result in implementation success in the long-term. It is possible that the politics involved in gaining initial CAP support from elected officials are dissimilar to those required for implementation. One staff member described the politics of climate planning well: "Know the political climate." They went on to stress the importance of knowing the city you are working in, and emphasized framing the plan accordingly.

Prior research on climate plans has found that in some cases climate plans simply serve as policy documents that consolidate existing programs and actions already present in the target community (Betsill, 2001; Betsill \& Bulkeley, 2004; Millard-Ball, 2012) Based on Case \#1 interviews, this was not the case to a great extent. Yet, the success of some of the most developed policies and programs in the plan were in line with that finding. Existing research on climate planning points to the importance of having a "local champion" (Betsill \& Bulkeley, 2004; Pitt, 2010a). In the case of this city, losing a champion was viewed by staff as a setback for its continued success after City Council acceptance. This is an important finding because there continued to be strong advocates and effective leadership for the plan, but losing a champion with influence in the City Manager's office was thought to have a lasting impact.

A valuable takeaway from Case \#1 is the impact of state action and state mandates in California. When interviewee's described motivations for creating 
the plan, fear of litigation, and the passage of $A B 32$ and SB 375 were mentioned a number of times. Moreover, some of the most successful measures postacceptance were those covered by state laws and action. When asked about how the city planned to monitor progress, one staff member said that due to the staff time necessary for a detailed monitoring program, a government mandate would be needed to put that system into place. Otherwise "an auditor or conservative manager would ask: Why is this being funded?" Although there are many grants available in California to prepare plans, there are few grants available for implementation or monitoring. This begs the question, given the limited resources in many jurisdictions, is it necessary to have state mandates for implementation of plans and monitoring of GHG emissions reduction for politically conservative communities to continue to take action?

Another finding is that although stakeholder groups were incorporated heavily and effectively in the committee that oversaw the plan, staff still believed it was difficult to effectively reach average citizens. One staff member would have liked to see more public outreach. Unlike other cases in this study, in this one a staff member felt that "There is more support now for sustainability," and that "Sustainability touches on a little bit of everything." The staff members appeared to feel that the term sustainability is a touchstone for many issues in the community and that there is broader support presently, then at the time the plan was created. This implies that negative connotations and politically negative associations of the term sustainability that are present in some cities are not in present in Case \#1. This idea is backed up by the fact that the anti-Agenda 21 movement was not cited in any interview as an issue in the planning process. 


\section{CASE 2}

\section{Location Description}

This city, located in Colorado, has the largest population in its county. The city has approximately 10,000 residents and has grown by nearly 20 percent in the last decade, but is expected to grow slowly in the future due to geographical constraints.

\section{Case Summary}

Interviews were conducted between March $6^{\text {th }}$ and March $1^{\text {st }}, 2014$. The CAP was developed, and accepted by City Council during Obama's first term. The committee that authored the plan consisted entirely of citizens. This group lobbied City Council to authorize the plan, which focuses only on municipal emissions. It is the only plan of the seven in the case study to do so. The CAP is also the shortest of all seven cases in this study. Despite this, the plan contains a large number of measures (in comparison to its size). However, each measure in the plan contains the least detail of any CAP in this study. The volunteer citizen committee wrote all of the measures included in the plan. There was essentially no city staff or departmental involvement in the plan, aside from the City Clerk assigned to the committee and staff feedback at various stages. The CAP faced minimal political opposition from community, but experienced "backlash" from the City Council which had "reservations." At the final City Council meeting only the plan's targets were adopted; measures included were "accepted", meaning that 
they are not legally binding. This occurred with a single vote majority. Of the plans adopted, Case \#2 has the poorest implementation outlook. This is in part due to a lack of staff buy-in, but also because the implementation plan is severely lacking.

\section{DESCRIPTION OF CAP fROM ANALYSIS}

Plan TItLE: The climate plan title includes energy and climate, but not sustainability.

The CAP focuses exclusively on municipal operations and emissions. Goals of the CAP included addressing climate change, community sustainability, and energy costs. The document is shorter and less detailed than the majority of CAPs analyzed. A detailed emissions inventory, broken down by sector is not included in the CAP. The reduction target is approximately 20 percent below [the year the plan was written] levels by 2020 . This target is based on the U.S. Mayor's Climate Protection Agreement and Colorado Climate Action Plan of 2007 targets. Although the plan is relatively short, it includes over 150 measures and essentially no detail for any. The sectors in the CAP with the most measures are transportation, energy, and waste. Measures included in the CAP are not assigned to any specific city agency and a detailed implementation strategy is not outlined.

\section{INTERVIEWS}


Two committee members who worked closely on the plan and one expert advisor/editor were interviewed. These included:

- A member of the City Council for a portion of the plan development process. This individual was also a member of the city's energy commission. This interviewee also served as a member of the energy committee that authored the plan.

- A resident of the community who peer reviewed the plan, serving as an advisor to the committee. This individual also directed a large scale climate plan in another city in the region. Has a depth of knowledge in climate planning and has written a few. Was previously a City Council member.

- A committee member who was a writer and editor for the plan. This interviewee played an important role in framing the policies included in the plan. Additionally, this individual worked closely with other energy groups in the region.

\section{Political Makeup of the Community}

The community's politics were described as a cultural mixing pot where the electorate is split on many issues and mixed between liberals and conservatives. The city is located between rural, politically conservative communities with economies based on resource extraction, and affluent environmentally minded communities. Residents in the city share both of these views on natural resources. It can be characterized as fiscally conservative, but many citizens are interested in environmental issues. 


\section{Motivation for Plan Creation}

The committee that was formed to create the plan comprised volunteer citizens concerned about a number of environmental issues. The region is affected by wildfires, drought, and periods of minimal snowpack. The plan was seen as a catalyst for the city to make a statement on climate change and take responsibility for its own energy use. In two interviews it was expressed that other plans in the region, and momentum on climate change at the state level, led to the plan's creation. The U.S. Conference of Mayors Climate Protection Agreement was signed and supported by City Council. In each interview, the municipal electric utility, owned and operated by the city, was seen as an important factor in the creation of the plan.

The decision only to focus on municipal operations and not create a communitywide climate plan was seen as a way to "lead by example." One interviewee reflected that they “didn't feel that the issue is embraced enough by the community as a whole to warrant a community-wide inventory," and that the decision to leave it out may have had to do with the fact that the county was planning to do an energy inventory in the future. A committee member felt that the planned "baseline inventory seemed best suited for municipal operations." Having former City Council members on the committee was also identified as a motivation for focusing exclusively on municipal operations.

\section{Terminology}


Discussions regarding specific terminology were not identified through interviews. However, the plan's title includes the word energy, highlighting that term as an important foundation of the plan. The contents of the plan and its structure were discussed considerably. The plan contains many programs considering its length when compared to other plans evaluated, and the committee discussed how to simplify the language of the programs therein. Discussions took place between the committee, staff, and the City Council regarding whether the plan should be advisory or should contain measuring, monitoring, and/or an enforcement mechanism. Many of these issues were raised by the City Manager who was described as hesitant to have overarching targets included in the plan.

\section{Negative Reactions/Responses to the Plan}

One committee member said that from the outset, "naysayers" appeared before City Council, expressing their concern surrounding the plan as "misplaced priorities" for the city, and downplayed the significance of climate change. Committee discussions resulted in the plan being called an energy plan, rather than a climate action plan, out of fear of backlash. Some committee members were "weary of the process." The plan was not seen as an easy sell to Council.

\section{Political Difficulty}

The majority of political difficulty for the plan centered on getting it through City Council. There was a 4-3 vote to authorize the plan and a 4-3 vote to adopt the targets. When the plan was presented to Council, it experienced some pushback. A few members of the Council felt that the plan was too far reaching. One 
committee member interviewed said that "the truth is we packed way too much into the plan," and tried to prescribe solutions rather than making policies and programs outcome based. Some Council and committee members felt that it would have been better if the plan had set goals, but left the process to reach those goals loosely defined. Council members wanted the goals to be realistic to achieve. One committee member said that it was challenging at Council to attempt to make the plan more than an advisory document. In the end only the plan's targets were adopted by Council, the measures were "accepted."

\section{Plan Creation and Community Involvement}

A group of citizens came forward and asked the Council to take action on the climate change issues; as a result the Council asked for individuals in the community to develop the plan. The CAP committee was made up of citizen volunteers who authored the plan and participated in specific work groups; this represented the majority of community involvement. Committee meetings were conducted in public and work sessions with the Council were structured as community meetings. Staff had minimal involvement in the plan. The Community Development Department and planning division were not involved whatsoever in the plan. The City Manager served an advisory role, and the "Public Works Director came to one meeting." The City Clerk was the most involved staff member whose role was to keep the plan in bounds in terms of feasibility and legality. Community mobilization efforts consisted of a couple of letters to the editor, and organizing and lobbying leading up to the final City Council meeting. However, not a single interviewee thought that the plan achieved overall community buy-in. 


\section{Plan Implementation}

Based on the interviews, the success of plan implementation does not have a promising outlook. It is believed that the city will support the plan politically but is unlikely to take implementing action. An element that has reduced the ability for plan implementation is competition for capital and general funds. The fact that there was not a great deal of staff buy-in for the plan also reduced its implementation potential once adopted. Moreover, the guiding committee was also essentially disbanded after the plan was adopted, darkening the future outlook of the plan.

One committee member said that the plan was "gathering electronic dust." However, the city has supported energy efficiency measures through energy efficiency coaching, rebates, and system upgrades. One interviewee said that the plan helped set broad objectives, enhancing the community's desire for action, its commitment to awareness surrounding climate change, but not specifically due to the expected success of each measure in the plan. A couple of individuals were identified in the interviews as strong advocates and drivers for the plan, but not necessarily champions. One interviewee stated that certain members of the committee were integral in getting the plan adopted by City Council, but did not think any of them continued to champion the implementation of the plan.

\section{Lessons Learned and Advice}


Perhaps due an unsatisfactory outlook concerning the plan's implementation, interview participants had a wealth of feedback regarding lessons from the process and suggestions for success. Committee members expressed a certain level of melancholy relating to the trajectory of the plan. One interviewee said that he was" supportive of the emotional effort of the plan, but didn't really feel like it was going to go anywhere." A committee member felt that they took the wrong approach by including mountains of prescriptive programs taken from other climate plans. Instead, a suggested approach is to keep it simple, set 5-10 year targets and goals from the outset. Once that is complete, the CAP creators can decide how to achieve them, and create a well-defined implementation strategy. Another reflection is that communities similar to the one profiled in Case \#2 value stability, and because of this, a pragmatic approach to CAP structure (and measures therein) is ideal for those locations. On interviewee said, "A community like this doesn't need to be on the cutting edge. It is more important to be straight forward and focus on tangible issues like reducing lifecycle costs and lifecycle risks."

Other lessons derived from interviews relate to working within city government and the community. The plan was created by volunteers, but staff buy-in is imperative for the success of implementation and tracking. For the plan, staff buy-in was not fully achieved. This may in part have to do with how programs were written; the plan language made it difficult to implement. There also needs to be an easier way for staff to track progress. For a climate plan to be successful, it is important to integrate policies into all aspects of city departments and other city goals. This did not really take place. The city also needs to be accountable for its actions. 
Another reflection is that the success of a plan in a community like this one "comes down to money at the end of the day. It also comes down to relationships within the community." One interviewee said that, "We as an environmental community have undervalued those relationships" (speaking broadly about environmental organizations and their efforts). For example, the Public Works Director has a lot of power and influence; a lot could be done if this individual is behind the cause. However, the Public Works Director was not highly involved or solicited for input in the planning process. The interviewee went on to say that when creating environmental policies like climate plans, it is important to understand what these change agents want, what the hot button issues of the community are, and to "frame the plan around that."

An additional piece of advice centered on how to market climate plans within the community. It is important to test words with the community, and find out how to motivate the community to act. The answer to this is unique to every town. Make the plan as agreeable as possible. Naming is important, based on the community it may make sense to name it an "energy independence plan," or a "21st century infrastructure plan." Essential considerations from the outset include: determining what the goals are, how those are will be achieved, and how the plan will be implemented. Trusting relationships are also important. Build relationships and trust with key "movers and shakers" in the community. It is vital to engage community rather than make people feel guilty and have them act as a result of that alone.

\section{Analysis and RefLection}


Case \#2 is the only climate plan in the study to focus principally on municipal emissions (although it does include a target for community-wide emissions reduction). This is notable, considering that the plan was created by a group of citizen volunteers and had minimal staff involvement. The fact that the plan was created by a group of citizens with no ability to implement the plan once it was approved by City Council is unusual and may have contributed to the problems associated with implementing the plan. In other interviews conducted as part of the study, municipal inventories and climate action policies were principally viewed as a method for cities to save money. Considering this, it is surprising that there was not more staff guidance or buy-in for the climate plan, especially on the part of the City Manager.

An important finding is that although the city in Case \#2 is not very large in terms of population, it does own and operate its own utility, distribution facilities and power lines. This appears to have made the city and at least some of its residents very conscious of electricity cost, energy efficiency, and alternative energy sources. Every person interviewed pointed to the city owned electric utility as an important driver for the climate plan as well as for other environmental initiatives relating to energy in recent years. Owning its own utility gives the city more say in how it obtains its energy. This can be seen as a significant factor leading to the creation and adoption of the city's climate plan. It also likely influenced the municipal emissions focus of the plan, especially considering that some City Council members were highly involved in the plans creation and were very aware of the importance of the city's electric utility. The title of the climate plan also prominently includes "energy", indicating that this emphasis is highly important as a goal and motivation for the plan. 
It may be noteworthy that although the plan focused exclusively on emissions reduction from municipal operations, there were some members in the community who expressed reservations of what adopting the plan would mean for the community. Some members of the City Council were described as being against regulatory programs included in the plan. This is interesting considering that measures included in the plan were primary dedicated to city energy use, transportation, and infrastructure. There seemed to be a libertarian view of the aim of the climate plan for some in the community. Some individuals were worried about the plan restricting their freedoms and said that "the city shouldn't control" them. This sentiment seems out of context considering that the plan did not involve many measures geared towards community-wide GHG emissions or community behavior. Perhaps this provides insight into why the climate plan committee decided to focus on municipal emissions rather than community-wide emissions. If the backlash existed when municipal operations were the primary focus, it could have been much more substantial if community-wide emissions and measures were included.

In addition to being the only case in the study that focused exclusively on municipal emissions, Case \#2's CAP was also the only one not to use ICLEI resources in some way when creating its climate plan. There has been research regarding what impact ICLEI has had on the diversity of climate plans and applicability of an ICLEI to specific communities (Bassett \& Shandas 2010, Pitt, 2010a). One committee member for the CAP said that "I personally didn't find ICLEl's resources that useful," in reference to a separate climate plan they were involved in writing previously. In other interviews conducted for this thesis study, 
ICLEI tools were identified as helpful (especially for staff) for creating emissions inventories and later for updating GHG emissions by sector. ICLEI resources were also seen as useful when selecting specific measures for inclusion in climate plans and providing access to a network of other communities who have gone through the process of creating a climate plan. Instead of using ICLEI, the measures included in Case \#2's climate plan were selected by analyzing those included in other climate plans reviewed by the committee. This process appears to have had an impact on the number of measures included (high) compared to the length and level of specificity of each measure (minimal).

Based on interviews, the outlook of plan implementation does not seem very positive. The plan may have raised overall awareness about a number of issues. However, based on the interviews, there are a few bright spots. Energy efficiency policy has taken off in recent years, and the community as a whole is characterized by one interviewee as in support of "green" causes. It is uncertain if this is at all related to the CAP. Regardless of the CAP process' impact, through recent actions, the city has shown its commitment to energy awareness. If nothing else the plan put a spotlight on the issues raised and policies present in the plan. By creating a climate plan, many members of the community became more aware of the issue. For Case \#2, the climate plan itself may not end up reducing a significant amount of emissions in the community, but separate energy efficiency measures and alternative energy priorities initiated parallel to the climate plan's creation may have a significant impact on GHG emissions reduction within the community 


\section{CASE 3: ENERGYSAVING VALLEY}

\section{Location Description}

The city is the largest in its county, with a population of over 150,000 . It is a cultural and business center in the region and is also home to a number of colleges.

\section{Case Summary}

Interviews were conducted between March $10^{\text {th }}$ and March $19^{\text {th }}, 2014$. The original CAP was created and released by City Council during Obama's first term. The CAP was developed by the city's policy department with input and inclusions of additional city departments. A task force comprised of stakeholders within the community was created and oversaw development of the plan. Case \#3's CAP emphasizes co-benefits, primarily "cost savings and energy efficiency." The city did not sign the U.S. Conference of Mayors Climate Protection Agreement, assuming that signing it would be politically polarizing, and that the city could make a commitment to sustainability without doing so. Although an anti-Agenda 21 constituency is active in the community, the plan and its process did not experience significant political difficulties. The plan received support from the City Council. However, the plan was never formerly approved by Council, and the CAP resolution was never ratified. Rather, it was "released" and implemented by the Mayor as a "de facto policy." Implementation of the plan has a bright outlook, and the implementation section of the plan is more detailed than most 
cases in this study. Many of the original plans goals have been achieved to date. An updated plan was created with new goals as a result.

\section{Description of CAP fROM ANALysis}

PLAN TITLE: The climate plan title includes energy and sustainability, but not climate.

The CAP and inventory are very detailed. The plan is aimed at reducing GHG emissions, mitigating air pollution, energy efficiency related to rising fuel prices, and economic development opportunities. Climate change is described as very likely human caused. Emission reduction measures focus primarily on energy efficiency. Municipal emissions account for less than five percent of the inventory total. There appear to be more municipal strategies included in the plan than the share of emissions warrants. The CAP reduction target is 20 percent [from inventory year levels] by 2020 . The plan has been updated twice since the inventory was created. Based on the inventory, transportation accounts for nearly 50 percent of total emissions. However, less than 15 percent of measures included in the CAP focus on transportation. Few specific measures in the plan are linked quantitatively to the inventory or targets. Because of this, it is difficult to determine whether the number of transportation measures affects the projected reduction potential.

Fewer overall measures are included in the plan than in other CAPs evaluated, but each is well defined and thought out. Additionally, the logic behind each measure included in the plan is very detailed. This is also the case for the 
implementation and financing plan. Some measures (primarily energy related) describe grant funding available. For implementation, the CAP and includes status, start date, completion date, and next steps for each measure. Each measure is realistically achievable and has expectations, milestones section, and next steps included. Each strategy and initiative is connected to funding. All measures are funded by the city itself or grants. Notably, most actions are policy related and do not require large funding sources. The most costly programs included in the CAP are energy efficiency related and have a significant pay back for each dollar spent.

\section{INTERVIEWS}

Two staff members who worked closely on the plan and one manager who served an advisory role were interviewed. These included:

- The current Director of Sustainability for the city. This individual served as the project manager for the plan as well as its update. The current project manager initially led a group focusing on growth as well as the sustainable energy task force for the plan. Another staff member led the project early on, but left the city partway through the process.

- A Project Manager in a city office that focuses on environmental measures. This individual was important in developing the original plan as well as its update.

- The sustainability manager at the utility board who served as a member of the plan's stakeholder group. This individual primarily served as an 
advisor regarding energy efficiency and utility measures included in the plan.

\section{Political Makeup of the Community}

The city is characterized as "conservative" but this has not always been reflected in the political affiliations of elected officials. High level city officials have been involved in national climate change issues (after the plan was created). The city is considered more progressive than the county as a whole. The community was said be weary of mandates which can create pushback, and that "people don't like to be told what to do, [they] are independent."

\section{Motivation for Plan Creation}

The primary motivations cited were "cost savings and energy efficiency." The plan was also seen as a way to address environmental concerns within the community. With a plan in place, a mechanism was created for tracking the goals and ensuring accountability. The aim of the plan was seen as "economic benefits, dollars saved, jobs, and emission reduction." One political figure was involved in motivating action towards climate change on behalf of the city.

\section{Terminology}

A great deal of thought went into how to develop the plan. It was purposefully not called a climate action plan, because "climate can be a polarizing word." Climate change is and has been controversial in the region. Co-benefits such as 
"Reducing energy consumption...bring[ing] jobs in, [and] sav[ing] money" were a focus of the plan. Energy and cost savings were terms that spoke to the needs of the community, and issues that any political party could get behind. Climate was replaced with sustainability in the plan's title and as its emphasis because it "was a broader, neutralizing term." In recent years however, the term sustainability has changed meanings politically and does not have the same level of broad appeal that it did at the time of the plan's creation.

\section{Negative Reactions/Responses to the Plan}

There were only small pockets of vocal opposition to the plan during the creation process, but groups and individuals were adamant about a number of things. The term sustainability received some backlash, as did stimulus money relating to environmental programs and earmarked dollars for specific measures. Some in the community that see certain environmental measures as a waste of tax dollars have said on occasion that "[stimulus] money should be sent back." The antiAgenda 21 movement has been an issue to some extent in the community. This has principally been in relation to sustainability and federal grants. In one instance the city "received an open records request for emails and documents relating to ICLEI."

\section{Political Difficulty}

As a precursor to the plan, the Mayor made a decision at the time not to sign the U.S. Conference of Mayors Climate Protection Agreement. It was thought that signing the agreement could be politically polarizing and not much would be 
gained by signing it. However, the Mayor authorized the plan's creation, under the assumption that the city could still create an effective plan and engage the community without signing the agreement.

The climate plan's cost saving focus helped win broad approval for it. The City Council was "aware and supportive" of the plan. A notable finding is that the plan was not formerly adopted by Council, but implemented by the Mayor (who had replaced the previously mentioned Mayor) as a "sort of de facto policy." The Council was never asked to approve the plan or its reduction goals (the resolution was never ratified).

\section{Plan Creation and Community Involvement}

The climate plan was developed primarily by the Policy Department, which coordinated input from other city agencies. A task force was created that oversaw development of the plan. Climate plan case studies were researched to create the plan. The task force held public meetings which resulted in the creation of work groups that focused on specific aspects of the plan. Work groups were created using an inclusive process and included an "open invitation for community members to join." Work groups employed an inclusive approach and promoted an "open door policy" for gathering ideas from stakeholders. An attribute found to be characteristic in many of the cases in this study was also true for Case \#3; the planning department was not heavily involved. However, it should be said the city does not have a traditional planning department in its agency structure. There is a regional planning agency, but it was not heavily involved in creation of the plan. 
The city's Mayor (during the plan's final stages) was identified in each interview as a champion for the plan. This mayor was elected after the more conservative mayor, who declined to sign the U.S. Conference of Mayors Climate Protection Agreement (but authorized the plan's creation). Other staff members were also described as champions for the plan and effective agents for "getting it done." However, most collaboration and involvement appears to have been focused on involving city agencies and important allies such as the business community. Neighborhood groups were also targeted in order to incorporate issues of importance to them in the plan. Aside from these efforts, work groups, and public meetings, the general public was not highly involved in the process. Direct engagement included a blog and a website. One staff member said that involvement of the general public "was a bit of a weak spot." Yet mechanisms were built-in to the climate plan to conduct future outreach relating to the measures included.

\section{Plan Implementation}

After the plan was "released" (rather than adopted) by City Council, it was well publicized. This publicity is cited as an important precursor for successful implementation of the plan. The press was interested and receptive of the plan, and newspapers covered it. In general there was excitement surrounding the plan, especially around measures dealing with solar energy. The city hit the ground running, emphasizing "quick wins" in terms of initiatives that were being rolled out. Overall, the community was said to be supportive of actions the city was taking. The Mayor was effective as a leader for the effort, one staff member 
said that in the community "there has been a cultural change and awakening" surrounding climate and sustainability issues.

Implementation is expected to be highly successful, evidenced by the fact that the plan has been revised and new version released in less than five years. This is a result of the majority of action items included in the original plan being completed. In the update new goals were created. However, most of the "lowhanging fruit" actions have been completed. Some measures have not been completed due to lack of funding, political will, or are not currently feasible. Because of this, outside funding for measures included in the plan is being heavily pursued.

As is the situation of many of the cases included in this study, tracking measures and their impacts has been difficult. An internal progress tracker is currently being utilized, but no extensive monitoring program is in place. One asset is that the plan is written in a way that makes the aim of each measure as specific as possible. The majority of tracking focuses on what steps are being taken for each measure included in the plan. Measures that have funding are evaluated based on the amount of dollars leveraged (e.g. rebate programs). Energy measures are one sector that has been evaluated based on a number of criteria. These include jobs completed (energy efficiency measures), capacity (for solar), and number of charges and length of charges (electric vehicles). It has been difficult to determine impacts of individual strategies. This is especially true because measures that focus on "behavior changes are hard to gauge." 


\section{Lessons Learned and Advice}

Staff involved in the plan had a wealth of advice for developing successful climate plans. The first important step is to frame the question around topics that the community cares about. A community driven process is essential. Developing a climate plan is a long process, and creating an inventory and goal is much less involved than creating a community-wide plan itself. Another important takeaway from the interviews is to be clear and public about measures and messaging early on and "be open and transparent about meetings." Furthermore, for climate planning, make sure each issue is tangible and "a shared interested that people can be united behind." This can take away the partisan aspect of the debate and can assist with community buy-in. Reaching out to neighborhoods and neighborhood group is also viewed as essential.

One staff member said that "there is no substitute for hard work and working through the community process about getting input." Plan developers must figure out how to make the process more equitable, "Are you hearing all the voices [in the community], including ones you usually don't?" Be transparent in that endeavor "strive to be equitable in your input collection." Bringing in non-profit groups and engaging important members of the community who represented various constituencies was vital. It is crucial to engage decision makers as well as the community. Invite respected individuals that can lend credibility. It is important to have support of the Chamber of Commerce and the business community. Business leaders that can speak peer to peer are very important (they have a distinct perspective), rather than just presenting a laundry list of how 
certain policies will "help" the community at large. From a political standpoint it is important not to polarize groups.

The other major category of feedback relates to how to work effectively within a city's bureaucracy. One of the most important first steps, even before beginning to develop the plan, is to identify the political champion(s) ("mayor, council, chamber-in that order ideally"). Think interdisciplinary. Work closely with various city departments and department heads. Department heads can carry each initiative forward. Not having fear of reprisal is important; engage as many departments and community groups as possible. In the process it was important to have movers and shakers on the task force.

Staff support at all levels is very crucial for success. Imbed policies in all aspects of city government, from small to large, "integrate sustainability into municipal operations." It is prudent to always have the end game in sight, and think of each approach in terms of how implementation can be successful. It is important when creating a CAP not to underestimate the time or data collection needed. Case \#3's CAP placed a heavy emphasis on feasibility and implementation from the outset. Procedures were instituted to track every minute detail in the plan in terms of value. As much as possible, each program or policy included in the plan was practical and did not require additional funding to be rolled out. Some measures were reliant on grants or other funding, but there was no "ask" for large sums in order to roll out the plan. This was made easier due to the structure of how each policy or program was infused into various departments. 
A last category of advice centered on how to effectively roll out energy efficiency programs. This is an important aspect of the plan due to its significant emphasis on cost savings and energy usage. Diversity exists within the community in terms of knowledge of available programs. Overall, there is support but not a groundswell that creates demand for energy efficiency; reduced rates are the primary driver for change. The utility uses the city's communications groups as a vehicle for reaching customers. It employs strategies such as mailings and newspaper ads. However, the utility is always conscious not to be overbearing with the customers as initiating more programs could raise the cost of utilities, creating backlash. For the most part, the utility attempts to optimize its operations and provide incentives for new technologies and energy efficiency. An important note is that there are mandatory energy usage measures only for municipal facilities. For residential usage, measures are voluntary. Due to this, education is paramount. Some individuals in the community have poor energy usage habits; this is also true of building community (in terms of construction techniques). This culture needs to change for a significant paradigm shift to take place. In recent years, "more and more, climate change is linked to energy efficiency in the community" and so is action.

\section{Analysis AND RefLection}

The architects of Case \#3 were very pragmatic in their approach to developing the city's climate plan. Economics, energy savings, and other co-benefits were well publicized and used as a device to gain support of city departments and business groups within the community. When developing the plan the energy committee prioritized involving stakeholder groups within the community. One of 
the most fruitful of these was the inclusion of the Chamber of Commerce and business leaders. Including business leaders is important in climate planning because politically, many of the criticisms levied at climate plan relate to how certain policies may harm economic growth or hurt small businesses through unnecessary regulation. For many of the cases in this study, this perception has been difficult to get past, reducing input from these groups, and sometimes even threatening the potential for success. In this case, business leaders were recruited as allies and used their unique perspective on the economic benefits that the plan could provide to speak with their peers and gain their support. This inclusionary approach helped frame the climate change discussion and reduced polarization within the community.

Staff buy-in from all departments was seen as crucial for the success of the plan in terms of implementation and as a way to create realistic measures that could be achieved. An interdisciplinary approach was utilized with measures included in the plan assigned to specific city departments. One way this was achieved was by using the support of champions within city government to include department heads in the process. With their support as well as that of staff at all levels, it was possible to entrench measures included in the plan in all realms of city operations. Research has shown that this is the best method for continued success of climate plans over time, as staff turnover occurs or political support wanes (Pitt, 2010a).

Case \#3 and Case \#1 employed the most detail of all climate plans involved in this study. Each measure in Case \#3's climate plan has a well-defined description, aim, and funding source. Interviewees expressed reservations 
regarding how any city can successfully monitor the GHG emissions impacts related to specific measures. This has been seen as an issue for many of the climate plans included in this study. However, it is apparent when speaking with city staff involved in the plan that a great deal of effort went into addressing the issue of measuring implementation. Each measure is tracked either by the energy committee responsible for overseeing the plan and associated updates, or the city department responsible for that specific measure. This highlights another important reason to infuse responsibility of each measure throughout city departments. In this way, the city does not need to create and fund a specific staff member to oversee plan monitoring and implementation, reducing the overall financial burden taken on.

Case \#3's CAP overcame a number of political obstacles in order to create a successful climate plan. A significant finding is that much of the plan's success has been achieved without overall support and involvement of each realm of city government. The city never signed the U.S. Conference of Mayors Climate Protection Agreement and did have a conservative Mayor who was not necessarily entirely behind the climate plan ideologically at the time the plan was initially developed. Yet, this Mayor was convinced enough by those in city government and city staff, that the plan made economic sense and approved its creation. This highlights the fact that mayors can get past partisan politics in order to make policy decisions they believe will benefit their community.

An important finding is that the plan was not officially adopted but rather accepted by City Council. The resolution outlining the climate plan's reduction goals was also never ratified by Council. This means that as a policy, nothing 
included in the plan is legally binding. After speaking to city staff, it appears that the decision not to formally ask Council to approve the plan or its reduction goals may have been done by staff intentionally to ease the process and possibly to reduce the chances of facing backlash from the community or City Council.

The climate plan also faced limited opposition within the community. This opposition may have been partially quelled by the fact that the plan was accepted rather than adopted, making measures city policy, but not official law. However, there is an anti-Agenda 21 constituency within the community and region, something that has been identified as an issue for other cases in this study. Staff appeared to primarily deal with this by listening to concerns but not engaging in debate regarding climate science. It should also be noted that staff indicated that the term sustainability has become politicized in recent years, and is more controversial than at the time the plan was created initially. This is something that has been seen in other cases as well.

\section{CASE 4}

\section{Location Description}

A city in southern California with a population of approximately 100,000 . The city is one of the five largest jurisdictions in the county. It is less than 50 miles from a more liberal county. The city has experienced a significant population increase in recent years due to a large annexation. 


\section{Case Summary}

Interviews were conducted between March $6^{\text {th }}$ and April $9^{\text {th }}, 2014$. The CAP was developed, and adopted by City Council during Obama's first term. The CAP in this case was created parallel to the city's general plan update. The same consultant team wrote both plans with direction from the planning department. Primary motivations for created a CAP include state legislation $(A B 32$ and $S B$ 375), and a desire to stimulate economic activity and job growth in the city. This desire is emphasized because most residents currently commute to jobs in the region. The term sustainability is seen a politically contentious in some instances, in part due to an active Tea Party presence in the region. Despite this, the CAP faced only minor opposition from a vocal minority focused on terminology included in the CAP rather than the plan itself. As a companion document to the general plan update, concentrated on energy and cost savings components (rather than GHG emissions reduction alone), the CAP received institutional backing as well as the support of the City Council. Because of its connection to, and internal consistency with, the general plan update, the CAP measures are well imbedded in city policy and departmental structure. To date, the majority of successful measures included in the CAP are those connected to state mandates. Funding for all measures included in the plan is not yet secured.

\section{DESCRIPTION OF CAP fRom ANALYSIS}

PLAN TITLE: The climate plan title includes climate, but not sustainability. 
Although the CAP was created in tandem with the city's general plan update it is a robust, stand-alone document (on the longer side of CAPs analyzed). Climate science is addressed as well as potential impacts including those on water supply, natural disasters, wildfires, air quality, and public health. The sources of GHG emissions (i.e. $\mathrm{CO}_{2}$ ) are described in detail, as well as the science behind this, however, human caused GHG emissions are implied, but not explicitly stated. In no part of the science section is it stated that the overwhelming scientific consensus ties climate change to anthropogenic causes. Co-benefits are emphasized in the CAP, including: pedestrian safety, jobs, cost savings, air quality, water reliability, and open space preservation.

The CAP reduction target is 15 percent below existing levels by 2020 . State legislation relating to climate change and GHG emissions is heavily referenced and very thorough, and provides the basis for targets. Municipal emissions account for approximately 10 percent of overall GHG emissions according to the inventory and have a reduction target of 20 percent by 2020 . The greatest amount of emissions come from the transportation sector which accounts for approximately 50 percent of overall emissions. However, transportation measures included in the plan account for only 18 percent of reductions towards the 2020 goal. Each measure included in the plan is described with a high level of detail. The CAP does have an implementation section, but it is not very expansive. This section sets the groundwork for implementation rather than laying out a detailed strategy. The funding structure for each measure also lacks depth. 


\section{INTERVIEWS}

Two consultants who managed and wrote the plan (on a single call), one staff member who worked closely with the consultants on the plan, and a staff member with knowledge of the plan (but not directly involved) were interviewed. These included:

- A planning staff Project Manager who developed the plan in tandem with the consultant team.

- Two consultants who worked on the climate plan as well as the city's general plan update were interviewed together. One served as the Project Manager for the plan. The other was the primary author.

- An Administrative Manager based in the City Manager's office who works on many energy initiatives. He was not directly involved in the plan, but followed it closely. Initially "skeptical of how to reduce energy usage and consumption" by using alternative energy sources, this manager has evolved into the go-to "energy guru" for the city.

\section{Political Makeup of the Community}

The city is largely residential and to some extent serves a "commuter bedroom community." Many residents in the community commute to large metropolitan areas in southern California. The community was characterized in one interview as being far from Berkeley, and more conservative than the coast. City staff identified the Tea Party as being active in the community. One mentioned, "The Tea Party has hijacked the word sustainability." 


\section{Motivation for Plan Creation}

A unique aspect of the plan compared to other cases in this study is that this climate plan was created in tandem with the city's general plan update. This relationship is important to consider from a research standpoint because it is unusual compared to the way that many climate plans have been developed. For the city it made economic sense to create the climate plan and update the general plan in tandem. One staff member said that "we are going to have to do a GHG emissions inventory eventually anyhow, so we might as well do it as part of the general plan update."

In all interviews, the California Attorney General's lawsuit against San Bernardino was mentioned. Guidelines from the Attorney General's office, mandatory state legislation (the sustainable community requirement to combine the housing element with air quality and regional transportation plans), and $A B 32$ and SB 375 are mentioned as reasons for creating the plan. Additional state action is expected in the future, and creating a climate plan was the recommended alternative to other strategies. By developing a climate plan, the city hoped to address state action and avoid related litigation.

The city also thought that action on climate change "should be done and needed to be done." In general, this is an important and primary driver for the plan. One staff member said that "the city is trying to get away from being a suburban bedroom community," and there is a desire to make the city more pedestrian friendly. The climate plan and general plan update focus on land use and zoning changes geared at drawing employment to the area and changing the current, 
high commuter dynamic. There is a desire in the community to draw jobs to the city. To this end the city is working with regional agencies on transportation initiatives, some geared towards creating alternate transportation options and reducing overall commute frequency-reducing overall consumption. Another motivating factor was to encourage alternative energy generation (such as solar). This is seen as a way to create new energy sources. Funding was available from federal stimulus money for this type of action as well.

\section{Terminology}

No efforts were taken to mask the climate change focus of the plan. The plan is named in a straightforward manner and human activity's impact on climate change is explicit. However, one consultant said that the term "global warming" is avoided as a general rule (in the industry) because "it is not representative of the entire condition, it's more of a global climate change condition." The fact that the climate plan was combined with the general plan update effort was also pointed to as a helpful attribute in respect to terminology. This circumstance may have possibly removed the magnifying glass that is sometimes directed at climate plans when they are developed as standalone documents. One interviewee said that in the case of similar types of projects, city staff has used a strategy of testing the waters of the stakeholder views regarding various issues by "push[ing] the buttons and see[ing] if there is any feedback within the community" to these types of measures. 


\section{Negative Reactions/Responses to the Plan}

The City Council and Planning Commission were knowledgeable and aware of the climate planning process. These bodies authorized funding to hire consultants to create the climate plan as part of the general plan update. Both groups were communicated with often about the two projects. This may have alleviated concerns regarding the climate plan. One staff member indicated that there was a great deal of preparation leading up to general plan update, a factor

which may have had an impact. However, since the plan was adopted there have been changes in the makeup and political leanings of the Council. It is possible that the current Council (especially one member in particular) would be less receptive now than when the plan was adopted, from the perspective of one interviewee. A staff member put it this way: "I wouldn't say the current make-up is as supportive as when it passed."

Within the community, there was a small but very vocal minority consisting of fervent anti-Agenda 21 activists. These individuals saw Agenda 21 as a "U.N. conspiracy" and climate change as "invented science." This group saw the climate plan as a chance for (or example of) the government exerting more control. Members of the community had concerns related to ICLEI resources being drawn upon for the plan (all of cases in the aside from Case 2 study used ICLEI). However, only one comment was submitted regarding this, and the community was not against the plan itself. For this plan, the ICLEI model was used for quantification measures and emissions factors, but not for creating policies included in the plan. City staff and consultants saw the use of ICLEl's 
model as a way for the city to more easily update the plan in the future rather than other available methods such as contracting consultants.

\section{Political Difficulty}

Some of those interviewed reiterated the fact that the climate plan's development as part of the general plan update was helpful in reducing political barriers. Adoption of the plan was made easier because officials were comfortable with the general plan update and the CAP was part of that. Yet, in the past, staff has found that including regulatory measures can create backlash in the community. Council has never asked staff to reduce regulations outright, but there are often questions regarding permitting processes, building codes, and energy and water efficiency measures.

As mentioned previously, there is a Tea Party presence in the community. This political group is known within the community to mention Agenda 21 if the city addresses climate change in any way. Other cities in the region have had trouble with this issue. A staff member recalled that "I know of one city in particular [in the region] that has removed the word sustainability from many of their documents, just so that they don't have to get into arguments or have people speak out in City Council meetings against what they are trying to do."

\section{Plan Creation and Community Involvement}

A notable finding for Case \#4 is that no specific champion of the climate plan was identified through interviews. In general, the Mayor and City Council were said to 
be champions of the general plan, which the climate plan was a subcomponent of. It was left up to staff and the consultants to develop the plan. In contrast to some of the climate plans analyzed in this case study, the Planning Department in Case \#4 was significantly involved in CAP development. The Planning Department reviewed policies, provided feedback regarding which agencies were responsible for implementing various actions, and provided data. The city's other departments (e.g. the utilities department) also provided feedback.

In terms of community outreach, the climate plan was not separated from the general plan update. There were over 10 workshops relating to the general plan update and components of these included specific elements of the climate plan. Yet, no workshop focused exclusively on the climate plan. For the plan itself the only outreach that was conducted included a web-based survey, and information posted online. One staff member felt that community buy-in may not have been achieved for the climate plan itself. In general, the primary takeaway from these workshops was feedback from the community linked to vehicle miles travel and related emissions. There was a desire for more jobs creation within close proximity to the city, because many residents currently commute to work throughout the area. A staff member said "[there are] many residents who understand what we are trying to do as far as economic development" and are aware that the city is taking steps to achieve a better jobs to housing balance.

\section{Plan Implementation}

Although there has not been much discussion about the climate plan itself within the community to date, in general, the community and City Council were happy 
that both the general plan update and the climate plan were completed in the short time frame that was allocated (less than two years). To date, the most successful measures in the plan are those required or fueled by state action and mandates. These include measures focused on water conservation, residential solar (including financial incentives), and energy efficiency. On the municipal side, standards and measures in the plan will be used by various departmentsfacilitating successful implementation.

One potential issue for the success of the plan was said to be that the city can't mandate behavior; they can only encourage measures and incentivize them. This may reduce the success of some of measures included in the plan. When the low-hanging fruit is gone, there may be City Council and staff discussion in relation to certain measures—such as "Why are we doing this?" Future state legislation may affect this discussion. One staff member felt that "as long as there [an] energy and cost savings component, rather than solely GHG reduction" measures included in the plan, it will have broad appeal. However, there is a fear that motivation may be lost concerning the plan's implementation with staff turnover-this issue was raised in one interview.

Currently, there is no specific general funding allocated to the climate plan. In one interview, certain actions included in the plan were characterized in the following way: "some measures are a wish list." In terms of monitoring, a number of programs are in place to evaluate the success of implementation. Annual review of implementation is built into the general plan. Benchmarks of energy, gas, and water usage are analyzed. Periodic air quality studies are required, and the CalEEMod (an emissions estimator) model is in place to track GHG 
emissions related to air quality for the plan. This model was required by the city to be included in order to track impacts of the plan. Similar to what has been found in other cases analyzed, the only all-encompassing method of evaluating success of GHG emissions reduction was identified as creating a new inventory or updating the existing one. To date, the city's evaluation of emissions data has found that "people are conserving more." Whether this is due to the climate plan is difficult to determine with certainty.

\section{Lessons Learned and Advice}

The majority of insights derived from the climate plan process for Case \#3 relate to best practices. Before the plan is developed it is important to choose a consultant with a proven track record and significant expertise. For the plan, a well-regarded consultant firm was chosen that was known to be leader in the field within southern California. It is also essential in the early stages to "become familiar with ICLEI, do background research with regional planning agencies as far as what you are going to be required to do for your housing element, how you are integrating transportation plan with the sustainable communities strategies that is [also] required to do." When creating a climate plan keep regional priorities in mind.

In Case \#4, the consultant team was involved from the very start of the general plan update and climate plan. The consultants described that it is "more challenging [to create climate plans] when separate from the general plan, people are reluctant to include new policies that may conflict with those in the general plan." Policies in the CAP are consistent with the general plan-making 
implementation easier for city staff. Staff provided a great deal of feedback through the initial stages of plan development and the project ran very smoothly as a result.

This interviewee believes that a climate plan's contents drive a plan's success and that well defined goals and targets are the backbone of an effective climate plan. Additionally, the policies included must be "realistic, achievable and feasible." From the consultant's perspective the goal is to make sure the city can actually follow through on measures included in the plan. Otherwise implementation can prove to be overwhelming. Make sure each measure is worded appropriately. With measures and implementation it is crucial to create change in increments. Involve the region as a whole; this can work well to create a unified message as well as when chasing funding and rebates. Commitment to investment is key. Ensure all stakeholders are at the table. With that said, those engaged in climate planning must expect and prepare for pushback. Certain industries complain about any change to the status quo.

One piece of advice (from staff) for successful climate plans in the region is that everything (benchmarks and success) must be tied to budget savings and very specific measurements. CAP developers have to clearly state co-benefits and keep in mind fiscal considerations. For example, "lets reduce the amount of electrify used in homes by $x$ amount thus savings $x$ dollar figure. That's what speaks to people and gets a buy-in in this region." For Council, the issue has to be tangible, you cannot just describe that the plan will result in the reduction of $x$ metric tons of $\mathrm{CO}_{2}$, one interviewee said. "Not only don't they understand what that means, they aren't going to care and they are never going to care about 
that." City officials understand cost savings related to solar, or LED lighting for example because "10 percent of our budget is tied up in water and electricity." It is important to include and emphasize utilities goals and policies that have "the most bang for the buck."

\section{AnAlysis AND RefLection}

A unique aspect of Case \#4 compared to other cases in this study is that this climate plan was created in tandem with the city's general plan update. This is important to consider from a research standpoint because it is unusual compared to the way that many climate plans are developed. According to the national CAP database (Boswell \& Greve, 2013a) only six percent of CAPs in California are created in this way. In addition, the most central theme that stood out in interviews of individuals involved in Case \#4 is that creating the plan as part of the city's general plan update was important for the CAP's success. This characteristic allowed the city and the consultants who wrote the plan to make sure both policy documents were internally consistent. Having both efforts connected also allowed for the practical aim of the climate plan to be connected to that of the general plan. The fact that community outreach meetings conducted were for both documents reduced the potential for negative backlash to the climate plan. It also appears that it may have helped the process of getting the climate plan adopted. City Council was very much a part of the general plan update process and viewed the climate plan as a component of that process.

Politically, the city and region were described as conservative with a "very active" Tea Party presence. A great deal of anti-Agenda 21 activity was also pronounced 
for Case \#4. Furthermore, the meaning of sustainability was said to be so contentious in the region to the extent that one municipality had removed the word from many documents. That being said, this political opposition did not appear to have had a substantial impact. Although the Tea Party and antiAgenda 21 movement was larger in Case \#4 than most other cases in the study, this seemed to have an insignificant bearing on the success of the climate plan. This is notable, because in no interview did any individual involved in the plan say that steps were taken to mitigate the impact of views in the community that expressed this political ideology. This is a significant finding considering that all other cases analyzed in this study, facing similar political atmospheres, discussed how they attempted reduce or minimize this in the planning process. Perhaps this absence of backlash is a result of the climate plan's creation being part of the general plan update.

In Case \#4, climate change, as a term, is not masked and the approach of addressing climate science is very straight forward. This contrasts with some cases in this study, especially considering the political climate described in the region. Yet, the consultants interviewed are very aware of the potential backlash that specific terms can cause in some communities. Presumably, the choice to include climate change (and describe the connection to human activity) was conscious. The consultants also said that the term global warming was not included as a rule in the field; this suggests that terminology used in climate plans is reflective of the current scientific understanding of climate change. This also begs the question of whether sustainability will eventually be removed from climate plan language in areas where the meaning has changed and taken on 
political connotations. For Case \#4, sustainability may have been a more controversial term than climate change in the climate action plan.

California's state policies (SB 375 and AB 32) and the litigation of San Bernardino were cited as a motivation for climate action in Case \#4. This was also a motivation found in all other California cases in this study where climate plans were led by city staff. For Case \#4 the majority of successful measures to date, in terms of implementation, are those required by state action and mandates. Because of this, measures included in the plan that focus on behavior may be less successful without additional state action. This idea is supported by the fact that for City Council, the most attractive measures in the plan deal with energy and cost savings, rather than a desire to reduce GHG emissions in their own right. An interviewee indicated that the current City Council may be less sympathetic towards the climate plan than when it was adopted. The role of staff is also something that could affect the plans success. Because the climate plan in Case \#4 was created by consultants at the direction of City Council, and no champion of the plan was identified in interviews; staff buy-in wasn't required. It is possible that with staff turnover, implementation of climate plan measures could suffer in city departments responsible for the measures. 


\section{CASE 5}

\section{Location Description}

A city in southern California with a population of fewer than 50,000 , located in the heart of a county dominated by Republicans. The community is wealthier than the national average and concerned with coastal issues. Tourism provides a significant amount of revenue for the community.

\section{Case Summary}

Interviews were conducted between March $13^{\text {th }}$ and April $8^{\text {th }}, 2014$. The U.S. Mayors' Climate Protection Agreement was adopted by City Council during Bush's second term, and the CAP was adopted by City Council during Obama's first term. Case \#5 is a prime example of a CAP created due to the influence of a driven and devoted citizen champion. It is one of two cases in the study where the CAP was authored exclusively by a committee consisting of members of the community. The city is viewed as more environmentally conscious than other areas in the politically conservative region. However, the part of the political difficulty the climate planning process faced was getting authorized by City Council initially. The climate planning champion (as well as others) created public momentum behind climate change. In this way, public opinion influenced the hold-outs (a minority) on the Council to sign the U.S. Mayors' Agreement and (later) authorize the plan's creation. Council directed a city-appointed body to give recommendations for reducing GHG emissions. Out of this a CAP 
committee was created that wrote the CAP (with minor guidance form city staff). Through the actions of the committee, citizens in the community were involved in the CAP and mobilized behind it. Concessions were made on certain measures included in the plan (due to perceived costs) and as a result, the plan was unanimously adopted by City Council. Implementation has begun and is in part tracked by staff progress updates to City Council.

\section{Description of CAP from Analysis}

PLAN TITLE: The climate plan title includes climate, but not sustainability or energy.

The CAP is relatively average in length (compared to other CAPs analyzed). Human activity that causes GHG emissions is described, but not the science behind climate change. Potential impacts of global climate change are somewhat generalized, with focus on water availability, energy availability and coastal effects. Co-benefits emphasized are economic and cost savings relating to energy and vehicular efficiency. The CAP's GHG emissions reduction target is 10 percent from present levels by 2012. Transportation and energy sectors are by far the largest sources of emissions, comprising approximately 35 percent of emissions each.

There are more than 90 measures included in the CAP, but not high level of detail. However, the vast majority of the measures included in the plan do not have clear GHG reduction outcomes and read more like policies and initial programs than specific reduction measures. The implementation section does 
not include a high level of detail. The city is assigned responsibility for some measures and others require coordination with outside agencies. A notable aspect of the CAP's implementation program is that it requires incorporating a new element into the general plan. There is no specific monitoring system included in the CAP aside from a section outlining expected results.

\section{INTERVIEWS}

Two members of the committee that developed the plan and one city staff person were interviewed. These included:

- A member of a City Council-appointed body focused on environmental issues. This person was the primary champion of the plan and chair of the committee that created it.

- A former president of a local civic association. Was recruited by the chair due to his known interest in climate issues. Became a member of the committee and was primarily involved in municipal operation measures.

- The staff liaison between the city and the committee that authored the plan. A city planner who ensured the committee was not violating any laws and who occasionally gave input and advice.

\section{Political Makeup of the Community}

In interviews, the community was characterized as more liberal than the surrounding region, which has a reputation for conservatism. The city is thought to have a slight Republican majority but is seen as an anomaly in contrast to the 
heavy Republican majority in nearby cities. The community feels its Republicans are more environmentally focused and more libertarian than in nearby areas. Staff views the city's citizens, Council, and the Planning Department as progressive. But in other interviews, the Council was described as split between Democrats and Republicans. In the past, residents have voted to raise taxes in order to preserve open space.

\section{Motivation for Plan Creation}

The primary champion and Chair of the plan viewed climate change as the most critical environmental issue currently facing the world. He wrote many letters to the editor and reached out to City Council members in order to build momentum behind the issue. In time, one City Council member brought forward a motion to sign the U.S. Conference of Mayors Climate Protection Agreement.

Once the agreement was signed, Council directed a city-appointed body to give recommendations for reducing GHG emissions. One committee member believed that the city itself wasn't going to develop it, and as a result, the cityappointed body formed a committee in order to start the climate plan. This committee was also made up of citizen volunteers. The climate plan is seen as a tool to take action on the climate change issue after the protection agreement was signed. It was the committee's desire to eventually incorporate the climate plan into the general plan. 


\section{Terminology}

There were no major discussions within the committee or city staff to mask any (sometimes controversial) terms such as climate, sustainability, or global warming. One committee member said, "No attempt [was] made to disguise it" Scientific research that attributes human activity to global climate change is explicitly described in the plan and is "very direct." There were no real debates about climate change or global warming as terms: "Due to the make-up of the [committee], they all believed it was real." However, the plan title included climate and not global warming as a way to reduce potential backlash and make it more politically acceptable.

A great deal of thought went into how to name the various bodies (under the larger committee) that were involved in drafting the plan. This included "finessing the language" when naming certain bodies under the larger committee. Several committee members debated how to structure the plan and its measures. A discussion took place within the committee about whether to make the climate plan "theoretical or practical." Early on, though, the committee decided that the plan should be something that can actually be implemented by the city. It should focus on "things that really could be accomplished, not blue-sky ideas."

\section{Negative Reactions/Responses to the Plan}

Before the climate plan was created, the process of signing the U.S. Conference of Mayors Climate Protection Agreement had one holdout in the City Council who thought action on issues like climate change should be made at a higher level of 
government. Yet, once momentum was built around the issue within the electorate, this Council member "came around." When it came down to the vote that authorized the plans creation, Republicans on the Council reluctantly voted for it (if at all). There was also backlash from some individuals within the community. At one Council meeting an attendee said that global warming was a fraud.

When it came to adopting the plan, there were some (roughly six) negative responses to certain measures on the part of the City Manager, who believed they were too expensive and that the city couldn't afford to implement them. The committee saw this as a "reasonable concern," and the measures in question were left out of the final plan. One committee member said, "This was almost to be expected. We accepted what [the City Manager] was saying without making a fight out of it."

\section{Political Difficulty}

There was not a great deal of political difficultly related to the CAP within the community. Part of this can be attributed to the commitment of the plan's primary champion and the committee members. Members of the committee were very influential members of the community, considered experts on environmental issues, and had irrefutable knowledge regarding the issues involved based on their professional backgrounds. For example, a well-known physicist was recruited to the committee by its chair (the champion) and his expertise was viewed as an important asset; "no one could refute his data or knowledge," according to one interviewee. At one point during the process a member of the 
appointed environmental body took the committee chair aside and said he might be too active, possibly even bringing a spotlight and a negative lens onto the larger environmental body, making it hard to be effective on issues other than the climate plan.

Notably, there was political backlash against the chair (and primary driver) of the climate plan once it was complete. One interviewee speculated that there were certain people in the city government and Council that did not want the committee to have as much authority and clout, or be as effective as it had with the climate plan. In an effort spearheaded by a conservative member of the City Council, the plan's chair was removed from his appointment on the city's standing environmental body. He was replaced. Soon after, the City Council reorganized the environmental body, reduced the number of members, and changed its name. One interviewee said that the Council "wanted [the environmental body] to work more effectively" and rein it in. No one interviewed was certain whether these actions were a result of the chair's success leading the climate planning process. A number of other members left due to this restructuring.

\section{Plan Creation and Community Involvement}

In contrast to the majority of climate plans, Case \#5 focuses on a plan created exclusively by members of the community. A charismatic and well-respected environmental leader in the community, the chair (and champion) led the committee. He in turn recruited members of the committee. Everyone interviewed identified the chair as the primary champion and motivator of the plan, and 
attributed much of its success to his actions. There were "many environmentalists on the committee who were important for the plan's success, but [the chair] was the primary champion," said one interviewee. The city is in close proximity to a number of colleges and universities from which staff and students were invited to participate. University professors, research, and intellectual resources were "relied upon heavily." The committee was composed of professionals, experts, and other pillars of the community.

City departments and city staff were not very involved in the process. The Planning Department was primarily in charge of overseeing the process. They made sure that measures were viable and recommendations could be carried out (for example, the Brown Act). One committee member said: "The city government served as the brakes and the committee served as the gas." According to an interviewee, the staff liaison "mostly made sure [the committee] followed laws and procedure." Once the draft plan was created and adopted by City Council, various measures were allocated to specific city departments by the planning department. In terms of civic associations, the Chamber of Commerce had some involvement in the plan. Its support "came and went" and the chamber backed away from publically endorsing the plan.

The community outreach strategy for Case \#5's CAP was thorough and effective. Educating the public and enlisting their support was a primary focus in the process. From the time before the committee was formed to when the plan was adopted, letters to the editor were written in order to engage the community on the climate change issues. These and other efforts helped keep the conversation and issue of climate change public. The committee held frequent public meetings 
that were open to members of the community. As a way to incentivize attendance, notable speakers were invited to each meeting to address various topics included in the plan. This was publicized and created a buzz within the environmental community. On average, 12 to 50 members of the public were present at each of these meetings.

Conceivably due to the fact that the committee was comprised of advocates rather than city staff, there was little fear about upsetting members of the community who may not have agreed that climate change is an issue that should be addressed. One committee member put it this way: "We didn't care if [climate change] was caused by natural conditions or is manmade-or, more likely, some combination of that. We were determined to do what we could do to lessen that, no matter where it came from." People who thought climate change was fictional never showed up to the meetings "or advocated anything like that."

\section{Plan Implementation}

The city and community responded well to the plan created by the committee, which involved members of the public. The plan was unanimously adopted by City Council. There were no articles or letters to the editor (in local newspapers) in opposition to the plan's adoption. The committee's Chair believed that the few outspoken opponents within the community seemed to admit defeat, neglecting to bring up issues with climate change post-adoption. However, for implementation to be successful, the plan must be fully integrated into the city's general plan. Post adoption, members of the city's appointed environmental body continued to push forward the goal of having aspects of the plan included in the 
city documents and city operations as a whole (for example, the municipal code). "That way the report wouldn't be stuck on a shelf and never looked at again," a committee member stated. The plan's outlook is seen in interviews as bright because now that it has been adopted, it is part of the city's overall policies and programs .Yet, the future of the plan's success rests in the hands of city departments and city staff.

In terms of monitoring success, the committee initially wanted to include a city audit of energy usage and carbon emissions in the plan, but this aspect of the plan was made less powerful as a tool during the plan's adoption process (it was a bit watered down, partially due to fiscal considerations). The committee chair felt strongly that having a "carbon audit is critically important, [and] needs to be robust and comprehensive." Thus far, the city has implemented a number of programs and measures included in the plan. Implementation of the plan is financed through the city's general fund. Since adoption, the Planning Department periodically provides progress updates to Council (when directed to do so). The plan is also designed to be updated every couple of years. In terms of measuring the plan's success in the form of GHG emissions reduction, there is no specific monitoring program in place.

To date, there has not been much publicity regarding the plan's implementation, from the perspective of one committee member. From that committee member's point of view, the success of plan implementation is dependent on citizens staying on top of the issue and City Council's actions. Future action on the plan depends largely on who gets elected to the City Council, because "politics are important for continued implementation." Currently, the Council's balance is split 
between environmentally minded individuals and others. Staff buy-in is also seen as a potential concern. One interviewee said, “I don't have a lot of confidence in the city managers - they are not intrinsically interested in this issue. In my view, they are more concerned running a smooth, orderly local government."

Moreover, in his interview, the committee chair said, "If I ever sense that isn't the case [that the city government continues to advance implementation of the plan], I will be jumping back into this with both feet."

\section{Lessons Learned and Advice}

Much of the advice derived from interviews focuses on how to gain community support for climate plans. It is essential to form a team that is "stacked" with individuals that are pillars of the community and experts on the issues, according to one interviewee. For Case \#5 this meant bringing in scientists, business leaders and professors from the region. These are individuals whose credibility cannot be easily questioned (a high-level political adviser, physicist, professors, etc.). It is also important to involve the business community. Next, CAP developers must have a deep understanding of the views of city staff. Find out where the City Manager stands in terms of climate change. Determine how the City Council members view the issue, and "how they view the responsibilities of the body you are a part of." It is helpful to have a "sensitive" City Council that is interested in the issue. To reduce political issues, the CAP committee needs a majority to be amenable to the issue. For Case \#5, the City Council directed the committee to complete the plan and had a desire to show that the city was taking steps towards the issue of climate change by developing a CAP. 
For plans created by individuals in the community, find out who the staff liaison is to guide you through the city ordinances. It is important to know how the city gets things done and implement accordingly. Look to the community at large and evaluate where the electorate stands on climate issues. This can be gauged in terms of letters to the editor on environmental topics. Successful climate plans need citizen involvement, as well as technical and scientific expertise. Make sure the plan is something that is reasonable to achieve.

In Case \#5, the champion's approach and organization was very important for reducing political criticism. For climate plans in general, finding a committed champion in the community is vital. One committee member advised those undertaking a CAP: "Find yourself a [name of plan's Chair redacted]!" Once committed to something, he and members of the group were going to see it through, no matter what. "Nobody was going to stop us from doing that," he said. "That's typical of how anything decent gets done-in my opinion anyway."

The plan's chair and champion had a number of reflections on the process and his experience. First off, "All politics are local," this is something he learned to understand through the process. As a general sentiment for working with cities: "Get involved in local and city politics and stay involved. When good people do that, good things can happen." There is a lot of posturing that goes on in city government. Finally, when evaluating the future outlook of climate planning in California: "AB 32 helped the process, but wasn't detailed enough. The State [of California] needs to do more than it's doing." 


\section{Analysis and Reflection}

Case \#5 represents the best example in this study of a successful grass roots strategy. This approach, and its success, can be heavily attributed to the committee chair and champion of the plan. This individual gained the support and backing of well-respected members of the community and recruited them to the committee. He was extremely effective in his approach by bringing the climate change issue to the attention of the public and City Council and framing the conversation. Resources such as the nearby university and regional environmental organization were utilized and relied upon to a great extent.

Notably, given the conservative region the plan was created in, terminology including climate change, sustainability, and global warming was not downplayed. This may be a result of the public support present for the plan through efforts such as writing letters to the editor and the impact of this on City Council. It may also be connected in part to the plan being created by members of the community rather than city staff. Perhaps because of heightened public interest regarding climate change, the City Council directed the appointed environmental body (with the assistance of staff) to create the climate plan. This was in part a way for Council to show that the community was taking steps towards addressing the issue of climate change. By adopting the plan the city was able to highlight its commitment to climate change and environment issues.

An interesting aspect of Case \#5 is that once the plan was adopted, there seemed to be some political ramifications. Although the climate plan was unanimously adopted by Council, the champion of the plan (and Chair of the 
committee) was removed from his appointment on the city's standing environmental body a short time after CAP completion. This may have been coincidental, but it is possible that in part it was a result of the perception that he had been too activist and outspoken in the methods he used to create the plan.

Plan implementation is also an interesting issue to consider for Case \#5. In other cases in this study, interviewees emphasized the importance of staff buy-in in order for implementation to be successful. In Case \#5 the climate plan was created by members of the community with minimal staff involvement. Since the plan was adopted, the City Council has directed city staff to take action on the plan. In the future, if the political makeup of the Council changes and if the climate plan is viewed as less of a priority, this dynamic may change. Because of this, it is not a forgone conclusion that the measures included in the plan will be successfully implemented. As a result, continued success of the plan is dependent on the community's vigilance in tracking the progress of the plan and pressuring Council to follow through on implementation of the measures included therein.

\section{CASE 6}

\section{Location Description}

A city in southern California with a population between 20,000 and 60,000 . It is almost completely built-out and primarily residential with a higher density than 
surrounding areas. The city was incorporated more recently than other communities in the region.

\section{Case Summary}

Interviews were conducted between March $13^{\text {th }}$ and April $8^{\text {th }}, 2014$. The plan was created during Obama's first term, and completed during Obama's second term. Case \#6 faced the most significant challenges of any CAP included in this case study. The CAP was created by the Planning Department along with a team of consultants. It was initially supported by City Council, yet no council member was a vocal supporter or champion of the plan. The CAP's title does not include terms such as energy and is not structured in a way that emphasis cost-savings or economic benefits as primary drivers. The community outreach and work shop program was well attended. Initial opposition to the CAP came from trade associations as well as business and development groups due to its perceived regulatory structure. There is a substantial anti-Agenda 21 presence in the community. One member of the community became the CAP's primary opponent. This individual eventually gained the support of certain members of the community and surrounding area who view Agenda-21, and climate plans as a proxy, as part of a U.N. conspiracy involving the government takeover of private property, and "sustainability" is a way to force people to live in high density housing and to accept redistribution of wealth. Due to the concerns of these individuals and others, the CAP was revised many times over two years, substantially increasing its cost to the city. Eventually, the CAP lost support from City Council, in part 
because of the estimated additional cost to tax-payers required to address public comments submitted to the Planning Department regarding various aspects of the CAP.

\section{DESCRIPTION OF CAP fROM ANALYSIS}

Plan TItLE: The climate plan title includes a term tied to the environmental movement, but not climate.

The CAP document is very detailed and includes over 150 measures (it is one of the longer CAPs analyzed. The CAP's description of climate science is the most extensive of all CAPs in the case study. The science and effects of climate change have very detailed description and are backed up with numerous sources. Notably, there is no distinct reduction target included in the CAP, but there is discussion of the $A B 32$ statewide reduction target of 15 percent below baseline by 2020 .

According to the emissions inventory, transportation is by far the largest source of GHG emissions, making up nearly 60 percent of all emissions, and more than double the next largest sector. The municipal share of city wide emission is extremely low, less than half of one percent. CAP measures are broken down by sector, and include a detailed description of the emissions reduction separated between quantitative and qualitative reductions. Plan implementation is detailed, but qualitative and voluntary in nature, emphasizing education over regulation. However, few strategies have implementation strategies assigned to specific 
departments. The plan assumes that various departments will be responsible in part for measures in their sector.

\section{INTERVIEWS}

A staff member, City Council member, and member of the plan's advisory committee were interviewed. These included:

- A senior level planner for the city. This staff member conceived the idea of creating the plan, and served as its project manager. Under the planner's direction, a consultant team was hired. This individual helped write the plan and its public outreach approach.

- An environmental professional and former Planning Commissioner. The interviewee was initially a community member who was involved in the plan's workshops and outreach, and later ran for City Council (and won) in order to bridge the gap between the community and the Council (thought there was a disconnect in communication).

- A former developer who sat on the board of a regional real estate association. Was proactive professionally on green development. Had a desire to be involved and reviewed what was proposed in the plan.

\section{Political Makeup of the Community}

The city is located in the heart of a conservative county, which provides the political context in which decisions about CAPs are negotiated and made. There is a politically active Tea Party element in the community with some involvement 
in the anti-Agenda 21 movement. Yet, the community is very mixed in terms of political make-up; city council members and mayors representing various political parties have been elected. The business community is small and does not generate a great deal of tax revenue, yet there are "a small number of businesses who are highly concerned with any restrictions that may be put on them" by the city, according to a City Council member. One interviewee generalized the community as "a progressive community interested in new ideas and new concepts." Many young working families and young professionals reside in the city.

\section{Motivation for Plan Creation}

The City had been interested in environmental issues and energy efficiency for some time. One interviewee described a green building program that was a precursor (by about five years) to the climate plan that was proposed by a City Council member. This program was not a movement driven by the citizenry. When the primary advocate on the Council departed, the program was attacked by the building community. Developers "slammed the programs as being too extreme." The program was described by one interviewee as "not written as well as it could have been" and included policies that could be legitimately criticized as overreaching.

The Planning Department picked up the idea of creating a climate plan. Part of this motivation was the feeling that State legislation (such as AB 32 and SB 375) is moving towards requiring action on climate change. By creating its own CAP, the city was thought to have greater control over its contents and less vulnerable 
to (state) Attorney General lawsuits. Another driver for the plan's creation was economic. It was felt that the plan would save money and increase economic competitiveness with surrounding cities in the region by attracting environmentally conscious professionals and green/technology businesses. The City Council supported the Planning Department in creating a climate plan. However, upon reflection, one interviewee said that they did not "recall any individual Council member being particularly interested in the [plan]" although, the proposal to initiate the plan was accepted by Council.

\section{Terminology}

Case \#6's climate plan is named in a way that could be seen as drawing negative attention in some communities where individuals are not proponents of climate science or terms such as climate change and global warming. In the plan's title one word [redacted] synonymous with the environmental movement is prominently displayed. When asked about this, the Project Manager said that at the time the climate plan was created, the City Council did not take issue with the word or term climate change (this would later change). Yet, a member of the community that was interviewed said the plan's “descriptive title did not take into account the opposition" within the community. Aside from the titling of the plan, a great deal of debate did not appear to take place regarding the use of scientific or climate change related terminology. 


\section{Negative Reactions/Responses to the Plan and Political Difficulty}

The plan faced extreme challenges through the climate planning process. Over time, political challenges and backlash from the community reached a critical stage, threatening the viability of the climate plan. When the plan began, there was a great deal of community support for the effort at public workshops focused on topic and sectors included in the plan. By one member of the communities' account, "There were 95 percent in support and about 5 percent had questions." Most of the early questions came from business groups and associations. Each individual interviewed agreed that these questions were initially addressed by staff to the satisfaction of those who asked.

Eventually, opposition to measures in the plan increased to a degree in specific sectors of the community, but as a whole the citizenry appeared to remain positive and unchanged in its view of the plan. Some members of business community had early concerns. However, "At the time, people didn't know the facts. They were making judgments and drawing conclusions prematurely, simply based on their preconceived notions that the programs were being promoted by tree huggers." There seemed to be a mentality of attacking the plan before it grew too big. Members and associations in the business and development community did not see a bright side or recognize any positive measures included, "[They] just attacked it generally on the grounds of increasing costs and regulations," based on their perceptions of the plan.

The tides within some of the community began to change when a vocal opponent of the plan-a member of the business and development community- 
"disrupted" a public meeting and also rallied a small group who supported the anti-climate plan cause. Shouting matches took place at this meeting. A staff member estimates that of this small contingent against the plan, only 6 of 10 were city residents. One person from outside the community "who didn't want to be told what to do" said "I'm going to go and turn my water on and let it run all night." The individual who had initiated the contestation began to drum up opposition to the plan and eventually ran for City Council on a platform denouncing it. This individual was the plan's primary opponent. Members of the business and development community united with community members ideologically opposed to the plan. Parallel to this action, the City Council did not play a strong role in the planning process or in advocating for it. The plan was supported by the City Council via their vote but members did not attend community meetings or assist in plan development. One interviewee said "I would expect that there would be an advocate or champion on the Council. I don't believe I saw one though."

Case \#6 had a great deal of ideological opposition towards climate change science and sustainability. Anti-Agenda 21 sentiment was very much a part this. The primary opponent of the plan was a self-proclaimed member of the Tea Party and staunch advocate crusading against the "U.N.'s Agenda 21 conspiracy." This crusade included the ideas that "everyone has the right and choice not to conserve," and that there is a U.N. conspiracy involving the government takeover of private property; climate change data is false; and finally, "sustainability" is a way to force people to live in high density housing and to accept redistribution of wealth. City staff found that addressing concerns raised 
by the primary opponent and their supporters about the plan was "pointless in the face of their world view. [It] doesn't help to use reason."

Externally, there was political opposition from trade associations. These included the business community, real-estate developers, apartment owners, and lobbyists largely against the plan. This outspoken (but minority) constituency had a massive impact on the plan. "They knew the political levers to pull." The plan was revised many times, with more than a dozen versions created (over two years) as a result of comments submitted. The original draft of the plan "was twice as robust as the final version," and included many more measures that were altered or removed in subsequent versions. Due to the consultant fees associated with numerous revisions, the plan's cost escalated nearly fivefold. The plan itself was "not really politically charged" before its opponents politicized it. Over time there came to be a change or resistance from members of the community towards the plan. Internal city politics from some of these outside pressures seemed to also play a role in reducing support from the City Council regarding the plan. The plan originally had mandatory measures, then only voluntary measures; this still didn't sway the opposition.

The final presentation of the plan to City Council was a politically and emotionally charged affair. The primary opponent of the plan had rallied a small but vocal opposition group. However, one interviewee said that, "Generally people in the audience were sympathetic to the cause." At the meeting, the primary opponent submitted over 100 questions through the City Council to be addressed by staff. In essence this action stonewalled the process, essentially filibustering the plan. After deliberation, Council unanimously tabled the plan, stunning staff. 
Notably, the Case \#6 interviewees stated different reasons for why the City Council made the decision they did. Two interviews emphasized the costs associated with answering the questions posed by the plan's primary opponent. The Planning Department estimated that answering the questions would cost the city more than $\$ 75,000$. One interviewee went on to say that the drawn-out time period and escalating costs of revisions had drained the patience of the Council. One interviewee, however, speculated that political meddling on the part of organized business interests was to blame. Although one Council member was an extreme opponent of the plan, other council members had originally supported the plan, and the "the rest of the Council could have voted [name redacted] down." This interviewee thought that one opponent on the Council didn't sway the others, but rather that business, development, and other interests had unduly influenced the Council.

\section{Plan Creation and Community Involvement}

In Case \#6, the Planning Department took the lead for the climate plan effort and was "the city agency." Other city departments were not highly involved. For example, the Public Works Director was not a supporter of the plan. One staff member in the Planning Department was described in all interviews as the primary champion. A former member of the City Council was also a strong advocate. There didn't seem to be any champion in the community.

The public outreach program for the target community was adapted by planning staff from a well-regarded climate plan from a city universally known as politically liberal. Around a dozen community workshops were conducted, each focusing on 
a specific topic included in the climate plan. In comparison to the majority of other cases in this study, the attendance was extremely high with over 100 community members participating. However, one interviewee said that the workshop attendance included many repeat attendees and “wasn't overwhelmingly representative of the community as a whole." Staff believed that community buyin was achieved for the people who attended workshops. Yet, once the business, real estate, and apartment groups were against the plan, “there wasn't much that could be done." This resistance was seen in the form of discussions with City Council members, support for the plan's primary champion, and official condemnation of the plan by representative associations.

Some interviewees believed that these groups were not brought into the planning process. One interviewee described an early meeting with stakeholders that was not open to the public: "What I found was that there were a number of contractors who weren't necessarily fluent with the terminology or with the practice of developing a climate action plan." Perhaps this contributed to views that the plan would increase costs through regulation and would not benefit certain sectors of the community. One interviewee felt that there didn't seem to be a mobilized constituency supportive of the plan that went past attending meetings and workshops. There was not an element within the community able to push against opponents on the council or business oriented associations that were against the plan. 


\section{Lessons Learned and Advice}

Staff confronted many significant challenges in the climate plan process; this situation led to a great deal of reflection in each interview. The way stakeholders were involved-or not-is one aspect of the development process that may have created issues and could have been done differently. An idea was that stakeholder groups in the community need to be identified and cultivated. One interviewee thought that more meetings should have been dedicated to these groups. It is important to "understand the HOA and management company relationships. The business organizations-the community groups."

In order to avoid the same opposition from industry groups that the plan experienced, staff must "Bring in people from important groups before you make it public," the goal being to determine what concerns they may have in private, in order to lay the ground work for collaboration in the future. That way the plan would not have had the same opposition from industry groups. One interviewee said, "[The city] did it too late and they did it in a public forum." This would not have guaranteed success, but could have resolved a lot of issues experienced before they became problems. Issues such as certain groups being unaware of how a CAP could benefit them, how they can provide input, or what the aim of specific measures can be. However, another interviewee stressed that these meeting must be public, because too often private meetings can and have reduced the transparency of government in the city.

Although many workshops were well attended, it was believed that the lack of champions within the general public posed problems for the plan. Advice relating 
to this was to build allies and "Make sure that you identify a team of experienced experts that know how to map out the process." It is essential to search out and find active supporters who are not afraid to get up and say they believe in the plan because "The backlash will come." Looking back, this should have been done in a much stronger way.

The lack of participation and backing from the City Council was also seen as a major flaw in the process. One interviewee said, "Support of the Council that goes well beyond simply voting for something is critical. If there was opposition to this initiative but Council members were all well-versed in what was going on in the meetings and heavily involved they would certainly be able to respond to the criticism or the inquiry. I didn't see that type of involvement or that type of commitment." An illustration of this is that the costs of the plan escalated substantially without the City Council really knowing how it happened. The interviewee also believed that the plan's primary opponent wouldn't have been able to manipulate the circumstance if there was more genuine support and involvement from the Council.

Some reflection also focused on the contents of the plan. It was suggested in one interview to leave out a discussion of climate change in the document. The plan may have been more successful if it was focused on economic development rather than environmentalism. Another idea was to include the GHG emissions reduction in the appendix. A brief plan, rather than an elaborate document was believed to be advisable "in this type of community," with politically a politically conservative and regulation adverse constituency. 
Another perspective provided in one interview was that there is a track record in the city of poorly dealing with opposition. The Council and staff "have shown a very poor ability to anticipate public reaction and deal with it before it got to the crisis stage." This interviewee felt that the city has never been good at creating strategic plans in the face of opposition. Additionally, other efforts have been diminished by intense opposition in the past.

In each interview a level of melancholy was expressed over potential losses associated with the course the climate plan ultimately took. A great deal of the effort that went into the plan and the important policies created during the process are currently tabled, according to one interviewee. Also, the substantial financial investment made by the city will be essentially wasted if the climate plan is not resurrected. The potential impact on those who participated in workshops is also disappointing. The trajectory of the plan "discouraged [community members involved] tremendously." A related fear is that it will be more difficult to mobilize the community for future planning initiatives.

\section{AnAlysis AND Reflection}

The substantial challenges of Case \#6 highlighted to this point underscore a number of issues pertaining to successfully conducting climate planning in politically difficult communities. One issue is how to market climate plans. In this case, the name of the plan and the language included seemed better suited for a more politically progressive community. It is startling how little awareness there seemed to be that backlash would take place against the plan. In many of the politically conservative cases included in this study, climate plans were focused 
on economic, cost-savings, and other co-benefits rather than overt environmental consciousness. These co-benefits are nearly universally supported regardless of political affiliation.

Involving stakeholders appeared to be another weak point for Case \#6's climate plan. Community workshops were extremely well attended, but many influential elements of the community were not represented. Moreover, although many members of the community were motivated, none were involved to the point where they could influence detractors or City Council. Overall, there appeared to be a lack of understanding from business, development, and real estate groups and associations regarding climate plans. In many of the other cases, great lengths were taken in order to reach these crucial stakeholder organizations.

Politics appeared to be the most significant hurdle for Case \#6. The plan's primary opponent and certain influential groups and their interests were pitted against staff and supportive members in the community. The political power of the former outweighed that of the residents who attended meetings as part of a successful community outreach effort. The City Council who had initially supported the plan surprised staff with a unanimous vote to table the plan. Regardless of what motivated this action, it seems clear that City Council was not highly involved in the planning process, invested in its success, or closely monitoring its progress. This highlights a lesson for success identified in many interviews conducted for this study. Buy-in from the City Council, is crucial for effective climate planning. For most plans city council members define the scope of the endeavor and determine its final legal status. 
One noteworthy finding is that Case \#6 is one of the few cases in the study where the planning department spearheaded the climate planning initiative. Unfortunately, other city departments such as the Public Works Department did not seem effectively motivated or invested in the plan. For Case \#6, one department, regardless of how motivated and devoted, could not drive through the CAP without support from other departments. The lack of support from the Council and powerful business groups in the community made success even more unreachable. For Case \#6, the support of the general public and community engagement alone were not enough to make the climate plan successful.

Finally, an important aspect of Case \#6 is the effect the process had on those involved. It is notable and highly unusual how far the plan was developed before it was tabled. This impacted the morale of those responsible for creating the plan. To some extent, staff became cynical about the political process of city government. Many revisions were made in order to address concerns without having a significant impact on opponents. In fact the most substantial impact of these revisions came to be escalating costs, which in turn made the plan a target of criticism. The worldview of the anti-Agenda 21 constituency was unshakable. Even when measures included in the plan became voluntary rather than mandatory, negative perceptions of the plan did not dissipate. From the perspective of some interviewees, political support from the Republican Party and the Tea Party for the primary opponent of the plan (who had never attended a City Council meeting before the plan was developed) trumped the efforts of the plans supporters (some of whom were active in the community). 


\section{CASE 7}

\section{Location Description}

A city in Kansas with a population of less than 20,000. Part of a metropolitan area, the city is a middle class suburb. It is primarily residential, with two small business corridors. Many residents commute outside city limits for work.

\section{Case Summary}

Interviews were conducted between March $18^{\text {th }}$ and March $1^{\text {st }}, 2014$. The plan was created during Bush's second term, and adopted during Obama's first term. The climate plan was written by the city's Economic Development department and an environmental task force consisting of community stakeholders assigned by the Mayor. As a precursor to the plan, the city signed the U.S. Conference of Mayors Climate Protection Agreement. The Mayor was an important advocate and champion for sustainability and viewed creating a climate plan as significant policy for the city. The climate plan faced very little political opposition at the time of adoption by resolution. However, since the plan was adopted there has been a change in the political makeup of the region. In the 2010 elections, the Tea Party became a powerful political force in Kansas. Many moderate Republicans in the region have been pushed out by more conservative counterparts (included on the City Council). Sustainability has become a politicized term. Anti-agenda 21 sentiment has increased in the area and sustainability is viewed as part of a U.N conspiracy by some. Additionally, a 
state anti-sustainability bill was introduced this year. Because of this city staff no longer publicizes certain measures included in the plan. Instead, cost-saving measures and measures visible to the public such as community gardens have been emphasized to date.

\section{DESCRIPTION OF CAP fROM ANALYSIS}

Plan TItLE: The climate plan title includes climate, but not sustainability or energy.

The main text (excluding the inventory) of the CAP is relatively short (in comparison to other CAPs analyzed). However, energy measures included in the plan have a high level of detail, including a basic cost-benefit analysis of energy and cost savings. Co-benefits emphasized are cost-savings and quality of life. Human activity is not discussed in relation to climate change. Usually, GHG emissions are discussed in the context of the U.S. Mayors' Climate Protection Agreement. The CAPs emissions reduction target is a 20 percent reduction by 2020. Transportation emissions account for approximately 60 percent of overall emissions, more than double the next largest sector. Emissions from highways comprise nearly 50 percent of all emissions in the city. Perhaps as a result, the plan often discusses the importance of regional collaboration in achieving reduction goals. The municipal sector's emissions are approximately one percent of all emissions according to the inventory. In terms of implementation, each strategy is discussed in the context of the total reduction target sought. City departments are assigned responsibility for measures included in the CAP. 
Funding for each measure is not described in depth. The CAP does not cover monitoring in detail; it is written similar to a first step and guiding document. The plan includes language stating that the city intends to follow ICLEls milestones.

\section{INTERVIEWS}

Two staff members and City Council member were interviewed. These included:

- The city's Community Development Director. This individual served as the staff project manager for the climate plan and coordinated with the environmental task force responsible for its completion.

- A City Council member and Co-Chair of the environmental task force. This task force directed staff to analyze emission reduction strategies. Strategies were selected for inclusion in the climate plan.

- A member of city staff who facilitated meetings of the task force and guided the process. This individual also wrote and edited measures included in the CAP — and was the primary staff point of contact for community members.

\section{Political Makeup of the Community}

The city was described as being located "in a very conservative state [Kansas]." The community was also described as "conservative" but not to the extent that Kansas is as a whole, especially at the level of state government. At the time of the plan's creation the city was "more progressive on some issues" and made up of "moderate Republicans", said one former staff member. In the last five years, 
this changed as a result of more Tea Party activity in the county, pushing many moderates out of city government. Additionally, the anti-Agenda 21 movement is currently very strong in the region (with the Tea Party affiliation).

\section{Motivation for Plan Creation}

Climate change was an issue that resonated with city staff and some City Council members. Residents were also interested in the issues of GHG emissions. The city signed the U.S. Conference of Mayors Climate Protection Agreement, a primary motivation and precursor to the CAP creation. Climate change was also an important issue, and core piece of the Mayor's agenda. The Mayor, a primary champion, prioritized the plan as a way to go beyond signing the Protection Agreement. It was believed that the plan could make the city more walkable and increase multimodal transportation options. Notably, one staff member believed that sustainability measures included in the plan such as energy efficiency, and energy savings, were a way for the city to reduce costs during the national economic downturn.

\section{Terminology}

The climate plan does not include a discussion of scientific research linking climate change to human activity. In both staff interviews the decision to leave this out was explained as a function of the plan's purpose being self-explanatory and because the city wanted to focus on itself. The majority of discussion regarding the plan centered on why action was needed, and the plan's committee members were sympathetic to the cause. However, the way the plan was 
marketed to the general public steered away from climate change and global warming, instead emphasizing sustainability, resiliency and adaptation. One Council member said: "It's irrelevant what [the plan] is called as long as people understand why we are pursuing it, and that it is important for future generations."

\section{Political Difficulty and Negative Reactions/Responses to the Plan}

The climate plan faced very little political opposition at the time of adoption. One staff member viewed the support of the climate plan and politically difficulties associated with it as comparable to other initiatives proposed by the city. There was little backlash within the community and three quarters of the City Council voted to adopt the plan. The Mayor's leadership, and marketing focused on tangible impacts of measures included in the plan, made the plan politically palatable. This marketing to elected officials and the community emphasized economic-cost savings. One staff member put the Mayor's message this way: “This isn't just about anthropogenic global warming...this is also about looking at how we pay our bills. How we do our work, how we want the city to be in 10-15 years, and what are we doing/what we can do to further the vision that we have for those goals."

However, framing the plan in this way did not appease certain members of the community, the same few "naysayers" that often complain about many city initiatives in general (infrastructure, taxes, "sustainability"). There were antiAgenda 21 members of the community who said that "The mayor and city

government were paid by the U.N." This so called "echo-chamber" (according to 
two interviewees) was not swayed by the argument that the CAP would save tax payer dollars. One staff member said: "When you are arguing with a conspiracy theorist, everything you say is part of the conspiracy, so you can't win," adding, "everything we did was suspect and all of the justifications we gave were suspect or manufactured according to their point of view." Staff made themselves available for questions, seeing this as the only course of action.

Notably, since the plan was adopted there has been more backlash from members of the community aside from the 10 or so individuals that had issues before. In recent years, "The term sustainability has become a politicized term" in the city and region, according to staff. This is viewed as connected to Tea Party influence in the region, and one interviewee believed that outside money was coming into local elections, perhaps from the Koch brothers. Opponents of "sustainability" were elected to Council after the plan was adopted, two of which had never voted in local elections. In recent years, members of the community have expressed criticism of climate science, and questioned whether addressing human activity linked to climate change is something that should be the role of government.

One interviewee described state bills introduced this year that say: "Cities cannot spend any tax payer dollars on sustainability programs." Because of this the city and staff have been reluctant to "talk about [sustainability] head on," and some programs have been put on the back burner as a result. According to the language in this legislation, staff said: “[The city] can't work on sustainability programs. We can't be affiliated with organizations that work on sustainability programs." This broad language is supported by newly elected members of the 
City Council. In one interview a Council member said: these members do not "believe in the concept period [of climate change]. They have told the mayor and I that we can't spend one penny on anything; that we need to vote no on everything...it's scary."

\section{Plan Creation and Community Involvement}

The climate plan effort was constructed by the Economic Development department. This department created an inventory and wrote measures for the plan. An environment task force consisting of approximately 10 stakeholders appointed by the Mayor evaluated measures for inclusion in the plan and devised new ones. This body later became a commission. Staff facilitated task force and community meetings and evaluated the feasibility of measures included in the plan. Interviewees identified the Mayor as the plan's primary champion, but city staff members in multiple departments were also identified.

Plan development was a two year effort. The community was mobilized through sustainability themed workshops, focusing on the topics included in the plan. These workshops were designed to inform the community about issues and measures included in the plan and in some cases outside speakers were brought in. Retreats and open houses were also held, involving many city departments. Neighborhood sessions were facilitated by the task force. According to one staff member, there was no overarching outreach campaign. However efforts were made to reach out to schools because as one interviewee put it: "Having kids sell it to their parents is a great way to get the message across. It's hard to say no to kids." Additionally, recycling and sustainability booths were erected at local 
festivals to inform residents about programs. Overall, staff viewed the plan as well received by the community. It was a pioneering plan in the area. As such it received positive press at its inception. A staff member emphasized the initial positive response and went on to say that "I am not positive that's where we're at now. Political winds have changed."

\section{Plan Implementation}

To date, those involved view implementation as relatively successful. An aspect of this is that the city has led by example, making energy saving and similar efforts visible at city owned facilities. To date implementation has taken an incremental approach. Visible impacts included in the plan have been pursued "out of the gate" in order to highlight progress for the community. Implementation of other strategies has been mixed. Post adoption, the city continued community outreach focusing on implementation. It also showed commitment to the plan by making the environmental task force a standing committee.

Since adoption the plan has become city policy. Implementation is financed through the city's general fund, capital fund, and grants (hoped for in the future). Impacts are tracked through the emissions inventory. Measures included in the plan influence purchasing decisions. One difficult issue in terms of implementation has been how to address highway emissions (which comprise the largest portion GHG impacts based on the inventory). According to staff there is very little the city can do about such a regional issue; highway emissions are "Out of reach." Notably, staff said that recently, many measures have not been publicized due to fears of anti-Agenda 21 backlash. 


\section{Lessons Learned and Advice}

For Case \#7, interviewees expressed a considerable amount of reflection on the climate plan process and advice for others undertaking such an endeavor. Overarching themes related to successful climate planning were gaining allies, educating the public, and framing the issue. The first step for staff is to identify political champions, "Start by enlisting leaders to spearhead the effort that can take the bullets." Next, it is important to assemble a task force representing a diverse range of community members that understand the issue and will educate others. This task force can involve business associations and regional bodies. With political backing and that of the task force, a platform can be constructed for the plan process. From the perspective of staff, "It's very easy to do an inventory" it is harder to get momentum and political support and adopt the plan itself. Additionally, it is important when initiating a climate plan to "take your time."

Public education and marketing of the plan is paramount. People are often worried about change. One interviewee advised “you can't succumb to the naysayers or you'll never get anything done." It is essential to market the climate plan to members of the community that know the least. Today, it is vital to use social media, to educate and engage. To the greatest extent possible, involve the youth and make sustainability public. This can be achieved by beginning with programs that are cheap, easily accessible, and visible. A way to increase visibility is to start with municipal facilities. In this way the city can lead by example and save the tax payers money. Then you can take that momentum; promote the plan by emphasizing what the city is doing, and "make the community more aware of what's going on and what they can do to help." 
Two interviewees suggested that the best way to achieve community buy-in is to emphasize the cost savings aspect of measures. A staff member believed that the cities will have very few people fighting against a CAP if the economic aspect is the focus. "Link it as much to economic positives as you possibly [can]." In this way the issue can be reframed. Staff felt that: "Trying to get anywhere on a green or sustainability initiative is as good as dead in a political climate [like this city]." Talking about science can be a "waste of breath", but framing it as an issue that has an impact on the city's bottom line and the way it can safeguard, administer, and protect the tax payers dollar can be effective. "In a sense you are giving [the community] sustainability without telling them its sustainability."

Another lesson taken away from interviewee's experience is to have faith in the aim of the plan and its measures. In the words of a City Council member: "Some people will be ill willed, ill mannered, and ill prepared to move into the future; do it anyway, do what's right anyway. Do it through kids, do it through communication." Eventually, as the plan gains momentum, the community will come around to sustainability because it makes sense. "They will save natural resources, they will save revenue and eventually they will make revenue."

Finally, one staff member had advice regarding implementation. Community outreach alone will not make a plan implementation successful. There has to be organization buy-in on the part of all departments and facilities in addition to the community. The biggest challenge is that sustainability has to happen everywhere. CAPs need to come about in a context where the change can actually occur. This cannot occur through the involvement of community members alone. Once the plan becomes part of the everyday organizational 
structure and the city's work flow, "You can point to that and say here's how we're changing here's how we're saving you money, here's how we're saving the environment."

\section{ANALysis AND REFLECTION}

Case \#7 is unique in comparison to other cases in this study in the way the CAP was developed. A hybrid approach was utilized with the plan written by city staff (the Economic Development department) and guidance from an environmental task force comprised of citizen stakeholders. The influence of the Economic Development department is clear, as the plan and its marketing are heavily focused on sustainability through co-benefits emphasizing cost-savings. The plan's municipal emphasis as a tool for community outreach highlights energy efficiency as a way to save citizen's tax dollars. This is notable because municipal emissions account for less than five percent of overall GHG emissions according to the inventory. Nonetheless, it appears that using city operations as an example for climate policy was effective in gaining public support for the CAP.

The economic emphasis used in Case \#7 also appears to have played a role in the political ease with which it was adopted. Although political winds have changed since adoption (discussed later), at the time, moderate Republicans were supportive the plan's use of sustainability as a way to reduce spending (through energy efficiency) and increase fiscal responsibility. An important finding relating to this is that one staff member believed this emphasis was seen as a way for the city to reduce costs during the (2008) national economic downturn. This finding is exciting to consider because if effective, this approach could be 
used to increase the use of CAPs in fiscally conservative areas. In Case \#7, staff found that focusing on the global responsibility and sustainability aspect of a CAP alone was not an effective argument in a city with Case \#7's political makeup. Stressing local impact and an internal focus was viewed as the most effective message.

In comparison to other cases in the study, the political transition that took place after the CAP was adopted was the most striking for Case \#7. The national rise of the Tea Party in 2010 led to a transition in Kansas ousting many moderate Republicans in the region (and some on City Council). The change also increased anti-Agenda 21 sentiments in the area and aversion towards sustainability programs. Anti-sustainability efforts increased statewide (including legislation against wind power) and bills were introduced at the state level aimed at sustainability. These political changes were unrelated to the CAP itself, but greatly affected the outlook for future sustainability efforts and climate planning in the region. An important finding relating to this is that one staff member felt the term sustainability has become politicized in the city and measures included in the plan have not been publicized in some cases due to fears of anti-Agenda 21 backlash.

Upon evaluation of the Case \#7 findings, it appears that in some respects the potential for political backlash was recognized and buffered against as part of the CAP process. Task force and staff members were aware of "naysayers" in the community, and understood that resistance was to be expected. This was viewed as inevitable and something that had to be overcome in order to institute meaningful CAP policy. Post-adoption, the city used legislative techniques to 
solidify the plan (by resolution) and made the environmental task force a standing committee. This seems to have been done in order make it difficult to erode the CAP progress if political winds changed later on. Interestingly, although the decision to leave out a scientific discussion of climate change in the CAP was said to be unintentional, it seems to have reduced opposition to the plan to some extent.

The way that staff dealt with anti-Agenda 21 views is important to consider from a CAP research perspective. Although there were opponents to the plan with fundamental ideological differences of opinion on what the purpose of the CAP was, this did not present a significant amount of difficulty in terms of adoption. For Case \#7, Agenda 21 opposition did not threaten the CAP's success. Through analysis of Case \#7, it appears that staff handled opposition by relying on allies including the Mayor (a primary champion), select City Council members, and stakeholders in the community for support. With this in place, the effect of a minority of detractors was reduced. Staff made themselves available to CAP detractors by fielding questions and having conversations through an open door policy, but recognized that this did not change the minds of opponents. By recognizing that the fundamental ideological differences in the CAP opponent's worldview were intractable, staff could focus on incorporating other stakeholders in the process rather than dwelling on opponents. Staff found that attempting to reason with supporters of an Agenda 21 conspiracy only provided fuel for those conspiracies. One interview summed up much of the opposition that CAPs in general face in the form of anti-Agenda 21 views: "This [plan] wasn't the source of the mistrust, it was another vehicle. The source was fundamentally a difference in political opinion." 


\section{CHAPTER 4: SUMMARY AND DISCUSSION}

This chapter draws comparisons between overarching themes in each of the seven case studies. The sample size was not large enough to conduct statistical tests due to the small number of cities identified as politically conservative (through the methodology used). Because of this, this chapter aims to build theories by highlighting notable findings, and draw connections between each climate plan and CAP process. To achieve this, data and findings from interviews and CAP analysis are evaluated in depth. These characteristics are also compared to findings from prior CAP research outlined in the literature review (Chapter 1). For the purposes of this thesis, CAP success is defined as action taken by city council in support of the plan and/or an encouraging plan implementation outlook. The primary sections of the chapter include a statement (italicized) which highlights important lessons learned for each theme or attribute, derived from case study findings. The subsequent content summarizes the evidence leading to this conclusion. See Table 3: Important Lessons Learned From Case Study Findings in the Appendix.

\section{BASIC CAP ANALYSIS COMPARISON}

In each case analyzed, CAP structure and scope vary, yet GHG emissions related to transportation constitute the largest single emissions source for all seven CAPs. 
Previous CAP research highlights the diversity of climate plans in terms of scope, structure, GHG targets and implementation framework (Wheeler, 2008; Bassett \& Shandas, 2010). This diversity is echoed in the CAP analysis of the seven cases studies evaluated in this research. The CAPs range from 24 pages (Case 2) to 104 pages (Case 1), with an average of 77 pages. Each CAP includes different baseline years and reduction targets. The most aggressive target is approximately 20 percent (Case 7), and least aggressive is approximately 10 percent (Case 5), from the baseline year emissions levels. Business-as-usual GHG emissions forecasts range from less than 10 percent over 27 years (Case 7) to an astonishing increase of over 150 percent in the next 26 years (Case 4) above baseline levels. The average number of total measures included in each CAP is 92, ranging from 24 (Case 7 ) to 172 (Case 6).

The transportation sector comprises the largest share of all GHG sources for each case averaging 49.5 percent, with approximately 59 percent (Case 6 and 7) being the highest and approximately 40 percent (Case 5 ) the lowest. This is slightly higher than the CAP database (Boswell \& Greve, 2013a) average of 41 percent. However, other sectors are not easily comparable because in each emissions inventory, sectors are defined in different ways. For example, some CAPs contain an energy sector, while others merely include residential, commercial, and industrial emissions. Three out of seven CAPs directly link reduction estimates for each sector to measures included in the plan. Notably, of the plans that do so, two (Case 1 and 7 ) of three project the greatest reduction in transportation, the largest sector in terms of GHG emissions (Case 4 does not). 


\section{CASE COMPARISON}

In total, 21 phone interviews were conducted. Interview data are derived from three phone interviews for each of the seven cases. The roles of each interview subject are as follows: ten city staff, one regional staff, five community members, three city council members, and two consultants. The interview findings, CAP analysis findings, and findings from prior CAP research are divided into four major categories:

- CAP Motivation

- Shared Characteristics

- CAP Development Process

- Adoption and Implementation Success (as well as failures).

\section{MOTIVATION}

Prior CAP research indicates communities that vote Democratic or have liberal political leanings are more likely to conduct climate planning (Hanak et al., 2008; Zahran et al., 2008b; Krause, 2011a; Krause, 2011b; Hawkins \& Wang, 2012). However, for this case study, focusing on CAPs in politically conservative cities, research by Lubell et al. (2009) is more relevant for case evaluation. This research cites more important factors as including: larger cities (Case 1 and 3), intellectual capital leading to innovation (Case 2 and 6), responses to rapid growth (Case 4 and 6), and areas with high socioeconomic status (Case 5). 


\section{Co-Benefits}

In these politically conservative communities, co-benefits were universally used to gain support for climate planning. In the vast majority of cases, energy related cost-savings and economic benefits are emphasized rather than GHG emissions reduction in its own right.

Accentuating Co-benefits (attributes of CAP measures aside from reducing GHG emissions explicitly) is a way for communities to gain support for CAPs (Betsill \& Bulkeley, 2004; Lindseth, 2004; Kamal-Chaoui \& Roberts, 2009; Dolan, 2010) and localize the issue (Kousky \& Schneider, 2003). By highlighting additional benefits included in the CAP, the plan can be more politically palatable. Specifically emphasizing cost savings (Kousky \& Schneider, 2003; Sharp et al., 2011) and energy efficiency can be more persuasive (Dolan, 2010) in some communities. Making long term economic benefits of climate action outweigh the upfront costs has been found to be particularly true in predominately conservative communities (Carter \& Culp, 2010). These case studies (of CAPs in conservative areas) are consistent with these findings from the literature. Energy and cost-saving emphasis are prominent and were often cited as motivating factors for CAP creation in the vast majority of cases (discussed below).

Many interviewees viewed creating a CAP as an important long-term planning goal, but stressed the importance of political will being present before the CAP could be developed. Emphasizing co-benefits was a common way to gain departmental, community, and elected official support-motivating CAP creation. The CAPs in all seven cases are heavily focused on energy rather than climate 
change broadly. All cases analyzed except for Case \#6 highly emphasize costsavings/economics, and four include health/ quality of life (Case 1, 3, 4, and 7). Others highlight sustainability (Case 1 and 3), or job creation (Case 1 and 4). It is an important finding that co-benefits were emphasized to such a great extent in each case, in part due to the political make-up of communities. The highest proportion of GHG emissions often come from residential and commercial activity — sectors that are not always affected by co-benefit measures-and an attribute found to be an obstacle for significant emissions reduction (Krause, 2011). Based on this attribute and the findings included in this case study, over emphasis on co-benefits may prove to be a barrier for implementing certain CAP measures in politically conservative communities.

A number of interview responses illustrate the importance of co-benefits for CAPs in conservative communities. One staff member speaking about Case \#4 believed that CAP benchmarks and success must be tied to fiscal considerations and tangible budget savings to receive community buy-in. According to this staff member, only by focusing on the energy and cost savings component (instead of outright GHG reduction) would a CAP have broad support in a community (with a similar political make-up to Case 4). In addition, the staff member believed that supporters cannot just describe that the plan will result in the reduction of $x$ metric tons of $\mathrm{CO}_{2}$ to elected officials because, "Not only do they not understand what that means, they aren't going to care and they are never going to care about that." This depiction of the attitudes of certain elected officials in Case \#4's community mirrors the attitudes of the "cautious" group in the Yale Project on Climate Change Communication's “Six Americas” (Leiserowitz et al., 2012). 
According to research by Leiserowitz et al. (2012), this group is unlikely to contemplate the climate change issue and may not have strong views regarding what, if anything, ought to be done about it. This is an important finding regarding CAP messaging in conservative communities, assuming that this response is reasonably representative. If the only approach to CAP marketing is through the cost-savings attributes of plan measures, substantial GHG emissions reduction in these communities could prove difficult.

Case \#1, \# 3, and \#7 provide further examples of how co-benefits can help market CAPs. The CAP measures of Case \#1 and \#3 are the most detailed (of the seven CAPs) and include cost-benefit analyses. A large number of programs focus on energy efficiency, often viewed as the most cost-effective approach to GHG emissions reduction. Notably, the city's Economic Development department guided the CAP process for Case \#7. This appears to have influenced the plan's marketing and language, which highlight sustainability through co-benefits emphasizing cost-savings. The city's mayor, a primary champion of the plan, was quoted as saying: "This isn't just about anthropogenic global warming...this is also about looking at how we pay our bills..." The economic emphasis also appears to have played a role in the political ease with which it was adopted. Interviewees in many of the other cases also indicated that co-benefits were helpful for marketing CAPs and making them politically palatable.

\section{State Mandates (California)}

In California, state mandates are viewed as important motivators for CAP creation in conservative cities, especially in the case of CAPs developed by city 
agencies. These mandates can influence measures included in each CAP as well as the success of measure implementation. State action can also serve as way to sell climate planning to community members and elected officials.

Findings from previous CAP research indicate that in politically difficult communities, state mandates aimed at GHG emissions reduction can offer political shelter (Bedsworth, 2010), and the most notable predictor for high quality CAPs is the influence of state mandates (Tang et al., 2010). The influence of state action and mandates is reflected in the four cases in this study located in California (Case 1, 4, 5, and 6). All four California CAPs mention AB 32 or SB 375, and most CAPs are front loaded with numerous state precedents, bills, legislation and actions relating to GHG emissions reduction or sustainability (Case 1, 4, and 6). In interviews relating to Case \#1, \#4, and \#6, expected state action on climate planning in the future and fear of inaction on GHG emissions reduction were expressed as motivations for undertaking climate planning initiatives. The latter is a reference to past Attorney General's lawsuits forcing places like San Bernardino County and Stockton to comply with AB 32. A notable finding is that the one California case (\#5) that did not indicate this action as a primary motivation for CAP creation was developed by citizens in the community, rather than city staff. This suggests that state regulatory authority has a greater impact on the staff of jurisdictions that may be affected by state action, than members of the community.

In some case study communities, creating a CAP was seen as way to give cities more autonomy in CAP design and measures included, with the expectation that state mandates would eventually require cities to undertake climate planning 
(particularly Case 6). In other cases (especially for Case 1 and 4) the implementation to date of CAP measures mandated by state laws and actions was most successful. One staff member echoed research by Bedsworth (2010), indicating that telling the community and elected officials that SB 375 requires the city to do $\mathrm{X}$ action put focus on the state rather than the city, providing political shelter for the CAP. In this way, it is possible that California state action could incentivize all cities, including those that are politically conservative, to undertake climate planning when political backlash or inaction within the community may be likely.

Furthermore, in some cities the most successful CAP measures target lowhanging fruit (principally Case 4). Research conducted by Hanak et al. (2008) demonstrates that it is easy for cities to direct the focus of measures on lowhanging fruit initially, like internal utility operations, which can establish policies of the community and thereby set the groundwork for community-wide programs in the future. Unfortunately, based on this case study's staff interviews, the completion of "easy-win" measures does not necessarily mean that expensive, or politically difficult community-wide measures, will be supported. Once these measures are exhausted, state action could be required to gain the support of elected officials for funding more difficult measures. Many interview responses parallel this difficulty-it is tough, if not impossible, for cities to mandate behavior, reducing the effectiveness of many CAP measures that are not backed up by law.

Another interesting finding, related to Case \#5, is that although state action was not viewed as a primary motivation for CAP creation, state mandates were 
regarded as essential for the success of climate planning across California. The chair of the committee that authored the CAP personally felt that although AB 32 and other measures were helpful in the process, more state action must be taken on the issue. This is important to note because the CAP was created by citizens, yet implementation of the plan is in the hands of city staff and the city council. If true, the relationship between state and federal mandates and local action merits further analysis. This relationship may be especially in true communities that may be reluctant to undertake climate planning on their own. This is a significant obstacle because it means that local action alone may not be enough to reduce GHG emissions nationwide.

Note: Of the three CAPs included in the study that are not located in California (Case 2, 3, and 7), only Case \#2's city is located in a state that has a CAP (Colorado). Colorado's Climate Action Plan was issued in 2007 by Governor Bill Ritter. The state plan was referenced in Case \#2's CAP document; however, in interviews the state CAP was not described as a motivating force for plan development. In Case \# 3 and \#7's cities (located in Tennessee and Kansas respectively), interviewees did not cite state action, mandates, or policies related to climate change as motivators for CAP development. Based on these findings, substantial evidence does not exist that allows for evaluation of the impact of state level climate policy on CAP development in these communities.

\section{Public Utilities}

The presence of publically-owned utilities motivates CAP creation in some conservative communities because of a perceived level of control over local 
energy issues. In such cities, municipal energy use and energy efficiency are points of focus.

It is an important finding that three of seven cases cited municipal (Case 1 and 2) or publicly owned (Case 3) utilities as motivators for undertaking CAPs. Previous CAP research supports this finding. Climate mitigation planning success has been linked to local governments that own their utilities (Pitt, 2010b), and local utilities are often integral players in CAP creation by encouraging conservation and providing incentives (Hanak et al., 2008). CAP research by ICLEI (2006) found that the unique characteristic of Fort Collins, Colorado and Burlington, Vermont, owning their utilities provided a greater level of control for creating climate plans due to more flexibility in terms of regulatory authority. The existence of public utilities may be a motivator for the energy efficiency and costsavings themed CAPs in politically conservative communities, such as Case \#1, \#2 and \#3.

Most publicly owned utilities were formed 50 to 100 years ago (Cardwell, 2013), a finding which is consistent with the cases in this study. Consumer-owned utilities (this includes city-owned utilities and public cooperatives) serve approximately 25 percent of the nation (RAP, 2011). In particular, public (electric) power companies serve approximately 15 percent of cities and towns compared to 68 percent by investor-owned electric utilities (APPA, 2013). A 2013 study found that on average customers of investor-owned electric utilities (IOUs) pay nearly 14 percent more than public customers (APPA, 2013). This is supported by a 2003 study indicating that in California, publicly owned utility rates were 41 percent lower than that of IOUs (Anaheim Public Utilities, 2011). However, 
according to Energy Information Administration, the average difference between public utilities and IOUs in terms of consumer costs varies by state (Cardwell, 2013 - see Appendix for a visual illustration of this). It is possible that these features contribute to a connection between public utilities and climate planning initiatives. The relationship that exists between a jurisdiction and its public utility could influence the level control a city can wield in terms of energy efficiency policy.

Due to concerns over rising utility costs, a lack of autonomy, climate change, and a desire to infuse a higher proportion of renewable energy in the grid-some cities serviced by IOUs, many jurisdictions are considering changing to publicly owned utilities (Cardwell, 2013). For example, Boulder, Colorado, released an analysis in 2013 indicating that by creating its own municipal utility, the city could reduce GHG emissions by 50 percent by receiving 54 percent of its energy from renewable sources (Cardwell, 2013). These attributes indicate that public utility ownership may be an important factor leading to climate planning in cities generally, regardless of political ideology. However, it is possible that these attributes could make climate planning more politically palatable in politically conservative communities.

The idea that publically owned municipal utilities influence CAP creation and structure is exemplified by these three cases (Case 1, 2, and 3). Even though the highest proportion of GHG emissions stem from transportation sources for all three CAPs, the language of each heavily emphases energy efficiency and associated cost-savings. Case \#2 is located in a city that owns its municipal utilities, and is the only case in the study that focuses exclusively on municipal 
operation through CAP measures and targets. All interviewees in this case referenced the municipal utility as an important driver for the CAP and environmental initiatives relating to energy in general.

For Case \#3, the utility board was important for reaching the community and linking climate change and sustainability to energy efficiency. The energy efficiency emphasis (relating to cost-savings) helped the CAP win approval from department head, elected officials and the community-and was also important for integrating sustainability efforts into municipal operations as part of implementation. The city's utilities department in Case \#1 also played an important role in the CAP process, with the utility director authorizing staff time for the effort. This department influenced the success of CAP measures through regulating GHG emissions and is the primary city department responsible for monitoring CAP implementation.

\section{The Great Recession}

Budget constraints can influence the desire to engage in climate planning in different ways. In certain cases, the fear of impacting private enterprise can reduce the will to participate in CAP implementation; in others, the attraction of reducing municipal energy costs can invigorate CAP efforts.

Six of the seven case study CAPs were developed and/or completed during or soon after the national economic downturn of 2008 . This recession greatly affected the budgets of cities across the U.S. and their ability to fund new comprehensive planning endeavors. It is impossible to determine with certainty 
whether budgetary constraints caused each case to become more economically focused than they otherwise would have been, but the differences between the case study communities provide interesting findings in terms of how CAP costs and benefits were perceived. The contrast between the recession's impact on Case \#1 and Case \#7 illustrate this point well.

Staff involved in Case \#1's CAP found that the timing of the plan (during the economic downturn) raised fears in elected officials and the community that it could hurt business. Because of these concerns, stakeholders from the business community were highly involved in the plan, and the communications strategy emphasized why the plan was good for business and how it would save money. Furthermore, because of the state of the economy, plan implementation has been hindered due to a lack of resources.

In contrast, a staff member involved in Case \#7's CAP viewed the economic downturn as a motivation for creating the plan. This interviewee believed that sustainability measures included in the plan such as energy efficiency and energy savings, were a way for the city to reduce costs during the national economic downturn. This finding is important because it may broaden the appeal of CAP creation in conservative communities that may not view GHG reduction alone as a reason to pursue climate planning, but highly regard fiscal responsibility. 


\section{Shared Characteristics}

The seven cases in this study share a number of characteristics that may be important for understanding how climate plans can be successfully adopted in politically conservative communities.

\section{CAP Titles}

Leaving out "climate" or "sustainability" in CAP titles can be a way to reduce political backlash and increase climate planning marketability in politically conservative communities.

Bassett and Shandas (2010) found that some individuals involved in climate action planning in politically conservative communities consciously chose to leave out policy language mentioning climate, carbon reduction, or environmental terms. This characteristic is consistent with the way some of the CAPs are titled in the seven cases. A majority (57 percent) include climate (Case 2, 4, 5, and 7). The majority of these (three of four) are located in California, where it is possible that state mandates provide political shelter. Two include sustainability (Case 1 and 3) and two include energy (Case 2 and 3), a rate of 29 percent for both terms. Only Case \#6 does not include any of the aforementioned terms but rather includes a term associated with the environmental movement.

In comparison, an analysis of the 245 CAPs included in Dr. Boswell and Dr. Greve's CAP database (Boswell \& Greve, 2013a) shows that 73 percent of plan titles include climate, 17 percent include GHG, seven percent include energy, six 
percent include sustainability, and four percent include other "environmental" terms. Although the seven CAPs included in this study are small in terms of sample size, this comparison suggests that conservative communities may be less inclined to include GHG or climate in CAP titles, and more likely to include energy or sustainability. Notably, Case \#6's CAP met the highest level of opposition and political backlash of any case based on interview data, and included a term often associated with the environmental movement in the plan title. A member of the community that was interviewed said the plan's "descriptive title did not take into account the opposition" within the community.

\section{Terminology}

In some cases, CAPs in conservative communities are prone to excluding climate science or GHG emissions connection to human activity, especially without the influence of state mandates.

In conservative communities, "sustainability" has been used to gain support for pragmatic CAP measures, but in recent years, political opposition to this term has changed the meaning of "sustainability" in these regions, reducing its political viability.

The science behind climate change and the scientific consensus that anthropogenic sources are the primary factor contributing to global GHG emissions were not discussed in many of the CAPs. Three of seven CAPs do not include an in-depth discussion of climate science. In addition, only three of seven CAPs include a description of a connection between climate change and human 
activity. An interview response (for Case 3) regarding terminology illustrates the political aspect of conducting climate planning in conservative communities: "climate can be a polarizing word." This concept was reiterated in many other interviews and may be less common in politically liberal communities.

The incorporation of climate science is an interesting characteristic to consider in CAP research, but a more notable finding of this research is how the term sustainability was used and has evolved in politically conservative communities. Interviews relating to the CAPs created in each case study provided rich and candid insights into the political aspect of using sustainability that could not have been gained by relying on other data sources exclusively. In a number of cases (described in the next paragraph) the term sustainability changed meaning and became politicized. This concept in very important for CAP research because sustainability is often used in many different ways and is sometimes a synonym for environmental programs in general. In climate planning this term has been used to highlight co-benefits such as rational use of resources, efficiency, and planning for the future.

In Case \#1, the CAP purposefully focused on sustainability rather than climate change and global warming. Staff stated that this was done in order to gain broad appeal for the plan within the community. Interestingly, in contrast to other cases in the study, staff believes that sustainability is a touchstone for many issues in the community and that there is more support presently, than at the time the plan was created. For Case \#3's CAP climate was also replaced with sustainability in the plan's title for a similar reason (it was considered a broader, more neutral term). However, in contrast to Case \#1, since the CAP was completed, 
sustainability has changed meanings politically and does not have the same level of broad appeal that it did at the time of the plan's creation. This change was echoed in many interviews (specifically Case 4 and 7) and believed to be related to the anti-Agenda 21 movement and its supporter's views on ICLEI and sustainability.

In Case \#4, interviewees felt that because of the community's political make-up, sustainability may have been a more controversial term to include in the CAP than climate change. The region has a substantial anti-Agenda 21 constituency, and other cities in the region have experienced opposition to sustainability programs and policies. In fact, one city in the region removed the word sustainability from many of their documents. In Case \#7, the increased political backlash to sustainability (and climate issues in general) was the most striking. Since the CAP was adopted, the national rise of the Tea Party in 2010 led to a transition in Kansas ousting many moderate Republicans in the region (and some on City Council). The change increased anti-Agenda 21 sentiments in the region, specifically targeting sustainability programs and policies. Antisustainability efforts increased statewide and bills were introduced aimed at cutting funding from anything related to sustainability. One staff member felt the because of this, measures included in the plan have not been publicized in some cases due to fears of political backlash. 


\section{CAP Development Process}

Bassett and Shandas (2010) evaluated 20 CAPs and found that planning departments were not central to CAP creation in many cases; rather economic

development or public works departments often played lead roles. Analysis of the seven case studies in this research mixed results supporting Bassett and Shandas. Three of the seven cases were written at least partially with the help of consultants (Case 1, 4, and 6). Two were written entirely by members of the community (Case 2 and 5). Only three were written at least partially by planning staff (Case 1, 4, and 6). In contrast three CAPs were written primarily by staff in city departments other than planning (Case 1, 3, and 7).

\section{Departmental Leadership}

In the conservative cities included in this study, CAPs were not primarily developed by planning agencies; rather, plan development was led by other city departments, or bodies created through the actions of elected officials.

Case \#4 and \#6 were the only cases in the study in which the CAPs were written in part by planning departments without heavy assistance from other city departments. Of these, Case \#6 was the least successful CAP included in the study. The success of Case \# 4's CAP was connected to its creation as part of the city's general plan update, this is unique as only six percent of CAPs in California are created in this way according to Dr. Boswell and Dr. Geve's national database (Boswell \& Greve, 2013a). In interviews this connection was said to be helpful for gaining the support of elected officials. In many interviews 
(of all seven cases) implementation success was viewed as contingent on staffbuy in from multiple departments. Case \#1, \#3, and \#7's CAPs were developed by city departments other than planning and received significant support from elected officials. These three cases exemplify a pragmatic, cost-benefit approach to CAP measures to a greater degree than the other four cases evaluated.

Perhaps as a result, these CAPs also received the highest level of departmental and staff buy-in for implementation of all the cases in the study. It is difficult to determine if these characteristic are connected with such a small sample size, but the findings are notable. It is possible that the regulatory nature of many planning departments impacts the ability with which they can implement such a long-range and comprehensive endeavor as a CAP.

\section{Involvement of Consultants}

Consultant involvement often led to the creation of CAPs which included a high level of detail, and in certain cases influenced the use of specific terminology that could be potentially sensitive in politically conservative cities.

Case \#1, \#4, and \#6's CAPs were managed by city departments, but written by consultants. Interestingly, each of these communities is located in California. This makes sense because the majority of CAPs that have been completed to date nationally are located in California-109 out of 245 according to Dr. Boswell and Dr. Greve's CAP database (Boswell \& Greve, 2013a), creating demand and a supporting industry. The CAPs in these cases are longer on average than other CAPs in the study, with a more detailed appendix and emissions inventory. Staff interviews for these cases indicate that consultants were hired because of their 
expertise, experience, and familiarity with the climate planning process. Another notable aspect of consultant involvement was reflected in an interview with the only two consultants interviewed in this research. From the consultant's perspective, the goal is to make sure the city can actually follow through on measures included in the plan after it is completed-an attribute crucial for the success of CAP implementation.

Notably, Case \#1 and \#3 interviewees said that specific terminology felt to be controversial in their politically conservative communities was excluded from the CAPs by consultants and that this is common practice. However, for Case \#6, hiring consultants through the difficult political process significantly increased costs to the city. Due to the consultant fees associated with numerous revisions (resulting from public comments and concerns), the plan's cost escalated nearly fivefold. This is an important finding, not necessarily because of the role of consultants in the CAP creation, but because without careful monitoring of CAP development by departments heads or elected officials, it is possible for political backlash to lead to unintended consequences, thereby reducing CAP viability.

\section{Community Members}

In conservative communities analyzed in this case study, the majority of CAPs include community stakeholder participation. However, CAPs developed entirely by citizens require staff involvement for success.

Many cases in the study included community member or stakeholder involvement in working groups, task forces, or advisory roles. In these cases, 
stakeholders or community members often shaped CAP scope or measures, but the general public at large was not necessarily highly involved in the process. However, CAPs developed primarily by community members with little input from city staff necessitates a high level of determination and will, as well as a high degree of trust between the government and community members. Case \#2 and \#5 were created in this way and stand in stark contrast of one another.

Case \#5 provides the best example of a successful community champion—rather than elected official-and community outreach strategy. Based on information derived from interviews, this champion rallied public support for climate planning within the community (and city council). Through his efforts as chair of the committee that developed the CAP, advancement of an effective community outreach strategy, and recruitment of influential individuals to the committee, the CAP was successfully adopted. In contrast, Case \#2, also created entirely by members of the community, did not gain overwhelming support from the city council, community at large, or department heads. The city council only adopted the CAP reduction targets, leaving the measures in legal limbo. The CAP includes the second greatest quantity of measures, but the least amount of policy detail, threatening the success of implementation and monitoring.

Case \#2 is also the only climate plan in the study to focus principally on municipal emissions, a notable finding considering that it was created by members of the community. A CAP that targets municipal operations, but does not receive heavy departmental buy-in, is unlikely to be successfully implemented. This idea was reflected in interviews, with one committee member saying that the CAP is currently "gathering electronic dust." However, it should be 
noted that the implementation outlook for Case \#5's CAP also includes a level of uncertainty due to a lack staff and departmental involvement. Although it is exciting to consider that in politically conservative communities the will of community members can overpower reluctance to engage in climate planning by elected officials or city staff, it is important to note that this trajectory may make CAP implementation difficult.

\section{ADOPTION AND IMPLEMENTATION SUCCESS}

Through the analysis of each of the seven case studies included in this research, a number of common themes emerge. Information regarding these themes is principally based on interview responses, but analysis of each climate plan is also drawn upon. This section focuses on four primary themes: pathways to completion (specifically adoption versus other routes), the role of champions, CAP buy-in, and difficulties encountered.

\section{Pathways to CAP Completion}

Adoption is not a prerequisite for CAP success, but a legal basis for the plan is important in politically conservative cities.

Due to the relatively small proportion of CAPs that are completed but not adopted, no prior research was located that analyzes this phenomenon. Additionally, analysis of Dr. Boswell's and Dr. Greve's CAP database (Boswell \& Greve, 2013a) did not yield any conclusive statistics relating to this characteristic. Of the seven cases included in this case study, two were completed, but 
accepted/released (Case 1 and Case 3 respectively) rather than adopted, one had its target adopted and measures accepted (Case 2), three were adopted by city council (Case 4, 5, and 7), and one was completed but city council took no action (Case 6). Because the research focus of this thesis is evaluating the characteristics of CAP adoption in politically conservative communities, the finding that four of the seven CAPs were completed but not fully adopted necessitates consideration.

The two CAPs completed and supported by city council action, but not adopted, were accepted (Case 1) and released (Case 3). Interviews of staff involved in these plans indicated that in both cases, this was due to lack of political will, or guidance from city council, ensuring that measures included in the plan would be voluntary rather than regulatory. Interestingly, this path did not appear to threaten the implementation outlook of either CAP. In fact, Case \#3 and \#1 employed the most detail of all climate plans involved in this study. Both include a greater degree of cost versus GHG reduction analysis in comparison to other CAPs in the study. This emphasis appears to have made plan implementation less difficult for each CAP.

Case \#3's CAP, although not formerly adopted by the city council, was instead implemented by the mayor as a "de facto policy." Additionally, staff did not ask the council to approve the plan or its reduction goals. Notably, the CAP measures do not require large funding sources (except for energy efficiency programs, which save money in the long-term). Due to this it is interesting that the plan received support from council and the business community, but not to the extent of adoption. Based on Case \#1 interviews, the business community 
also influenced the community and elected officials not to make the plan compulsory. Business leaders on the CAP task force influenced the scope of measures included in the plan and the legal "teeth" of policies and programs. By reducing pressure to adopt each CAP, and make measures into law, the success of both plans was not threatened by opponents fearing costly regulation. Both plans have secured wide support from city agencies and the lack of adoption does not seem to have affected CAP progress or the level of funding that measures receive.

The three cases in which CAPs were adopted in their entirety benefited primarily from the long-term outlook of this legal status. In each case, political will was present in the form of elected official support for the CAP and adoption, ensuring that if this support waned in the future, the legal status of each plan would continue to solidify it as city policy. An important finding related to this is that although political will was present for adoption, this did not necessarily guarantee that it would continue to exist for plan monitoring or implementation, or that the plan would be successful post-adoption. This manifested itself differently for each CAP: the city council make-up changed and political opposition increased after adoption (Case 7), measures that do not have associated cost-savings may be difficult to implement (Case 4), and a lack of staff support and departmental involvement linked to implementation (Case 5).

Of the seven cases in this study, two are the least successful by a wide margin (Case 2 and 6). For Case \#2, the CAP reduction targets were adopted by the city council, but the measures were not. For the CAP, this attribute appears to have significantly diminished the plan implementation outlook. In the end, Case \#6's 
CAP did not receive continued support from the city council. Because of this, although city staff was highly involved in the plan development process, implementation proved to be unachievable. Based on these findings, it seems that in the politically conservative communities included in this research, adoption is helpful, but does not guarantee implementation success. Adoption indicates city council support, which is crucial for long-term CAP success, but this support can be achieved even if a CAP is not officially adopted. Implementation success in contrast is dependent on long-term support at all levels of government and community buy-in.

\section{The Role of CAP Champions}

CAP research has shown that for cities to undertake climate planning in the first place requires a great deal of political will and leadership (Bassett \& Shandas, 2010). Political support of public officials can aid in implementation and increase CAP comprehensiveness (Krause, 2011b). Gaining political support has been found to be particularly difficult in conservative areas (Carter \& Culp, 2010). In the analysis of the seven cases in this study, political support for climate planning was found to be present in conservative cities (especially in the case of city staff), but not to the same degree as research has shown exists in more liberal communities (Leiserowitz, 2006; Sharp et al., 2011). This may make the political obstacles to CAPs greater in conservative cities, and conceivably the role of an effective champion even more essential. Prior research indicated that CAP champions fill the role in a number of ways-some guide or manage the process (Betsill \& Bulkeley, 2004), some see it as a moral obligation or potential for 
political gain (Betsill, 2001), and others have a unique aptitude for grassroots organizing or technical expertise (Pitt, 2010a).

The role of a champion was found to be extremely important for CAP success in this case study research, echoing previous CAP research findings. Of the five most successful cases evidenced by departmental and community buy-in, implementation outlook, and support of elected officials (Cases 1, 3, 4, 5 and 7) - the achievement of all but one (Case 4) was linked to the involvement of a CAP champion. Based on interviews, some degree of significant support (ideally a champion) is important at the staff-, elected official-, and community-level in order for a CAP to be adopted (or accepted/released) and implemented effectively. Notably, Case \#4's CAP was adopted without the assistance of a strong champion, even in the face of political opposition to sustainability within the community. Although no individual champion was identified, the plan's success may be connected to the fact that the CAP was developed in tandem with the city's general plan update which benefited from substantial city council support.

\section{MAYORAL SUPPORT}

Mayoral backing is particularly helpful in politically challenging communities; it can shape policies, as well as influence the level of elected official/community member participation and support.

Mayoral support was an important factor in CAP adoption (or other favorable action by council) in a number of cases discussed in this section. Political 
scientists have argued that partisanship does not impact cities to the same extent as higher levels of government (Ferreira \& Gyourko, 2009) and that mayors can transcend partisan divides (Barber, 2013; Einstein \& Kogan, 2012). It is possible that the same is true for the role mayors in conservative cities play in climate planning policy. Mayoral support was an important factor in CAP adoption (or other favorable action by council) in a number of cases discussed in this section. A number of political scientists have argued that partisanship does not impact cities to the same extent as higher levels of government $(F \& G)$ and that mayors can transcend partisan divides ( $\mathrm{E} \& \mathrm{~K}$, Barber). It is possible that the same is true for the role mayors in conservative cities play in climate planning policy.

The CAPs for Case \#1, \#3, and \#7 benefited from strong staff project managers who served as advocates and championed the plan, but also notably from mayoral champions who supported the effort and built a coalition that included business leaders and other elected officials. This was especially important for Case \#3 and \#4, located in Tennessee and Kansas cities, (respectively) which experienced difficulties associated with publically conservative constituencies often reluctant to pursue GHG emissions reduction planning. In all three cases, these mayors helped facilitate the creation of new departments (or city offices) designed to oversee plan development and implementation. Notably, Case \#1 and \#3 both experienced mayoral changes during the CAP creation process. Interestingly, for Case \#1, the first mayor was more supportive of the CAP than the subsequent mayor; for Case \#3, this was reversed. Case \#7's mayoral champion was involved in the entire CAP process, perhaps contributing to the plan's adoption (in comparison to Case 1 and 3). Thus, one of the hallmarks of 
successful championing appears to be the ability to influence others to "take up the cause."

Bassett and Shandas (2010) found that in some cases, climate planning efforts were connected to the mayor's office because the mayor wanted to link the CAP to that office rather than another city agency, increasing their role and influence in the process. The findings of these three cases reflect this characteristic to some degree. However, in this study, mayoral involvement was found to be a way for the city to dedicate staff time, and involve important members of the community, more than for the purpose of process control or political gain. Perhaps this is because many CAP are created in politically liberal communities that widely support environmental initiatives, adding to the political capital and achievement of a mayor's administration.

However, one symbolic mayoral action evaluated in prior CAP research (Wheeler, 2008; Bassett \& Shandas, 2010) was not found to have a great impact on CAPs in this study. In four of seven cities (Case 2, 5, 6 and 7) or 57 percent of cities, the mayor signed the U.S. Conference of Mayors Climate Protection Agreement. This compares to 26 percent in the national CAP database (Boswell \& Greve, 2013a). It should be noted that in two of the four cases (Case 5 and 6 ) the mayor who signed the agreement was not in office at the time city council took action on the issue. Based on the case study findings, signing this agreement does not appear to be a significant indicator for successful adoption. This is illustrated by the fact that one of the four cases that signed the agreement (Case 2) the CAP was not fully adopted and in another (Case 7) the CAP was not adopted at all. Importantly, Case \#3's Republican mayor did not sign the 
agreement due to the belief that this action could be politically polarizing and not much would be gained by signing it. This is a notable finding regarding attitudes towards national and international climate change agreements in politically conservative communities. According to the results of this research, participation in these types of symbolic agreements may have little impact at the local level and are is not required for successful CAP adoption or implementation. This is supported by data that shows the high level of CAP implementation success in Case \#3, in comparison to Case \#2 and Case \#6's CAPs, which are effectively un-implementable.

\section{CITY COUNCIL SUPPORT}

For the cases included in this study, city council support is the most essential element for CAP success, because councils make the final policy determination after CAP completion. However, their support for climate planning initiatives can be highly influenced by community sentiments regarding "climate change", pointing to the importance of community attitudes for successful climate planning.

In all seven cases, the support of city council was perhaps the most crucial indicator of CAP success. Although staff, community, and mayor champions are essential for CAP development, action on the plan and its legal basis ultimately rests in the hands of city council members. The least successful CAPs (Case 2 and 6) received the smallest amount of city council buy-in. However, in a number of cases, specifically Case \#5 and \#7, city council CAP support was influenced by climate planning champions. In Case \#7, the mayor spearheaded the political marketing effort and handpicked stakeholders for the CAP task force. The mayor 
knew key individuals in the city well and encouraged city council involvement in the process.

Case \#5's CAP benefitted from a quintessential community champion. In the words of one interviewee, in order for a CAP to be successful, "Find yourself a [name of plan's chair redacted]!" This citizen champion (and CAP committee chair) rallied public support for climate change mitigation, hand-picked well respected and influential community members for the committee, and led the plan development process. With this strategy, he applied pressure to the city council for climate change action (gaining the support of less supportive members) and this contributed to council action on the CAP as a way to highlight the city's commitment to the climate change issue.

\section{Buy-in}

Prior CAP research puts heavy emphasis on the importance of community buy-in for successful climate planning (Lubell et al., 2009; Pitt, 2010a; Pitt, 2010a; Gremillion, 2011). A significant amount of CAP research also stresses the importance of support from business leaders (and groups), or lack thereof, in the success of CAP adoption and implementation (Bulkeley and Betsill, 2003; Hanak et al., 2008; Pitt, 2010b; Millard-Ball, 2012). Less research exists regarding the role of staff buy-in, but points toward jurisdictional coordination as a challenge for success (McCarney, 2009) and the reliance of implementation ability on interdepartmental collaboration (Millard-Ball, 2012). Yet, there is a substantial gap in research gap concentrated on evaluating the impact of staff buy-in relation to successful CAP adoption. It is possible that this research gap exists because it 
is assumed that most CAPs are created by city agencies, implying a significant level of support for the climate planning process. Research by Pitt (2010a) is one exception to this and indicates that staff or departmental participation and leadership, as well as awareness and concern about climate change impacts, is essential for CAP success. CAP adoption in politically conservative cities (in this case study) was found to be most successful in cities with staff/departmental and business community buy-in, rather than community buy-in from the general public (except for Case 5).

\section{“Community” BuY-IN}

In conservative communities, CAP buy-in from the general public can be more important for implementation than CAP adoption (or completion). Often community stakeholder buy-in is more crucial than that of the general public and public workshops serve as a compulsory aspect of the planning process rather than an integral contribution to CAP development.

Community buy-in is a very general term that can refer to a number of groups. In most cases this type of buy-in denotes involvement of private citizen stakeholders (including business groups and lobbyists) or the general public at large. It is important to highlight this difference, because while powerful private citizens are important for CAP development and successful marketing, it is the general public's adherence to CAP measures and acceptance of communitywide behavioral changes that make CAP implementation ultimately successful. CAP research findings indicate that community involvement is essential in the 
early stages of CAP development as a way to gain momentum for adoption and continue it through implementation (Pitt, 2010a).

Based on information derived from interviews, the majority of individuals involved in each CAP felt that a community driven process is essential for long-term success. However, in many cases although stakeholders were incorporated into the planning process, the general public was not highly involved (Case 3) or even aware after the CAP was adopted (Case 2, 3, and 7-as well as Case 1 to some extent). In some sense, it appears that although most CAP processes involve community workshops as a rule of thumb, this does not always lead to community-wide buy-in-a necessary outcome for truly successful CAP implementation. These findings may be linked to the nature of conducting climate planning in a politically conservative community, where some passionate individuals are interested in climate change issues, but many citizens in the general public can be indifferent to the aim.

The concept listed above is supported by an opinion expressed by a staff member in Kansas (Case \#7) who argued that the majority of people in many cities are only concerned with the basic functions of city government; when the CAP was adopted the people who were already interested in the issue were aware, but by and large, the community in general (those less interested in the process) were not aware that it had been adopted (or in the case of some, did not care). This comment was built upon by a city council member (for the same case) who felt that for the plan to be completed in similar cities "you can't succumb to the naysayers or you'll never get anything done." This raises the question of whether in cities where residents are indifferent to the CAP process, 
long-term implementation of measures will be successful. However, it is important to make a distinction between the role of the larger community as a factor in CAP adoption, in comparison to CAP implementation. Research findings suggest that successful completion or adoption of CAPs in conservative cities does not necessarily require buy-in from the general public as a whole-other factors are more important.

\section{BUSINESS COMMUNITY BUY-IN}

In conservative cities, buy-in from the business community is often essential for CAP support and viability. Absence of this type of buy-in can have serious ramifications for CAP success.

This case study research suggests that involving the business community (e.g. chambers of commerce, lobbyists groups, small business owners, developers, builders associations, the real estate industry) is essential for successful CAP adoption (or completion) in politically conservative communities. All of the five most successful CAPs (aside from Case 4) gained the support of the business community and involved them in stakeholder committees, task forces, and work groups. In contrast, the least successful CAPs (Case 2 and 6) failed to successfully incorporate business leaders and their concerns in the CAP process and measures. Prior CAP research indicates that the extent to which businesses support CAPs varies (Hanak et al., 2008), but that co-benefits can influence this dynamic (Lindseth, 2004), such as the economic gain related to energy efficiency and related job creation (Betsill, 2001). Yet, because CAP measures (especially those involving regulation) can affect businesses (Kousky \& Schneider, 2003), 
opposition from business interests can present a challenge in some communities (Bulkeley and Betsill, 2003). Based on the findings of this thesis, this opposition can be the greatest challenge for climate planning in conservative communities.

In four of the seven cases, incorporating the business community into the CAP process resulted in substantial buy-in, but also influenced the plans themselves. This includes the aim of measures contained within (Case 1 and 3), or an emphasis on the cost-savings co-benefits of CAP language and measures (Case $1,3,7$ and 5 to some extent). This trend makes sense as it is the expected outcome of a cooperative process. More importantly, the co-benefit approach assisted in gaining the support and buy-in from influential groups and leaders in the community that may have otherwise been skeptical of the intentions of the CAP. For some CAPs, certain members of the business community had concerns, but eventually supported it. For Case \#1, a contributing factor to this was the involvement of a well-respected business leader who spoke peer to peer from an economically-based perspective. This finding mirrors that of Hanak et al. (2008) indicating that collaboration with business groups is one form of partnership that has led to CAP success. This characteristic appears to be even more in pronounced conservative communities, and was an important factor in the success and failures (Case 6) of many of the cases in this study.

A lack of collaboration, partnerships, and buy-in from business groups was especially pronounced in Case \#6. For Case \#2 there was not a great degree of business community buy-in and involvement because the CAP focused exclusively on municipal emissions rather than community-wide emissions. Case \#6's CAP experienced a variety of difficulties, so it is challenging to objectively 
determine the extent to which each variable contributed to the lack of action by city council once the plan was completed. However, the plan's primarily opponent (effectively the CAP's "anti-champion") was a member of the development community which as a whole had concerns linked to a perception that the plan would increase regulations.

Notably, the city's business community (in Case 6) is small and does not generate a great deal of tax revenue; yet a lack of understanding from business, development, and real estate groups negatively affected the plan's success. One interviewee believed that this was a result of city staff and consultants bringing these associations into the process too late, and not properly educating them regarding the benefits that could result from a city CAP. With such a staunch anti-champion and no political champion or powerful advocate within the community, the plan ultimately failed. It is impossible to say whether the lack of business community buy-in was the primary reason for this-the city council had the final say-or if a different approach could have thwarted the efforts of the anti-champion—but it was most certainly a contributing factor to the CAP's political ruin. Pitt's (2010b) CAP research indicates that cities better equipped to overcome a lack of support or blatant opposition from elected officials, the business community, or citizens at large-could have a greater likelihood of CAP adoption. 


\section{AGENCY BUY-IN}

Agency-wide and department head buy-in can be particularly important in conservative cities for the long-term success of climate action planning, perhaps more so than the involvement of committed individual staff members.

Although there is not a great deal of research regarding departmental buy-in itself, a number of attributes have been determined to influence departmental action and support. The city in Case \#1 first focused on internal practices and operations with climate planning measures before moving on to a communitywide CAP; this has been seen in other cites as well (Feiock et al., 2010; Feiock \& Francis, 2010). In this way cities can increase public awareness (Tang, 2010); the CAP development process in Case \#7 provides a strong example of this. Many department heads are persuaded to support CAPs due to the perceived economic co-benefits of energy efficiency measures (Dolan, 2010)—exhibited in Case \#1, \#3 and \#7-and by focusing on the city itself, it is possible to reduce political obstacles (Betsill, 2001). This was found to be true in many cases in terms of energy efficiency measures, but did not seem to increase CAP support in Case \#2.

Departmental buy-in manifested itself in a number of ways for each of the seven cases. One example is through the allocation of staff time. Allocating dedicated staff to CAPs and incorporating a broad based effort (Pitt, 2010a) is essential for adoption and implementation. For Case \#1, the city's utility director authorized staff time for the CAP, an extremely important action during the early 
stages of plan development. Five cases (Case 1, 3, 4, 5, and 7) employed the organizational support and buy-in for their CAPs by assigning responsibility of each plan measures to a specific city agency. In interviews of city staff (in regards to Case 3 and 7), organizational buy-in from all city departments was said to be crucial for the success of CAP measures. This was reiterated in a Case \#1 staff interview where staff also stressed identifying champions in each department who can be counted on.

In this case study of CAPs in conservative communities, long-term staff buy-in was found to be extremely important. An assessment of Case \#4's CAP shows that with staff turnover, it is possible that CAP implementation of climate plan strategies could suffer in city departments responsible for the measures. Case \#1's CAP lost an important staff champion in the mayor's office which one staff member believed may hurt its long-term outlook. For Case \#5, the case with the most successful community outreach strategy (but lack of staff involvement), the future of the plan rests in the hands of city staff. Staff buy-in of individuals with little to no involvement in the plan is important for implementation because each CAP measure was allocated to a specific city department by the planning department.

The least successful CAPs in the case study (Case 2 and 6) received very little buy-in among city departments. Case \#2 committee member interviews indicate that some of those involved in the CAP believe that plan success is reliant on the integration of CAP policies into all aspects of city operations, departments, and goals. However for the CAP, this was not achieved. This is important to note because the unique characteristic of the climate plan focusing exclusively on 
municipal operations, but being developed by community members. A municipal CAP without departmental buy-in or heavy involvement faces an uphill battle, regardless of how committed members of the community are to the cause. In addition to the other troubles Case \#6's CAP faced, it did not gain widespread agency support outside of the one that crafted it (the planning department). Unfortunately, other city departments such as the Public Works Department did not seem effectively motivated or invested in the plan. Similar to the situation in Case \#2, one department on its own, regardless of how motivated and devoted, cannot drive through a plan without support from other departments.

\section{Political Difficulties}

In the conservative communities included in this case study, political difficulties are often considerable. Tea Party and Agenda 21 opposition is the most sizable and difficult to address. This type of political obstruction has increased in recent years.

Local governments face institutional and political barriers when creating policies to address GHG emissions (Betsill, 2001). This was found to be especially true in the conservative communities included in this case study. Negative responses to CAP measures from elected officials and business communities were handled in most cases by altering or removing measures (Case 1 and 5) and addressed with little difficulty (expect for Case 6). Other approaches to addressing concerns involved making CAPs voluntary rather than compulsory (Case 1, 2, 3, and 6) or changing the plan title (Case 2, and 3). In some cities (Case 1, 5, 7) staff believed that without a strong focus on the economic aspect of CAP measures, 
certain community members and elected officials would not have been supportive of the action. But in certain instances making accommodations did not reduce the ferocity with which some CAP opponents opposed the climate planning initiatives. This is particularly notable because political difficulties are common obstacles when undertaking climate planning initiatives in conservative communities.

The vast majority of entrenched political opposition the seven CAPs faced is related to the Tea Party (Case 4, 6 and 7), sustainability and other "climate" terminology (all except Case 2), and anti-Agenda 21 constituencies. Of these three factors (which were related in many communities), anti-Agenda 21 sentiments proved to be the most significant issue politically. Four of seven cases (Case 3, 4, 6, and 7) experienced anti-Agenda 21 backlash. A wide spectrum exists in terms of the level of this resistance and the effect it had on the

process, but in all cases, opposition to the CAP was very vocal. In the four cases, this issue was handled in different ways.

\section{IMPACT OF THE ANT-AGENDA 21 MOVEMENT}

A small quantity of research exists regarding the effect of anti-Agenda 21 sentiments on climate planning, particularly in politically conservative communities. The most detailed study of anti-Agenda 21 activity is research recently conducted by Frick et al. (2014) concerning Agenda-21 opposition in the form of legislation at the state level, and links the movement to Tea Party and Republican voting patterns (see Appendix for map and description). According to this research, the recent widespread national increase of anti-Agenda 21 
legislation opposing sustainability could indicate a long-term trend and is rooted in a perception that sustainability policies are built on subversive guiding principles. Another notable finding is that the anti-Agenda 21 movement involves citizen participation from individuals that have not been involved in planning issues in the past. Frick et al. (2014) suggest that there is a need for additional research regarding anti-Agenda 21 and how to channel this type of conflict positively in planning and sustainability debates.

This thesis addresses this research gap and illuminates the impact of the antiAgenda 21 movement through findings from four cases (Case 3, 4, 6, and 7) located in politically conservative communities. Case \#3, located in Tennessee, experienced Agenda 21 opposition to a lesser degree than the other three cases. Opposition centered on sustainability and related federal grants. As a result the city received an open records request for emails and documents relating to ICLEI—a common target for anti-sustainability and anti-Agenda 21 constituencies. Case \#4's city is located in a region containing a strong Tea Party, anti-sustainability and anti-Agenda 21 presence, so much so that this has affected the policy language that communities in the areas use. The CAP encountered a small but very vocal minority consisting of fervent anti-Agenda 21 activists known within the community to mention Agenda 21, ICLEI, and a "U.N. conspiracy" if the city addresses climate change in any way. However, this did not seem to present significant barriers to the CAP and no steps were taken to mitigate the impact of the constituency that expressed this political ideology. Only one comment was submitted, which took issue with the CAP's use of the ICLEI model, but not the plan itself. 
Case \#6 and \#7 faced the most substantial Agenda 21 opposition. Interviews regarding the climate planning process in Case \#7 indicate that in the last five years, the Tea Party has become a powerful political force in the region and as a result the anti-sustainability/anti-Agenda 21 movement is currently very strong. During CAP development, the influence of this movement was not as much of a force in comparison to its influence presently. As the plan was developed, this anti-Agenda 21, so called "echo-chamber" was not swayed by any rational economic argument of how the CAP could benefit the community, according to interviewees. Because of this, staff members made themselves available for questions to this constituency, but understood that a certain level of backlash was to be expected and that the plan needed to move forward regardless. No real concessions were made to these members of the community in terms of plan language or measures included. Staff and task force members took this approach in part because_-as one staff member said_-"When you are arguing with a conspiracy theorist, everything you say is part of the conspiracy, so you can't win...everything we did was suspect and all of the justifications we gave were suspect or manufactured according to their point of view." However, since adoption, due to the strengthening of these movements, some CAP measures have not been publicized due to fears of anti-Agenda 21 backlash.

In the face of Agenda 21 opposition, Case \#7's CAP was adopted; the CAP from the community is Case \#6 was not adopted. Case \#6's CAP began development almost two years later than the other three cases that experienced Agenda 21 opposition. Interviews of staff involved in other cases that experienced Agenda 21 opposition indicate that these sentiments have increased in recent years. That being said, the anti-Agenda 21 movement was one of a number of factors that 
contributed to the trajectory of the CAP (others being: business community opposition, lack of city-wide departmental buy-in, and underwhelming city council support).

Case \#6's city has a politically active Tea Party element which includes the antiAgenda 21 movement. This constituency exhibited significant ideological opposition towards climate change science and sustainability. The plan's primary opponent exploited this and promoted the idea that the CAP was linked to a global U.N conspiracy. As displayed in Case \#7, city staff found that addressing anti-Agenda 21 concerns was "pointless in the face of their world view. [It] doesn't help to use reason." Unlike Case \#6, staff and consultants addressed the comments and concerns by making measures voluntary and altering the scope of measures and CAP language. Importantly, this did not reduce any of the antisustainability, anti-climate planning, or anti-Agenda 21 sentiments toward the plan. The plan was revised more than a dozen times (over two years) as a result of comments submitted; yet in the end, even more comments were submitted at the final city council meeting.

\section{Political Opposition Discussion}

Analysis of the seven cases reveals that political opposition to climate action planning can manifest itself in myriad ways. Research by Hanak et al. (2008) indicates that participants in local climate planning believe that the extent to which community members, businesses, and elected officials support climate policies varies, but support is consistently high among staff. The findings of this case study show a strong correlation with this attribute, particularly the 
comparison between members of the business community/elected officials and staff. For elected officials, this could be because they are more likely to be wary of the impact on their careers by being associated with a (potentially) politically controversial policy. On the other hand, staff members answer, for the most part, to their superiors. However, it also may be due to the fact that interview participants for each case agreed to be interviewed in the first place, excluding staff members who may have been less supportive of climate planning initiatives in each conservative community. 


\section{CHAPTER 5: IMPLICATIONS AND CONCLUSION}

In the introduction and review of literature included in this thesis, the importance of reducing global GHG emissions in order to mitigate hazardous impacts to human civilization is outlined in detail. With the current stagnation of international and federal action on this issue, addressing climate change at the local level appears to be the best avenue for GHG emissions reduction. In the past few decades, a new approach—the climate action plan—has proliferated as a way to develop a mechanism for combating GHG emissions at the point of origin. However, an analysis of 245 CAPs that have been completed to date nationally shows that approximately 90 percent of CAPs are located in communities identified as politically Democratic based on county level 2012 Presidential Election data. In order for a significant reduction in GHG emissions to occur through local action, it is essential for all cities to undertake climate planning, including those that are not: predisposed to having concern for environmental issues (Pitt, 2010b), creating a CAP in order to unify programs that already exist (Betsill, 2001), or merely reinforcing existing values. Previous climate planning research has focused CAPs as a whole, which are primarily concentrated in liberal communities. However, this prior research has not explored the discrepancy between CAPs created in liberal (the vast majority) as opposed to conservative jurisdictions (a select few), explicitly. This case study of seven CAPs created in politically conservative cities addresses this research gap. 


\section{RESEARCh LiMitations}

For the purposes of this research, "conservative communities" are operationalized as those that have a Republican voting record based on county level 2012 Presidential Election data. Due to the fact that the United States operates within a two-party system, communities that vote Republican (or Democratic) do so for myriad reasons. Many types of conservatives exist in the United States, and some Republicans have liberal tendencies on certain issues, whereas Democrats hold conservative views on issues as well. Political conservatism can be rooted in social, religious, or economic values, among others. In this thesis, political conservatism is determined based on research precedents and the best available data. Yet, election data alone cannot possibly capture the nuances of conservative ideology in America. This research recognizes that certain assumptions exist when defining cities as conservative in this way. These assumptions are necessary to conduct this type of case study, and the research methodology does not control for liberal cities located in Republican counties. For example, certain communities may be fiscally conservative but very environmentally minded, and still vote Republican. Furthermore, this research recognizes that there are limitations in understanding the complex political ideology by defining it as a county level pattern in one race; a dynamic which is further complicated by the fact that the one race selected was a presidential election. These cases are not statistically representative of politically conservative communities as a whole, but they illuminate the political challenges faced in some conservative communities and the extent to which this can influence CAPs. 


\section{Hypothesis AND Research QUestions}

The principal aim of this thesis is to expand the understanding of the political nature of climate action planning and specifically how politics in conservative cities influence the adoption (or completion) of CAPs. For the purposes of this research, CAP success is defined as action taken by city council in support of the plan and/or an encouraging plan implementation outlook. Often success in terms of CAP adoption or acceptance is different than implementation success. Additionally, existing CAP literature is used to define the characteristics of "climate action plans in general." The primary objective of this thesis is to answer the following four questions related to CAP development in politically conservative communities:

1. Are the same characteristics of successful climate planning found in prior CAP research applicable to climate action plans created in politically conservative communities?

2. Can CAP structure, language, or co-benefits influence the perceptions of GHG emissions reduction strategies that may be present in conservative communities?

3. Does the political climate of conservative communities affect the structure, motivation or success of the CAPs created within them?

4. Can analysis of CAP processes and attributes in conservative communities provide valuable information regarding how to implement future climate planning strategies in places with a similar political climate? 
And ultimately to address the hypothesis: Climate action plans adopted in conservative communities differ in motivations, type, and political backing, when compared to climate action plans in general.

Question 1: Are the same characteristics of successful climate planning found in prior CAP research applicable to climate action plans created in politically conservative communities?

Findings in this case study support prior CAP research indicating that planning initiatives can be valuable in spotlighting the topic of GHG emissions and related impacts, as well as raising public awareness in communities that may be have limited political support initially (Moser \& Ekstrom, 2011; Tang et al., 2010). In terms of public awareness, case study evaluation of CAPs created in conservative communities indicated that, similar to climate planning initiatives in general: CAP development can be a way for cities to lead by example (Betsill, 2001), climate policy may be largely symbolic in order to appeal politically to certain constituencies (Feiock et al., 2010; Zahran et al., 2008b), CAP development can be a method for merely unifying programs that already exist (Betsill, 2001; Millard-Ball, 2012), or CAP measures may be very similar to existing policies that are already present (Betsill \& Bulkeley, 2004). Similar to the research findings of Millard-Ball (2012) regarding communities with pre-existing environmental leanings, CAPs created in conservative communities can be a way for cities to market themselves as "green" leaders in the region. In the case cities, CAP development was also a way for conservative communities to raise awareness about climate change impacts (Moser \& Ekstrom, 2011). 
In previous CAP research, there is near universal consensus on the importance of an effective champion, and strong leadership, for CAP success. These characteristics were also found to be extremely important for CAP success in politically conservative communities. The CAP success in cities evaluated in the seven case studies was contingent on leadership of elected officials and a high level of support and involvement from staff, public officials, and community champions. Through the analysis of these cases, leadership and the role of champions (particularly elected officials) appear especially important in cities where the political ideology of the community may be more reluctant to accept global climate change as a pressing issue; however, future research is required to make this determination.

Additional attributes cited in previous research as leading to CAP development or success, include: effective funding, collaboration, and the influence of state mandates. The findings of the seven cases in this thesis support this prior research. Dedicated CAP staff and funding (Pitt, 2010a; Pitt, 2010b) were important for the adoption (or completion) and implementation of the most successful CAPs. In the politically conservative communities included in the seven cases, state mandates aimed at GHG emissions reduction offered political shelter (Bedsworth, 2010) and influenced CAP quality (Tang et al., 2012), particularly in California. Collaboration with stakeholders and private actors (Hanak et al., 2008; Pitt, 2010a) was also found to be important for CAP success.

A number of characteristics of successful climate planning found in prior CAP research were found to be less important for cities included in this case study. Betsill (2001) found that reframing climate change as a local issue can be an 
effective way to gain support for climate planning initiatives in many communities, this was not successful in the majority of cases, although crafting CAP measures based on community values was successful. Research by Zahran et al. (2008a) indicates that communities facing the greatest risk from adverse impacts of climate change are more likely to engage in climate planning. In interviews, this was not indicated as a motivation to develop CAPs in the majority of conservative communities examined in the seven cases. Colleges and non-profits (Pitt, 2010a) were helpful for the climate planning process in some cases, but not defining in terms of success. Notably, widespread participation from the general public (Pitt, 2010a) was not found to be important for CAP success in the form of adoption (or completion). More important characteristics included participation from the business community and elected officials.

Question 2: Can CAP structure, language, or co-benefits influence the perceptions of GHG emissions reduction strategies that may be present in conservative communities?

Prior CAP research emphasizes that using co-benefits to gain support for climate planning initiatives can be vital, especially in politically conservative communities. This research of seven cases suggests that stressing co-benefits as an approach to climate planning can be the most effective method for gaining support in conservative communities CAP initiatives. The findings of each of the seven cases illustrate that co-benefits are the most compelling way to market CAPs and gain acceptance, as well as support, for plan measures. Accentuating the economic benefits, cost-savings, and energy efficiency aspects of climate planning measures resulted in improved political backing from elected officials 
and citizens. The analysis of data included in Chapter 3 suggests that this approach fits in well with the pragmatic values and tenets of fiscal conservatism. Importantly, many interviewees involved in the CAP processes pointed to the cobenefit attribute as a reason that the CAP in their city was successful. Interestingly, this economic and cost-savings focus appears to have made the CAP developers in these conservative communities overstress specific measures related to energy efficiency and municipal operations.

The emphasis on economic and cost-saving measures in the majority of the seven cases also influenced the structure and terminology included in the majority of CAPs. Although the transportation sector was the greatest contributor of GHG emissions for all cases, in many instances the quantity of measures related to energy efficiency, or energy sector reduction targets, was higher than that of transportation specific measures. In most cases, CAP terminology relating to economic benefits was abundant, yet scientific terminology or explanations were excluded. This finding suggests that economic co-benefits can highlight the need to address issues related to climate change (such as in alternative energy sources and energy efficiency); but that this abstraction may fail to mobilize conservative communities behind measures focused exclusively on GHG emissions reduction. Economic co-benefits may raise awareness of climate planning in general, but co-benefits that relate to quality of life and sustainability (cited in some cases), may be more effective in influencing perceptions of climate planning urgency in conservative communities. The research findings of this thesis suggest that although highlighting co-benefits may lead to climate policy enactment, in conservative cities, the opinions of climate change skeptics who 
doubt the idea that human activity is the root cause, are not affected by cobenefit CAP marketing.

Question 3: Does the political climate of conservative communities affect the structure, motivation or success of the CAPs created within them?

With such a small sample size, it is challenging to assess the degree to which political climates affect conservative communities in general. However, findings relating to political difficulties and negative reactions/responses in the seven cases located in conservative cities highlight the political nature of CAP development. Analysis of the cases indicates that obstacles and barriers identified in prior CAP research appear heightened and more likely in conservative communities. When public sentiment is not entirely behind climate planning, the title, terminology used, and aim of CAP measures included are often altered. Political champions are important for CAP success, but in politically conservative communities, elected officials may face significant community, business, and peer skepticism when championing a plan. This resistance to climate planning is unlikely to be as pronounced in politically liberal cities. Additionally, across the seven cases, initial CAP creation was more likely to be motivated by economic considerations, mayoral priorities, and state mandates or expected legal ramifications (in California), than pressure from the general public or GHG reduction for the sake of mitigating climate change outright.

Many factors are involved in producing a successful CAP. However, political support at all levels of government was extremely crucial for CAP success in each case included in this research. In a most cases, active and vocal 
constituencies were present in the community that opposed certain aspects of CAPs. This opposition was handled in a variety of ways for each case, but often involved altering certain features of the CAP. According to these findings, in order to address this, CAP developers in politically conservative communities may change CAP language, leave out an explanation of climate science, make the plan voluntary rather than compulsory, remove controversial measures (such as expensive regulatory measures), focus implementation on the most politically viable measures, or include less aggressive emissions reduction targets. In the majority of cases these alterations were effective in facilitating the adoption (or completion) of a politically viable CAP.

Question 4: Can analysis of CAP processes and attributes in conservative communities provide valuable information regarding how to implement future climate planning strategies in places with a similar political climate?

Due to the scope of this thesis and the number of cases included, it is difficult to draw overarching conclusions regarding CAPs adopted (or completed) in conservative cities. However, case analysis and the review of findings provide a window into the challenges faced by practitioners conducting climate planning in politically conservative communities. A number of themes and lessons emerge that offer valuable insights into conducting climate planning in politically difficult communities. The analysis of each case's CAP process, and interviewee's lessons learned in particular, illustrate specific "best practices" and strategies that are important for practitioners engaged in, or preparing to engage in, climate planning. These themes, lessons, and reflections, can be found in an ensuing section of this chapter titled "Statement to Professionals." This section includes 
12 lessons and best practices for climate planning practitioners that provide valuable information regarding how to incorporate future climate planning initiatives in cities with a similar political climate, as well as any city where political difficulties exist, is apparent.

Hypothesis: Climate action plans adopted in conservative communities differ in motivations, type, and political backing, when compared to climate action plans in general.

For the purposes of this hypothesis, existing literature is used to define "climate action plans in general." Research evidence from the seven cases included in this study refutes the hypothesis: climate action plans adopted in conservative communities do not differ substantially in motivations, type, and political backing, when compared to climate action plans in general. Comparison of the case study findings and prior CAP research indicates that both classifications (action taken by city council in support of CAPs in general and for CAPs in conservative communities) share the characteristics of: requiring strong leadership, dependence on adequate funding, and being impacted positively by state mandates. Although there is not enough evidence overall to support the hypothesis, some evidence does supports the hypothesis. See Table 1: Evidence Supporting/Refuting Hypothesis, below: 
Table 1: Evidence Supporting/Refuting Hypothesis

\begin{tabular}{|c|c|c|c|}
\hline Characteristic & Literature Review & Findings & $\begin{array}{l}\text { In Support of } \\
\text { Hypothesis? }\end{array}$ \\
\hline $\begin{array}{l}\text { The Great } \\
\text { Recession }\end{array}$ & $\begin{array}{l}\text { There is no conclusive evidence } \\
\text { related to fiscal constraints } \\
\text { connected to the } 2008 \\
\text { economic downturn in prior } \\
\text { CAP research. }\end{array}$ & $\begin{array}{l}\text { Budget constraints can influence the desire } \\
\text { to engage in climate planning in different } \\
\text { ways. In certain cases, the fear of impacting } \\
\text { private enterprise can reduce the will to } \\
\text { participate in CAP implementation; in } \\
\text { others, the attraction of reducing municipal } \\
\text { energy costs can invigorate CAP efforts. }\end{array}$ & $\mathrm{N} / \mathrm{A}$ \\
\hline $\begin{array}{l}\text { Involvement of } \\
\text { Consultants }\end{array}$ & $\begin{array}{l}\text { No conclusive findings } \\
\text { regarding consultant } \\
\text { involvement from the literature } \\
\text { review. }\end{array}$ & $\begin{array}{l}\text { Consultant involvement often led to the } \\
\text { creation of CAPs which included a high } \\
\text { level of detail, and in certain cases } \\
\text { influenced the use of specific terminology } \\
\text { that could be potentially sensitive in } \\
\text { politically conservative cities. }\end{array}$ & $\mathrm{N} / \mathrm{A}$ \\
\hline $\begin{array}{c}\text { Community Member } \\
\text { Involvement }\end{array}$ & $\begin{array}{l}\text { No conclusive findings from the } \\
\text { literature review regarding } \\
\text { CAPs developed exclusively by } \\
\text { community members. }\end{array}$ & $\begin{array}{l}\text { The majority of CAPs include community } \\
\text { stakeholder participation. However, CAPs } \\
\text { developed entirely by citizens require staff } \\
\text { involvement for success. }\end{array}$ & $\mathrm{N} / \mathrm{A}$ \\
\hline CAP Comparison & $\begin{array}{l}\text { Climate plans vary widely in } \\
\text { terms of GHG targets, and } \\
\text { some lack a framework for } \\
\text { implementation. }\end{array}$ & $\begin{array}{l}\text { In each case analyzed, CAP structure and } \\
\text { scope vary, yet GHG emissions related to } \\
\text { transportation constitute the largest single } \\
\text { emissions source for all seven CAPs. }\end{array}$ & No \\
\hline Co-Benefits & $\begin{array}{l}\text { Conservative communities } \\
\text { consciously choose to leave out } \\
\text { policy language mentioning } \\
\text { climate, carbon reduction, or } \\
\text { environmental terms, instead } \\
\text { focusing emphasis on cost } \\
\text { savings and economics. }\end{array}$ & $\begin{array}{l}\text { In these politically conservative } \\
\text { communities, co-benefits were universally } \\
\text { used to gain support for climate planning. In } \\
\text { the vast majority of cases, energy related } \\
\text { cost-savings and economic benefits are } \\
\text { emphasized rather than GHG emissions } \\
\text { reduction in its own right. }\end{array}$ & No \\
\hline
\end{tabular}




\begin{tabular}{|c|c|c|c|}
\hline State Mandates & $\begin{array}{l}\text { State mandates aimed at GHG } \\
\text { emissions reduction can offer } \\
\text { political shelter and influence } \\
\text { CAP quality. }\end{array}$ & $\begin{array}{l}\text { In California, state mandates are viewed as } \\
\text { important motivators for CAP creation in } \\
\text { conservative cities, especially in the case of } \\
\text { CAPs developed by city agencies. These } \\
\text { mandates can influence measures included } \\
\text { in each CAP as well as the success of } \\
\text { measure implementation. State action can } \\
\text { also serve as way to sell climate planning to } \\
\text { community members and elected officials. }\end{array}$ & No \\
\hline Public Utilities & $\begin{array}{l}\text { Climate mitigation planning } \\
\text { success has been linked to } \\
\text { local governments that own } \\
\text { their utilities, and local utilities } \\
\text { are often integral players in } \\
\text { CAP creation by encouraging } \\
\text { conservation and providing } \\
\text { incentives. }\end{array}$ & $\begin{array}{l}\text { The presence of publically-owned utilities } \\
\text { motivates CAP creation in some } \\
\text { conservative communities because of a } \\
\text { perceived level of control over local energy } \\
\text { issues. In such cities, municipal energy use } \\
\text { and energy efficiency are points of focus. }\end{array}$ & No \\
\hline $\begin{array}{l}\text { Departmental } \\
\text { Leadership }\end{array}$ & $\begin{array}{l}\text { CAP development processes } \\
\text { are often led by mayors offices, } \\
\text { public works, environmental } \\
\text { departments, rather than } \\
\text { planning departments. }\end{array}$ & $\begin{array}{l}\text { In the conservative cities included in this } \\
\text { study, CAPs were not primarily developed } \\
\text { by planning agencies; rather, plan } \\
\text { development was led by other city } \\
\text { departments, or bodies created through the } \\
\text { actions of elected officials. }\end{array}$ & No \\
\hline Political Will & $\begin{array}{l}\text { CAP development requires } \\
\text { considerable leadership and } \\
\text { political will. }\end{array}$ & $\begin{array}{l}\text { This characteristic was reflected in the } \\
\text { seven cases. }\end{array}$ & No \\
\hline $\begin{array}{l}\text { City Council } \\
\text { Support }\end{array}$ & See above & $\begin{array}{l}\text { For the cases included in this study, city } \\
\text { council support is the most essential } \\
\text { element for CAP success, because councils } \\
\text { make the final policy determination after } \\
\text { CAP completion. However, their support for } \\
\text { climate planning initiatives can be highly } \\
\text { influenced by community sentiments } \\
\text { regarding "climate change", pointing to the } \\
\text { importance of community attitudes for } \\
\text { successful climate planning. }\end{array}$ & No \\
\hline
\end{tabular}




\begin{tabular}{|c|c|c|c|}
\hline Agency Buy-in & $\begin{array}{l}\text { Dedicated CAP staff and } \\
\text { funding are important for } \\
\text { adoption and implementation } \\
\text { success. }\end{array}$ & $\begin{array}{l}\text { Agency-wide and department head buy-in } \\
\text { can be particularly important in conservative } \\
\text { cities for the long-term success of climate } \\
\text { action planning, perhaps more so than the } \\
\text { involvement of committed individual staff } \\
\text { members. }\end{array}$ & No \\
\hline Terminology & $\begin{array}{l}\text { Conservative communities } \\
\text { consciously choose to leave out } \\
\text { policy language mentioning } \\
\text { climate, carbon reduction, or } \\
\text { environmental terms, instead } \\
\text { focusing emphasis on cost } \\
\text { savings and economics. }\end{array}$ & $\begin{array}{l}\text { In some cases, CAPs in conservative } \\
\text { communities are prone to excluding climate } \\
\text { science or GHG emissions connection to } \\
\text { human activity, especially without the } \\
\text { influence of state mandates. } \\
\text { In conservative communities, "sustainability" } \\
\text { has been used to gain support for pragmatic } \\
\text { CAP measures, but in recent years, political } \\
\text { opposition to this term has changed the } \\
\text { meaning of "sustainability" in these regions, } \\
\text { reducing its political viability. }\end{array}$ & $\begin{array}{l}\text { Yes, to some } \\
\text { degree }\end{array}$ \\
\hline CAP Titles & See above. & $\begin{array}{l}\text { Leaving out "climate" or "sustainability" in } \\
\text { CAP titles can be a way to reduce political } \\
\text { backlash and increase climate planning } \\
\text { marketability in politically conservative } \\
\text { communities. }\end{array}$ & $\begin{array}{l}\text { Yes, to some } \\
\text { degree }\end{array}$ \\
\hline $\begin{array}{l}\text { Pathways to CAP } \\
\text { Completion }\end{array}$ & $\begin{array}{l}\text { No conclusive findings } \\
\text { regarding adoption versus } \\
\text { acceptance or other types of } \\
\text { city council action. }\end{array}$ & $\begin{array}{l}\text { Adoption is not a prerequisite for CAP } \\
\text { success, but a legal basis for the plan is } \\
\text { important in politically conservative cities. }\end{array}$ & Yes \\
\hline Community Buy-in & $\begin{array}{l}\text { Widespread participation from } \\
\text { the general public is key for } \\
\text { CAP success. }\end{array}$ & $\begin{array}{l}\text { In conservative communities, CAP buy-in } \\
\text { from the general public can be more } \\
\text { important for implementation than CAP } \\
\text { adoption (or completion). Often community } \\
\text { stakeholder buy-in is more crucial than that } \\
\text { of the general public and public workshops } \\
\text { serve as a compulsory aspect of the } \\
\text { planning process rather than an integral } \\
\text { contribution to CAP development. }\end{array}$ & Yes \\
\hline
\end{tabular}




\begin{tabular}{|c|c|c|c|}
\hline $\begin{array}{c}\text { Business } \\
\text { Community Buy-in }\end{array}$ & $\begin{array}{l}\text { Collaboration with stakeholders } \\
\text { and private actors is important } \\
\text { for CAP success. There are } \\
\text { differences in the extent to } \\
\text { which businesses support } \\
\text { climate-related actions. }\end{array}$ & $\begin{array}{l}\text { In conservative cities, buy-in from the } \\
\text { business community is often essential for } \\
\text { CAP support and viability. Absence of this } \\
\text { type of buy-in can have serious } \\
\text { ramifications for CAP success. }\end{array}$ & Yes \\
\hline Political Difficulties & $\begin{array}{l}\text { No conclusive findings } \\
\text { regarding Agenda-21 opposition } \\
\text { to CAPs. }\end{array}$ & $\begin{array}{l}\text { In the conservative communities included in } \\
\text { this case study, political difficulties are often } \\
\text { considerable. Tea Party and Agenda } 21 \\
\text { opposition is the most sizable and difficult to } \\
\text { address. This type of political obstruction } \\
\text { has increased in recent years. }\end{array}$ & \\
\hline & & & Yes \\
\hline $\begin{array}{c}\text { Climate } \\
\text { Vulnerability as } \\
\text { Motivation }\end{array}$ & \begin{tabular}{|l|} 
Communities facing the \\
greatest risk from adverse \\
impacts of climate change are \\
more likely to engage in climate \\
planning.
\end{tabular} & $\begin{array}{l}\text { This was not found to be a motivation for } \\
\text { CAP creation in the majority of cases. }\end{array}$ & Yes \\
\hline
\end{tabular}


The political obstacles present in CAPs in general are intensified in the conservative cities in the majority of cases included in the study. This heightened level of political opposition can influence CAP motivation, measures, structure, and terminology, yet there is not enough significant research available for comparison regarding how much this same type of opposition influences CAPs in general. One challenge of determining the extent to which conservative politics affect CAPs in this research is rooted in the lack of hard evidence tied to the thesis methodology used to determine political conservatism. In one respect, the methodology appears sound in that all cities included in the study were described as conservative by interviewees, but this evidence is based on a small sample size and purely qualitative. The following paragraph outlines the degree to which findings from this research address the hypothesis and are applicable to the political nature of climate planning.

A number of CAP studies have indicated a voting history of selecting Democratic as opposed to Republican candidates can be an indicator for engaging in climate planning or CAP success to some extent in communities (Hanak et al., 2008, Zahran et al., 2008b; Krause, 2011b; Sharp et al., 2011; Hawkins \& Wang, 2012). Chapter 2 of this thesis supports this finding, indicating that the vast majority of CAPs have been adopted (or completed) in cities located in politically liberal counties, and in many cases the only CAPs created in Republican voting states are located in one of the state's few liberal counties (based on the methodology for identifying conservative versus liberal locations). This attribute raised the question: Is there a reason for CAPs adoption/completion usually occurring in liberal communities as opposed to conservative communities? Evaluation of the cases included in this research provides important insight into 
why this phenomenon exists. The findings show that many cities located in Republican jurisdictions experience substantial political opposition to climate planning from members of the community or elected officials. This creates a situation where city staff or other CAP developers must be hyperaware of how the plan is structured and perceived within the community.

\section{IMPLICATIONS}

The mantra of current CAP planning is "think globally, and act locally" (Lindseth, 2004), but the emphasis and marketing of the majority of CAPs in this study support Betsill's (2001) revision to this; "think locally, act locally" (p. 404), in order to frame the issue in a local context. This was found to be true in five of seven cases which emphasized economic co-benefits. However, this approach reduced the level of political support for other types of measures as well as their effectiveness and implementation outlook in the conservative cities included in this study. This raises an important question: If the only types of measures with wide support in certain communities focus on co-benefits associated with costsaving through energy efficiency, can long-term GHG emissions reduction take place in politically conservative communities? Perhaps, this focus on the economic aspect of climate planning is just the first step, a mechanism to gain support for climate action planning, but less economically "attractive" measures must be implemented for meaningful nationwide GHG emissions reduction to be achieved. The findings of CAPs created in conservative cities suggest that the best way to influence the development of climate policies with high reduction potential, but less attractive co-benefits is through state and regional level mandates. 
Research of CAPs created in conservative communities has important implications regarding the politics of CAP development. As is the case with many comprehensive policy documents, CAP developers in conservative communities must wrestle with gaining political will to fund measures. The most successful and effective CAPs were funded by being institutionalized into city operations or securing outside funding such as grants, reducing the city's financial burden and long-term commitment. The least successful CAP's long-term success impacted negatively by unclear funding structures, or escalating costs. Because of the fiscal conservatism ideology present in many cities in the study, CAP funding may have been more contentious than in liberal communities. In addition, the least successful climate plans in this case study did not receive steadfast political support from elected officials or agency-wide buy-in and were less likely to incorporate: all stakeholders, a community specific CAP structure, or the ideological values of certain constituencies.

The findings of this research indicate that in politically conservative communities where some citizens and groups are reluctant to support climate planning based on preconceived ideas, a number of strategies can provide political protectionallowing certain constituencies to support prudent measures that might contradict their broader ideologies. Incorporating business leader stakeholders and their views in the CAP development process is extremely important in communities with a similar political make-up as cities included in this research. This is achieved by identifying champions in business associations or the Chamber of Commerce early on in the process who have an ability to explain climate planning principles and assets to their peers. Stressing the pragmatic nature of energy efficiency and cost savings co-benefits and marketing CAPs in this way is 
also a helpful approach. Notably, CAPs do not necessarily have to be adopted to be successful in terms of implementation (they can be accepted, or released). However, support from elected officials is paramount in politically conservative communities. Although the findings of the seven cases cannot necessarily be used to draw broad conclusions about conservative communities as a whole, this research highlights important findings regarding how politics can influence climate action planning. This research adds to the existing CAP literature by exploring the political aspects of climate planning.

\section{Statement to Professionals}

Many of the lessons extrapolated from this case study research are valuable for working in any community that may experience political backlash from a CAP. Although often associated with conservative opposition to climate planning and climate science, this opposition can exist in many cities, and as a result certain findings may be universal. If the results and analysis of these seven case studies are generally applicable and hold true in other politically conservative communities, then the following are important implications for planning practice:

\section{Lessons and Best Practices}

1. Select Terms Carefully: Removal of terms such as climate or sustainability in CAP titles, or an explanation of climate science from the plan, can reduce political backlash and increase climate planning marketability in politically conservative communities. However, practitioners must strike a balance. 
Removing numerous terms can lead to a knowledge deficit regarding climate science and the importance of mitigating climate change in the community, which can reduce the effectiveness of CAP implementation.

2. Rely on State Mandates when Possible: State action and state mandates are important motivators for CAP and can be a selling point to community members and elected officials. State mandates can also provide political cover for climate planning initiatives.

3. Economic Co-benefits can be Persuasive: In communities where support for CAP measures may be politically sensitive, co-benefits relating to economic cost-savings associated with energy efficiency are an effective way to gain support for climate planning.

4. Start with Municipal Operations: The promise of reducing operational costs is a way to gain support for climate planning from department heads and elected officials, and can be achieved by highlighting potential energy efficiency savings for municipal facilities related to CAP measures. This type of agency-wide buy-in can be particularly important in conservative cities for the long-term success of climate action planning.

5. Departmental Buy-in is Key: Community stakeholder participation is integral to CAP success in cities with a diverse political make-up, but staff involvement and departmental buy-in are more important factors for creating and completing a politically viable CAP. Agency wide-buy in is important in the CAP development process for the long-term implementation success of CAP measures.

6. Compromise is Important: CAP practitioners must be willing to compromise on certain measures included in climate plans. Although not ideal for overall GHG emissions reduction, removal of certain costly or controversial 
measures can be crucial for CAP feasibility in conservative communities. CAP buy-in is the primary goal initially and sets the groundwork for future policy and reductions initiatives.

\section{Environmental Membership Organizations can be Controversial:}

Deciding not to join ICLEI or other sometimes controversial or politically polarizing climate change related organizations can be an effective way to reduce political CAP backlash. However, practitioners must weigh this decision carefully. By failing to join international and national organization of this type, the benefits associated with CAP resources, networks, and experienced professionals cannot be utilized.

8. Adoption is not Required: CAP adoption-as opposed to other avenues to acceptance by a city council-is not a prerequisite for CAP success; in fact, making plan implementation voluntary rather than compulsory is a way to gain political support for CAPs in some cities. However, it is important for the long-term success of CAPs for each plan to have legal standing. In addition, the legal standing of CAPs is especially vital in communities experiencing staff or elected official turn-over resulting in a less supportive political makeup for climate planning.

\section{Mayors can Influence Community-wide Climate Change Perceptions:}

Mayoral involvement in CAPs is particularly helpful in politically difficult communities and can shape policies influencing the level of elected official and community participation and support. The use of executive power can be a way to allocate staff time or resources, or to supply a legal basis for CAPs. The findings of this research support the argument of some political scientists that mayors can transcend partisan divides. 
10. CAP Success Relies on City Council Support: In communities where CAP measures may face political opposition, city council backing is the most essential element of elected official support required for CAP success; however, this backing can be influenced to a significant degree by community sentiments regarding climate change (either positively or negatively).

11. Involvement of the Business Community is Crucial: In conservative cities, buy-in from the business community is often essential for CAP viability. Absence of this type of buy-in can have serious ramifications for CAP success.

12. Be Prepared for Agenda 21 Opposition: Tea Party and Agenda 21 opposition are often the most significant political obstructions to climate planning and the most difficult to address in conservative communities (and have increased in recent years). ${ }^{1}$ The most effective way to address this type of opposition at the local level is to assess its likelihood of occurring and then draw on the backing and resources of staff, elected official, and community CAP champions who can publicly counter to this type of obstruction. To achieve this, CAP developers must sustain the support of these champions throughout the planning process. CAP developers must understand that this type of political backlash is expected, but that in most cases the aim of these groups is to completely impede the CAP process. While it is important for practitioners to listen to the voices of all community members, placating the demands of the Agenda 21 opposition movement by altering CAP measures

\footnotetext{
${ }^{1}$ Cities included in this case study are located in two states (Kansas and Tennessee) that recently passed anti-Agenda 21 measures at the state level.
} 
and scope is a strategy that may not be successful in decreasing this type of opposition.

\section{Future Research and Research Outcome}

One of the most important outcomes of this research is that it provides the basis and groundwork for future research regarding CAP development in conservative communities. A significant product of this thesis is the literature review which consolidates prior research of what characteristics lead to CAP success and affords a foundation for future research focusing on the political nature of climate action planning. The aim of this section is to evaluate the performance of this case study of seven conservative CAPs and highlight current gaps in CAP research knowledge.

\section{Alterations to Research Approach}

Upon completion of and reflection about this thesis, it became apparent that the research process and structure could have been altered in several ways that would have benefited the overall outcome and application of results. More time and resources would have allowed for cases to be selected only if interview participants agreed to less a restrictive level of anonymity. This would have resulted in fewer cases being analyzed, but in greater depth; and a final product illustrating the challenges of CAPs identified by name in a few select cities. This would have allowed future CAP researchers the ability to analyze the results of this thesis with a greater level of detail. 
In retrospect, the thesis results could have been more fruitful (in terms of applicability) if emphasis had been placed on the role of state mandates as well as state climate policy, and the impact of these forces on CAP development and motivation. Additionally, with more time and resources, a more thorough analysis could have been used to evaluate specific measures included in each plan, highlighting common themes and approaches.

\section{Future Research}

The analysis and evaluation of the case study research findings illuminate a number of important aims of future CAP planning research. These are divided into two distinct categories: addressing gaps in general CAP research and potential for future research focused on CAPs created in politically conservative communities.

\section{GENERAL CAP RESEARCH}

The findings of the seven cases included in this study identify three distinct knowledge gaps in the current body of CAP research:

1. The extent to which the legal status of CAPs affects their implementation outlook and eventual success. CAPs can be adopted by resolution or ordinance and this difference could very well affect implementation success. Scant research exists comparing the implementation of CAPs that have been adopted, accepted, or released. 
2. For many CAP measures, developing effective implementation and monitoring procedures proves difficult for cities. The results of this research conclude that no well-developed and universally applicable process exists for monitoring plan measure successes and related GHG emissions reduction. In many cases, plan funding as well as staff and community member involvement dissipates after CAP completion. The outcome of research evaluating successful implementation and monitoring strategies would benefit climate planning practitioners immensely.

3. Based on the literature review and case study findings of this research, it appears that measures focused on the energy efficiency sector have: met the highest level of implementation success, been extremely politically palatable, and experienced the greatest strides in recent years. In contrast transportation related emissions often represent the greatest share of overall emissions. Measures targeting these emissions, especially those targeted at vehicle miles travelled (VMT), are less politically viable. Future CAP research should assess this phenomenon and address how transportation related emissions reduction strategies can be effective-gaining the level of community-wide and political support afforded to energy efficiency measures.

\section{CAP RESEARCH In CONSERVATIVE CoMmunities}

This thesis is an important first step in evaluating the characteristics of CAPs developed in politically conservative communities and how climate planning initiatives can be expanded to these communities. Through the analysis of thesis 
findings resulting from this case study, five important CAP attributes specific to conservative communities should be evaluated in future CAP research:

1. The research findings suggest that expanding state level climate policy is important for successful local climate action, but is largely out of reach for planning practitioners. However, it is important to evaluate how state policy influences CAP success and development in conservative communities. It is necessary for future research to evaluate if state policy and regulatory standards/requirements result in uniform pressure for conservative communities throughout the state; and (in light of the findings in this case study research) determine why some cities respond to these policies with proactive planning, while others do not.

2. Address the current emphasis on economic co-benefits present in CAPs developed in conservative communities and evaluate ways to expand support to measures that are more difficult to implement but yield greater GHG emissions reduction.

3. A direct comparison of liberal and conservative CAP measures, and in particular, if specific measures and types are measures are left out or removed from CAPs in order to make them politically acceptable in conservative communities.

4. Opportunities for successfully bringing stakeholders from the business community into the CAP process—as well as the most compelling ways to message and market CAPs in conservative communities.

5. Effective ways to address Tea Party and Agenda 21 opposition to climate planning initiatives. 


\section{BIBLIOGRAPHY}

Note: The Climate Action Plans for each of the seven cases studies have been redacted from this list in order to maintain anonymity and confidentiality.

[APPA] American Public Power Association. (2013). Public power: Shining a light on public service. Washington, DC: American Public Power Association.

Anaheim Public Utilities. (2006). California Municipal Utilities Association Brochure. Retrieved from http://www.anaheim.net/utilities/images/AnaheimCUMABrochure.pdf

Barber, B. (2013). If mayors ruled the world. New Haven: Yale University Press.

Bassett, E., Shandas, V. (2010). Innovation and climate action planning: Perspectives from municipal plans. Journal of the American Planning Association, 76(4), 435-450.

Bedsworth, L. \& Hanak, E. (2010). Adaptation to climate change: A review of challenges and tradeoffs in six areas. Journal of the American Planning Association, 76(4), 477-495.

Betsill, M. \& Bulkeley, H. (2006). Cities and the multilevel governance of global climate change. Global Governance: A Review of Multilateralism and International Organizations, 12(2), 141-159. 
Betsill, M. \& Bulkeley, H. (2004). Transnational networks and global environmental governance: The cities for climate protection program. International Studies Quarterly, 48(2), 471-493.

Betsill, M. (2001). Mitigating climate change in US cities: Opportunities and obstacles. Local Environment, 6(4), 393-406.

Betsill, M. and Bulkeley, H. (2007). Looking back and thinking ahead: A decade of cities and climate change research. Local Environment, 12(5), 447-456.

Boswell, M., Greve, A. and Seale, T. (2012). Local climate action planning. Washington, DC: Island Press.

Boswell, M., Greve, A. (2013a) Climate action plan (CAP) database [Data file and code book]. California Polytechnic State University. Unpublished raw data.

Boswell, M., Greve, A. (2013b). CAP review \& analysis database [Data file]. California Polytechnic State University. Unpublished.

Brunner, R. D. (2001). Science and the climate change regime. Policy sciences, 34(1), 1-33.

Bulkeley, H. and Betsill, M. (2003). Cities and climate change. London: Routledge.

Ca-ilg.org. (2014). The basics of SB 375. Institute for Local Government. Retrieved from http://www.ca-ilg.org/post/basics-sb-375 
CARB. (2014a). Senate Bill 375 regional targets. Arb.ca.gov. Retrieved from http://www.arb.ca.gov/cc/sb375/sb375.htm

CARB. (2014b). Scoping Plan: California Air Resources Board. Arb.ca.gov. Retrieved from http://www.arb.ca.gov/cc/scopingplan/scopingplan.htm

Cardwell, D. (2013, March 13). Cities weigh taking over from private utilities. New York Times. Retrieved from http://www.nytimes.com/2013/03/14/business/energy-environment/citiesweigh-taking-electricity-business-from-privateutilities.html?pagewanted=all\&_r=0

Carter, R. H., \& Culp, S. (2010). Planning for climate change in the west. Policy Focus Report: Lincoln Institute of Land Policy, 1-57.

Cooper, C., Haspel, M., \& Knotts, H. (2009). The value of Voterfiles for US state politics research. State Politics \& Policy Quarterly, 102-121.

Dolan, D., Soule, G., Greaney, J. and Morris, J. (2010). Warming up to climate action - a survey of GHG mitigation through building energy efficiency in city climate action plans. Carbon and Climate Law Review, (2), 161-172.

Dunlap, R. \& McCright, A. (2008). A widening gap: Republican and Democratic views on climate change. Environment: Science and Policy for Sustainable Development, 50(5), 26-35.

Einstein, K., \& Kogan, V. (2012). Partisanship and representation in local politics: New evidence from mid-size US cities. Unpublished. 
Epa.gov. (2014). Climate change action plans: State and local. US EPA.

Retrieved 2 April 2014, from http://epa.gov/statelocalclimate/state/stateexamples/action-plans.html\#all

Ferreira, F., \& Gyourko, J. (2009). Do political parties matter? Evidence from US cities. The Quarterly Journal of Economics, 124(1), 399-422.

Feiock, R. \& Francis N. (2010). Explaining the adoption of climate change policies in local government. Midwest Political Science Association's annual meeting, Chicago, IL USA.

Feiock, R., Francis, N. \& Kassekert, A. (2010). Explaining the adoption of climate change policies in local government. Pathways to Low Carbon Cities Workshop, Hong Kong, China, December 13-14, 2010, $22-25$.

Flyvbjerg, B. (2006). Five misunderstandings about case-study research. Qualitative Inquiry, 12(2), 219-245.

Frick, K., Weinzimmer, D., \& Waddell, P. (2014). The politics of sustainable development opposition: State legislative efforts to stop the United Nation's Agenda 21 in the United States. Urban Studies, 1-24.

Geddes, B. (1990). How the cases you choose affect the answers you get: Selection bias in comparative politics. Political Analysis, 2(1), 131-150. 
Grandterracecityca.iqm2.com. (2014). San Bernardino County Regional Greenhouse Gas Reduction Plan. City of Grand Terrace, California. Retrieved 4 February 2014, from http://grandterracecityca.iqm2.com/Citizens/Detail_LegiFile.aspx?MeetingID $=1027 \& \mid \mathrm{D}=1174$

Gremillion, T. (2011). Setting the foundation: How local climate change adaptation initiatives can pave the way for a regulatory regime that works. ExpressO. Available at: http://works.bepress.com/thomas_gremillion/2

Hanak, E., Bedsworth, L., Swanbeck, S. and Malaczynski, J. (2008). Climate policy at the local level: a survey of California's cities and counties. Public Policy Institute of California.

Hawkins, C. and Wang, X. (2012). Sustainable development governance: Citizen participation and support networks in local sustainability initiatives. Public Works Management \& Policy, 17(1), 7-29.

Hinkes-Jones, L. (2012, August 29). The anti-environmentalist roots of the Agenda 21 conspiracy theory. The Atlantic Cities. Retrieved from http://www.theatlanticcities.com/politics/2012/08/anti-environmentalist-rootsagenda-21-conspiracy-theory/3091/

ICLEI (1995). Second Municipal Leaders' Summit on Climate Change, Berlin $27-$ 29 March. Retrieved from: http://archive.iclei.org/documents/Global/2nd_Summit_Declaration.pdf 
ICLEI (2006). Combating climate change: A comprehensive look at local climate protection programs. Retrieved from: http://www.icleiusa.org/actioncenter/learn-from-others/Case_Studies_Dec-2006

Icleiusa.org. (2013). Climate action planning resources. ICLEI Local Governments for Sustainability USA. Retrieved 3 December 2013, from http://www.icleiusa.org/action-center/planning/climate-action-planning Icleiusa.org. (2014). How ICLEI can help your local government. ICLEI Local Governments for Sustainability USA. Retrieved 3 February 2014, from http://www.icleiusa.org/about-iclei

Icleiusa.org. (2014). FAQ: ICLEI, the United Nations, and Agenda 21. ICLEI Local Governments for Sustainability USA. Retrieved from http://www.icleiusa.org/about-iclei/faqs/faq-iclei-the-united-nations-andagenda-21\#what-is-agenda-21

Jacobson, G. (2013). How the economy and partisanship shaped the 2012 presidential and congressional elections. Political Science Quarterly, 128(1), $1-38$

Jamison, P. (2012, August 29). Fears of Agenda 21 go mainstream in the Republican Party platform. The Tampa Bay Times. Retrieved from http://www.tampabay.com/news/politics/national/fears-of-agenda-21-gomainstream-in-the-republican-party-platform/1248666

Johnson, G. (2009, August 6). California's global warming bills to be discussed. Inside Bay Area. Retrieved from http://www.insidebayarea.com/ci_13004575 
Kamal-Chaoui, L. \& Roberts, A. (eds.) (2009). Competitive cities and climate change. OECD.

Kansas State Legislature. (2012). House Resolution 6032: Resolution opposing and exposing the radical nature of United Nations Agenda 21. Topeka: Kansas State Capitol.

Kaufman, L., \& Zernike, K. (2012, February 2). Activists fight green projects, seeing U.N. plot. The New York Times. Retrieved from http://www.nytimes.com/2012/02/04/us/activists-fight-green-projects-seeingun-plot.html?pagewanted=all\&_r=0

Kousky, C. \& Schneider, S. (2003). Global climate policy: Will cities lead the way? Climate Policy, 3(4), 359-372.

Krause, R. (2011a). Symbolic or substantive policy? measuring the extent of local commitment to climate protection. Environment and Planning C: Government and Policy, 29(1), 46-62.

Krause, R. (2011b). The motivations behind municipal climate planning: An empirical assessment of how local objectives shape the production of a public good. Prepared for FSU Devoe Moore Symposium: Co-Benefits of Local Sustainability. Retrieved from: http://localgov.fsu.edu/workshops/sustainability/papers/Krause_FSU_sympo sium_paper_12-9-11.pdf

Leiserowitz, A. (2006). Climate change risk perception and policy preferences: The role of affect, imagery, and values. Climatic change, 77(1-2), 45-72. 
Leiserowitz, A., Maibach, E., Roser-Renouf, C., Feinberg, G. \& Howe, P. (2012)

Global warming's six Americas, September 2012. Yale University and George Mason University. New Haven, CT: Yale Project on Climate Change Communication. Retrieved from http://environment.yale.edu/climate/publications/Six-Americas-September2012

Lindseth, G. (2004). The Cities for Climate Protection Campaign (CCPC) and the framing of local climate policy. Local environment, 9(4), 325-336.

Lubell, M., Feiock, R., H \& Y, S. (2009). City adoption of environmentally sustainable policies in California's Central Valley. Journal of the American Planning Association, 75(3), 293-308.

Lutsey, N. \& Sperling, D. (2008). America's bottom-up climate change mitigation policy. Energy Policy, 36(2), 673-685.

Maggioni, E., Nelson, H. \& Mazmanian, D. (2012). Industry influence in stakeholder-driven state climate change planning efforts. Policy Studies Journal, 40(2), 234-255.

McCright, A. \& Dunlap, R. (2011). The politicization of climate change and polarization in the American public's views of global warming, 20012010. The Sociological Quarterly, 52(2), 155-194.

McCright, A. \& Dunlap, R. (2003). Defeating Kyoto: The conservative movement's impact on US climate change policy. Social Problems, 50(3), 348-373. 
McCarney, P. (2009). City indicators on climate change: Implications for policy leverage and governance. World Bank's 5th Urban Research Symposium Cities and Climate Change: Responding to an Urgent Agenda, Marseille, France.

Millard-Ball, A. (2012). The limits to planning causal impacts of city climate action plans. Journal of Planning Education and Research, 33(1), 5-19.

Moser, S. and Ekstrom, J. (2011). Taking ownership of climate change: Participatory adaptation planning in two local case studies from California. Journal of Environmental Studies and Sciences, 1(1), 63-74.

Parry, M. (2007). Impacts, adaptation and vulnerability. Cambridge: Cambridge Univ. Press.

Puff.lbl.gov. (2014). State greenhouse gas reduction requirements: Energy aware planning guide report. Retrieved from http://puff.lbl.gov/transportation/transportation/energy-aware/energyawareghg-reductions.html

Pitt, D. (2010a). Harnessing community energy: The keys to climate mitigation policy adoption in US municipalities. Local Environment, 15(8), 717-729.

Pitt, D. (2010b). The impact of internal and external characteristics on the adoption of climate mitigation policies by US municipalities. Environment and planning. C: Government \& policy, 28(5), 851.

Portney, K. E., \& Berry, J. M. (2010). Participation and the pursuit of sustainability in US cities. Urban Affairs Review, 46(1), 119-139. 
[RAP] Regulatory Assistance Project. (2011). Electricity regulation in the US: A guide. Montpelier, Vermont: The Regulatory Assistance Project.

Reams, M., Clinton, K., \& Lam, N. (2012). Achievement of climate planning objectives among US member cities of the International Council for Local Environmental Initiatives (ICLEI). Low Carbon Economy, 3(4).

Republican Platform 2012. (2012). 2012 US Republican Party Platform. Tampa Bay. Retrieved from http://www.gop.com/wpcontent/uploads/2012/08/2012GOPPlatform.pdf

Rogers, S., \& Cage, F. (2012, November 7). Full US 2012 election county-level results to download. The Guardian. Retrieved from http://www.theguardian.com/news/datablog/2012/nov/07/us-2012-electioncounty-results-download\#data

Seawright, J., \& Gerring, J. (2008). Case selection techniques in case study research a menu of qualitative and quantitative options. Political Research Quarterly, 61(2), 294-308.

Sharp, E., Daley, D. and Lynch, M. (2011). Understanding local adoption and implementation of climate change mitigation policy. Urban Affairs Review, 47(3), 433-457.

Tang, Z., Brody, S., Quinn, C., Chang, L. \& Wei, T. (2010). Moving from agenda to action: Evaluating local climate change action plans. Journal of Environmental Planning and Management, 53(1), 41-62. 
Tennessee General Assembly. (2012). House Joint Resolution 587: A Resolution Relative to United Nations Agenda 21. Nashville: House of Representatives State of Tennessee.

The New York Times. (2012). President - live election results. The New York Times. Retrieved from http://elections.nytimes.com/2012/results/president

The New York Times. (2013, March 13). Private vs. government utilities. The New York Times. Retrieved from http://www.nytimes.com/interactive/2013/03/14/business/private-vsgovernment-utilities.html?ref=energy-environment\&_r=1\&

The Washington Post. (2013). 2012 Presidential election results. The Washington Post. Retrieved from http://www.washingtonpost.com/wpsrv/special/politics/election-map-2012/president/

United Nations (1992). United Nations Conference on Environment \& Development Rio de Janeiro, Brazil, 3 to 14 June 1992: Agenda 21. New York, NY. Retrieved from http://sustainabledevelopment.un.org/content/documents/Agenda21.pdf

U.S. Census Bureau. (2014, January 25). American FactFinder DP02: Selected social characteristics in the United States 2008-2012 American Community Survey 5-Year Estimates. Retrieved from http://factfinder2.census.gov/

Usmayors.org. (2008). The Agreement: Mayors Climate Protection Center. Retrieved from http://www.usmayors.org/climateprotection/agreement.htm 
Usmayors.org. (2014). Mayors Climate Protection Center: The Agreement. Retrieved from http://www.usmayors.org/climateprotection/ClimateChange.asp

Wattenberg, M., \& Brians, C. (2002). Partisan turnout bias in midterm legislative elections. Legislative Studies Quarterly, 27(3), 407-421.

Weber, E. (2006). Experience-based and description-based perceptions of longterm risk: Why global warming does not scare us (yet). Climatic Change, 77(1-2), 103-120.

Wheeler, J. (2006). ICLEI case studies - combating climate change (2006). Retrieved from: http://www.icleiusa.org/action-center/learn-fromothers/Case_Studies_Dec-2006

Wheeler, S. (2008). State and municipal climate change plans: The first generation. Journal of the American Planning Association, 74(4), 481-496.

Wikipedia. (2014). United States presidential election, 2012. Retrieved 27 February 2014, from http://en.wikipedia.org/wiki/United_States_presidential_election,_2012

Yin, R.K. (2014 \& 1994). Case study research: Design and methods (5th Ed. \& 2nd Ed.). Los Angeles: Sage Publications

Zahran, S., Grover, H., Brody, S. and Vedlitz, A. (2008a). Risk, stress, and capacity explaining metropolitan commitment to climate protection. Urban affairs review, 43(4), 447-474. 
Zahran, S., Brody, S., Vedlitz, A., Grover, H. \& Miller, C. (2008b). Vulnerability and capacity: Explaining local commitment to climate-change policy. Environment and planning. C, Government \& policy, 26(3), 544.

Zahran, S., Brody, S., Vedlitz, A., Lacy, M. \& Schelly, C. (2008c). Greening local energy: Explaining the geographic distribution of household solar energy use in the United States. Journal of the American Planning Association, 74(4), 419-434. 


\section{APPENDIX}

\section{Chapter 2: Procedures and Methodology}

\section{List of Interview Questions (detail)}

\section{GeNERAL QUESTIONS}

- What was your role in the plan's development?

- What was the motivation for creating a climate action plan (i.e. was there a unique vulnerability)?

- What terminology did you use during the climate action process? I.e. specific terminology, or topics relating to climate science (please explain).

- Did adoption of the initiative experience any backlash from groups or individual in the community? For example, the mayor, city council, planning commission, citizenry, etc.? (Which of the above?)

- (Follow up) Did any groups or individuals mention Agenda 21?

- Was the process politically difficult? Why? How did you deal with this?

- How would you characterize the political beliefs/leanings of your community?

- Was a "local champion" (such as community organizer, Mayor, Council Member, etc.) key to the CAP being taken all the way from initiation to adoption/acceptance? (If so, who?)

- What role did the planning department play?

- How was the community mobilized? 
- Was community buy-in achieved? YES/NO If YES, how?

- In general how active are state, federal, non-profit or community groups in your jurisdiction? Were any of these involved in the climate plan?

- Based on your personal knowledge, how long did the climate action planning process in your community take from its initial stages to eventual adoption/acceptance?

Post Adoption (or ACCEPTANCE, APProval)

- What was the community's response once the plan was adopted/accepted?

- How successful do you think implementation will be in your community post adoption/acceptance?

- Do you believe the local government will continue to support the CAP both fiscally and symbolically? Why or why not?

- How will the impacts be tracked? Is there a monitoring system in place? How well is this system working to date?

\section{Personal Reflection}

- Hypothetically, if I were to begin a climate plan in a community similar to yours, what advice would you give me in order to have a successful plan from the beginning to the point of adoption by City Council?

- Do you have any suggestions, best practices, or lessons learned that you would like to share from your experience? 


\begin{tabular}{|l|l|}
\hline \multicolumn{2}{|c|}{ CAP ANALYSIS TEMPLATE } \\
\hline BASIC INFORMATION & \\
\hline Jurisdiction name & \\
\hline Plan title & \\
\hline Lead agency/primary author & \\
\hline Adoption (Acceptance/Completion) date & \\
\hline Number of pages & \\
\hline Legal status of plan & \\
\hline Plan version. (prior versions?) & \\
\hline CONTENTS &
\end{tabular}

Are the following included in the plan:

. Climate science basics/primer

. $\quad$ Local climate change impacts

. $\quad$ Community-wide GHG inventory

. $\quad$ GHG emissions forecast

. $\quad$ GHG reduction targets

- $\quad$ Emissions reduction policy/programs

- Adaptation policy/programs

. $\quad$ Financing plan

$\begin{array}{ll}\text {. } & \text { Monitoring and evaluation program }\end{array}$

\section{PARTICIPATION}

Was there an internal advisory group or climate

action team? (membership and role).

Was there a public advisory body? (membership and role).

Was there a citizen participation program?

Committee structure (mayor/public

works/planning/consultants)

\section{GHG EMISSIONS INVENTORY}

Protocol/method/software used for the GHG emissions inventory.

Baseline year for the inventory.

Community-wide and municipal emissions levels

for the baseline year

Distribution of community-wide and municipal emissions (\% by sector)

\begin{tabular}{|l|l|}
\hline Types of Measures (by Sector) & Number of Measures \\
\hline Education & \\
\hline Land use & \\
\hline Transportation & \\
\hline Energy & \\
\hline
\end{tabular}




\begin{tabular}{|l|l|} 
Water & \\
\hline Waste & \\
\hline Municipal & \\
\hline Economy/Jobs/Housing & \\
\hline Total & \\
\hline "Business-as-usual" forecast level(s) and \\
year(s)? & \\
\hline Reduction target(s) and year(s) & \\
\hline What is the justification for the target? & \\
\hline Is there a separate GHG inventory document? & \\
\hline EMISSIONS REDUCTION & \\
\hline $\begin{array}{l}\text { Approximate number of emissions reduction } \\
\text { strategies in the plan }\end{array}$ & \\
\hline $\begin{array}{l}\text { Are all GHG emissions sectors from the } \\
\text { inventory (e.g., energy, transportation, waste, } \\
\text { etc.) represented in the strategies? }\end{array}$ & \\
\hline $\begin{array}{l}\text { Distribution of Emissions Reduction (by } \\
\text { Sector) }\end{array}$ & Reduction \% Share of \\
\hline Education & Target \\
\hline Land use & \\
\hline Transportation & \\
\hline Energy & \\
\hline Water & \\
\hline Waste & \\
\hline Municipal & \\
\hline Economy/Jobs/Housing & \\
\hline Total & \\
\hline $\begin{array}{l}\text { Number of strategies that include GHG reduction } \\
\text { estimates }\end{array}$ & \\
\hline $\begin{array}{l}\text { Are the strategies linked quantitatively to the } \\
\text { inventory and reduction targets? Do they } \\
\text { collectively achieve the reduction target? }\end{array}$ & \\
\hline $\begin{array}{l}\text { Are there strategies that do not have clear GHG } \\
\text { reduction outcomes or are not accounted for in } \\
\text { the inventory (e.g., plastic bag bans, food } \\
\text { miles)? Is their inclusion in the CAP explained? }\end{array}$ & \\
\hline IMPLEMENTATION & \\
\hline $\begin{array}{l}\text { Does the plan include } \\
\text { phasing/timing/prioritization of strategies? }\end{array}$ & \\
\hline $\begin{array}{l}\text { How many of the strategies have responsibility } \\
\text { for implementation assigned to a particular body } \\
\text { or department? }\end{array}$ & \\
\hline Funding structure & \\
\hline $\begin{array}{l}\text { How many of the strategies have cost estimates } \\
\text { included? }\end{array}$ & \\
\hline How many of the strategies have funding & \\
\hline
\end{tabular}


sources identified?

How many of the strategies have indicators for monitoring identified?

\section{STRUCTURE AND MOTIVATION}

Language/terminology used

What Co-benefits are emphasized?

Municipal emissions/energy use/cost savings

focus?

Energy action plan?

Adaptation Plan (is there specific vulnerability)?

Part of a larger sustainability, planning initiative,

or hazard plan?

MEMBERSHIPS

U.S. Conference of Mayors Climate Protection

Agreement $(\mathrm{y} / \mathrm{n})$

Cities for climate protection membership $(\mathrm{y} / \mathrm{n})$

ICLEI membership/ICLEI model $(\mathrm{y} / \mathrm{n})$

\section{REGIONAL INFLUENCE}

Does the state the plan is located in have a

CAP? Is this referenced?

State/regional programs (e.g., AB32, SB375, or

state mandate of any kind)

University town status/role (and \% college

educated)

\section{POLITICAL INFLUENCE}

How is the science behind climate change dealt with?

Party status of elected officials who approved

adoption/implementation (if applicable)

The role of elected officials (i.e. mayor, city

administrator) in terms of adoption

\section{OTHER}

Notes

Written by/Key players 
Chapter 4: Summary AND Discussion

Table 3: Case Study Research Findings

\begin{tabular}{|c|c|}
\hline \multicolumn{2}{|c|}{ Important Lessons Learned From Case Study Findings } \\
\hline CAP Comparison & $\begin{array}{l}\text { In each case analyzed, CAP structure and scope } \\
\text { vary, yet GHG emissions related to transportation } \\
\text { constitute the largest single emissions source for all } \\
\text { seven CAPs. }\end{array}$ \\
\hline Co-Benefits & $\begin{array}{l}\text { In these politically conservative communities, co- } \\
\text { benefits were universally used to gain support for } \\
\text { climate planning. In the vast majority of cases, energy } \\
\text { related cost-savings and economic benefits are } \\
\text { emphasized rather than GHG emissions reduction in } \\
\text { its own right. }\end{array}$ \\
\hline State Mandates & $\begin{array}{l}\text { In California, state mandates are viewed as important } \\
\text { motivators for CAP creation in conservative cities, } \\
\text { especially in the case of CAPs developed by city } \\
\text { agencies. These mandates can influence measures } \\
\text { included in each CAP as well as the success of } \\
\text { measure implementation. State action can also serve } \\
\text { as way to sell climate planning to community } \\
\text { members and elected officials. }\end{array}$ \\
\hline Public Utilities & $\begin{array}{l}\text { The presence of publically-owned utilities motivates } \\
\text { CAP creation in some conservative communities } \\
\text { because of a perceived level of control over local } \\
\text { energy issues. In such cities, municipal energy use } \\
\text { and energy efficiency are points of focus. }\end{array}$ \\
\hline $\begin{array}{l}\text { The Great } \\
\text { Recession }\end{array}$ & $\begin{array}{l}\text { Budget constraints can influence the desire to engage } \\
\text { in climate planning in different ways. In certain cases, } \\
\text { the fear of impacting private enterprise can reduce } \\
\text { the will to participate in CAP implementation; in } \\
\text { others, the attraction of reducing municipal energy } \\
\text { costs can invigorate CAP efforts. }\end{array}$ \\
\hline CAP Titles & $\begin{array}{l}\text { Leaving out "climate" or "sustainability" in CAP titles } \\
\text { can be a way to reduce political backlash and } \\
\text { increase climate planning marketability in politically } \\
\text { conservative communities. }\end{array}$ \\
\hline
\end{tabular}




\begin{tabular}{|c|c|}
\hline Terminology & $\begin{array}{l}\text { In some cases, CAPs in conservative communities } \\
\text { are prone to excluding climate science or GHG } \\
\text { emissions connection to human activity, especially } \\
\text { without the influence of state mandates. } \\
\text { In conservative communities, "sustainability" has } \\
\text { been used to gain support for pragmatic CAP } \\
\text { measures, but in recent years, political opposition to } \\
\text { this term has changed the meaning of "sustainability" } \\
\text { in these regions, reducing its political viability. }\end{array}$ \\
\hline $\begin{array}{l}\text { Departmental } \\
\text { Leadership }\end{array}$ & $\begin{array}{l}\text { In the conservative cities included in this study, CAPS } \\
\text { were not primarily developed by planning agencies; } \\
\text { rather, plan development was led by other city } \\
\text { departments, or bodies created through the actions of } \\
\text { elected officials. }\end{array}$ \\
\hline $\begin{array}{l}\text { Involvement of } \\
\text { Consultants }\end{array}$ & $\begin{array}{l}\text { Consultant involvement often led to the creation of } \\
\text { CAPs which included a high level of detail, and in } \\
\text { certain cases influenced the use of specific } \\
\text { terminology that could be potentially sensitive in } \\
\text { politically conservative cities. }\end{array}$ \\
\hline $\begin{array}{l}\text { Community Member } \\
\text { Involvement }\end{array}$ & $\begin{array}{l}\text { In conservative communities analyzed in this case } \\
\text { study, the majority of CAPs include community } \\
\text { stakeholder participation. However, CAPs developed } \\
\text { entirely by citizens require staff involvement for } \\
\text { success. }\end{array}$ \\
\hline $\begin{array}{l}\text { Pathways to CAP } \\
\text { Completion }\end{array}$ & $\begin{array}{l}\text { Adoption is not a prerequisite for CAP success, but a } \\
\text { legal basis for the plan is important in politically } \\
\text { conservative cities. }\end{array}$ \\
\hline Mayoral Support & $\begin{array}{l}\text { Mayoral backing is particularly helpful in politically } \\
\text { challenging communities; it can shape policies, as } \\
\text { well as influence the level of elected } \\
\text { official/community member participation and support. }\end{array}$ \\
\hline $\begin{array}{l}\text { City Council } \\
\text { Support }\end{array}$ & $\begin{array}{l}\text { For the cases included in this study, city council } \\
\text { support is the most essential element for CAP } \\
\text { success, because councils make the final policy } \\
\text { determination after CAP completion. However, their } \\
\text { support for climate planning initiatives can be highly } \\
\text { influenced by community sentiments regarding } \\
\text { climate change, pointing to the importance of } \\
\text { community attitudes for successful climate planning. }\end{array}$ \\
\hline
\end{tabular}




\begin{tabular}{|c|l|}
\hline $\begin{array}{c}\text { "Community" Buy- } \\
\text { in }\end{array}$ & $\begin{array}{l}\text { In conservative communities, CAP buy-in from the } \\
\text { general public can be more important for } \\
\text { implementation than CAP adoption (or completion). } \\
\text { Often community stakeholder buy-in is more crucial } \\
\text { than that of the general public and public workshops } \\
\text { serve as a compulsory aspect of the planning process } \\
\text { rather than an integral contribution to CAP } \\
\text { development. }\end{array}$ \\
\hline $\begin{array}{c}\text { Business } \\
\text { Agemmunity Buy-in }\end{array}$ & $\begin{array}{l}\text { In conservative cities, buy-in from the business } \\
\text { community is often essential for CAP support and } \\
\text { viability. Absence of this type of buy-in can have } \\
\text { serious ramifications for CAP success. }\end{array}$ \\
\hline Buy-in & $\begin{array}{l}\text { Agency-wide and department head buy-in can be } \\
\text { particularly important in conservative cities for the } \\
\text { long-term success of climate action planning, perhaps } \\
\text { more so than the involvement of committed individual } \\
\text { staff members. }\end{array}$ \\
\hline Political Difficulties & $\begin{array}{l}\text { In the conservative communities included in this case } \\
\text { study, political difficulties are often considerable. Tea } \\
\text { Party and Agenda 21 opposition is the most sizable } \\
\text { and difficult to address. This type of political } \\
\text { obstruction has increased in recent years. }\end{array}$ \\
\hline
\end{tabular}




\section{Public Utilities}

FIGURE 3: HOW MUCH MORE OR LESS PRIVATE UTILITIES COST THAN PUBLIC UTILITIES

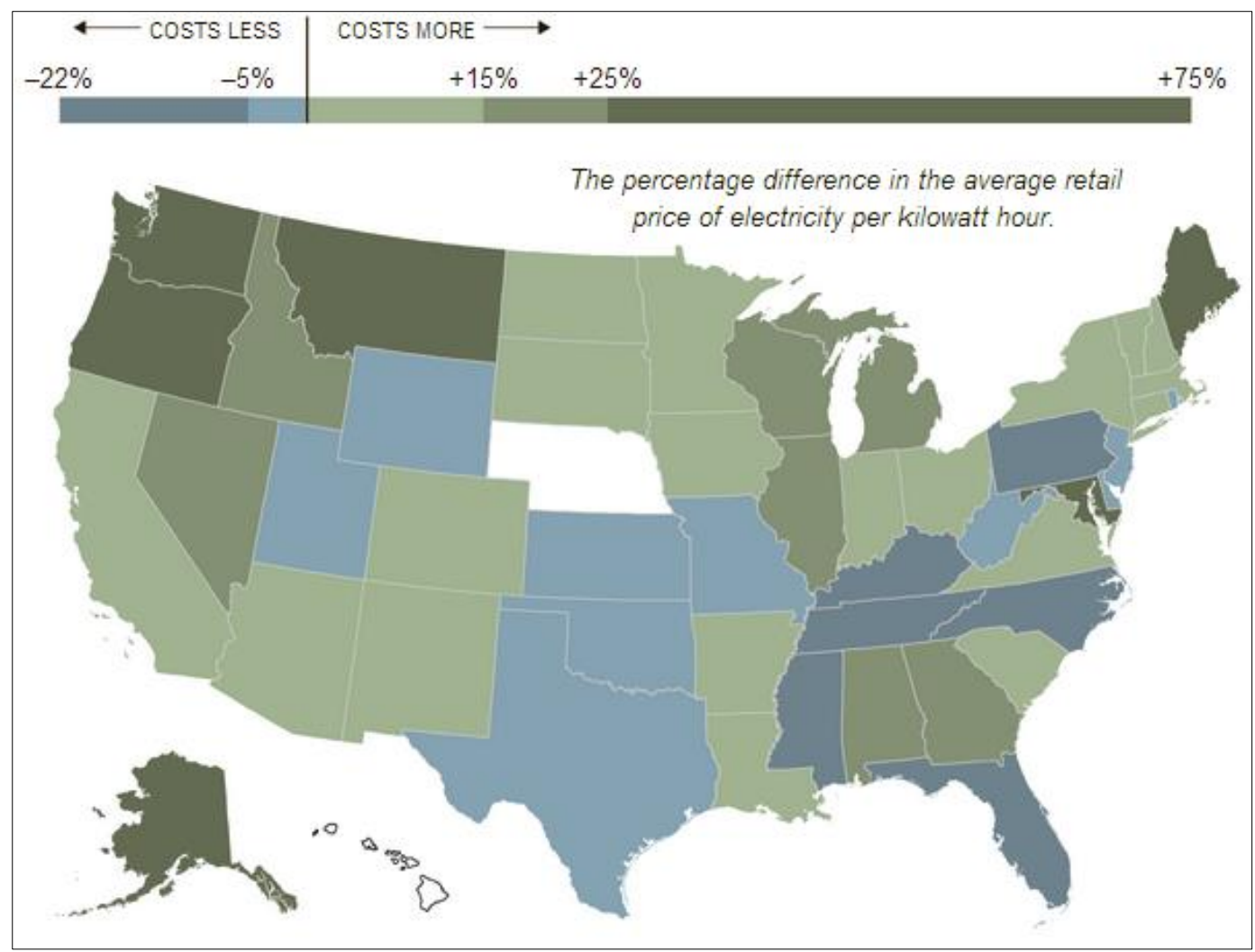

The New York Times. (2013).

\section{Political Difficulties of Climate Planning}

Anti-Agenda 21 initiatives related to sustainability or other similar types of planning practices have been proposed in 26 states and passed in five. The vast majority of states (21 of 25 ) that have proposed this type of legislation are located in states that voted for Republican candidates in the 2010 congressional election. 
Figure 4: StATE LEVEL ANTI-AGENDA 21 LEgISLATION

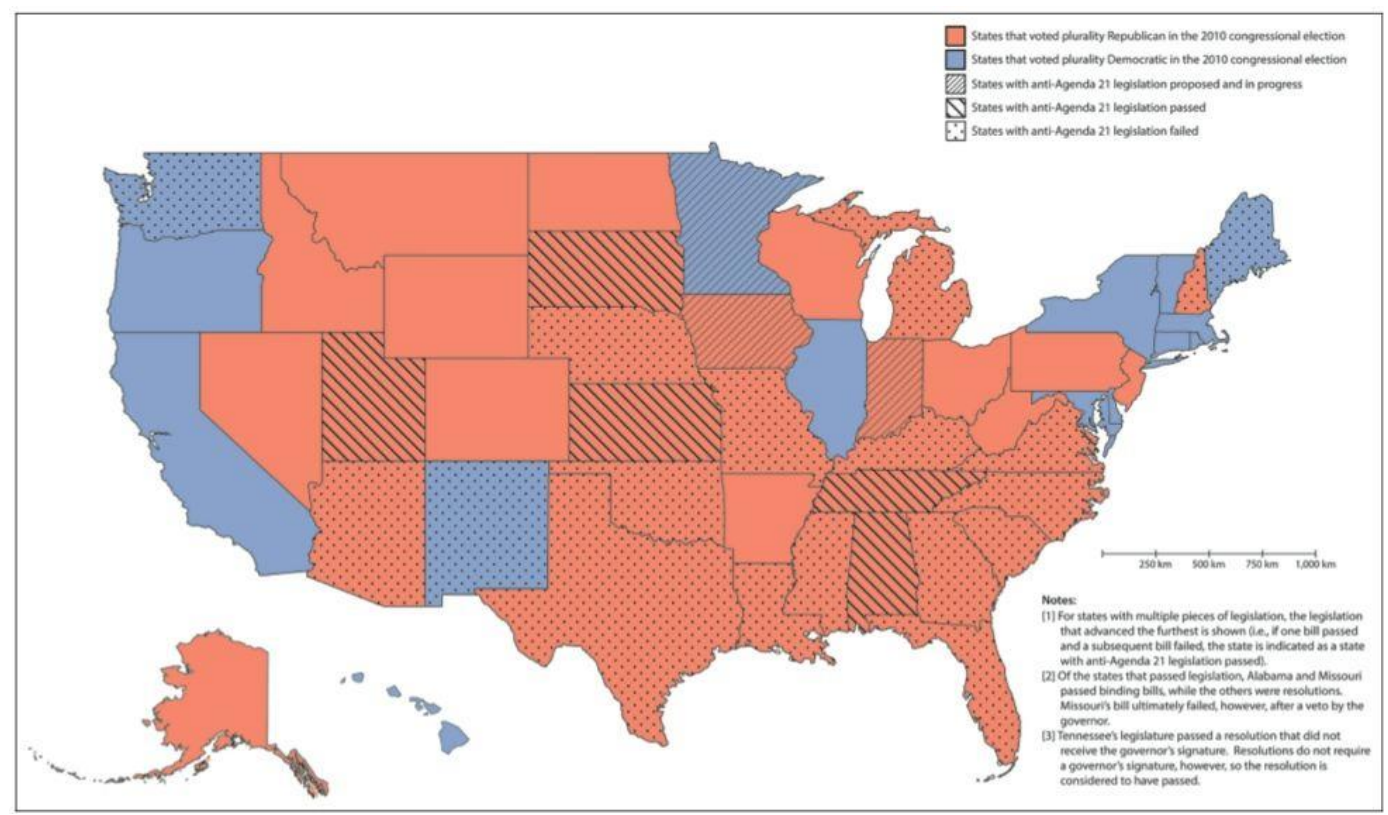

Status of state legislation in relation to the percentage of votes for Republican candidates for U.S. Congress House seats in the 2010 federal elections

(Frick, et al., 2014, p. 12) 